\title{
Dynamic urinary graciloplasty
}

Citation for published version (APA):

Heesakkers, J. P. F. A. (1997). Dynamic urinary graciloplasty. [Doctoral Thesis, Maastricht University]. Universiteit Maastricht. https://doi.org/10.26481/dis.19970704jh

Document status and date:

Published: 01/01/1997

DOI:

10.26481/dis.19970704jh

Document Version:

Publisher's PDF, also known as Version of record

\section{Please check the document version of this publication:}

- A submitted manuscript is the version of the article upon submission and before peer-review. There can be important differences between the submitted version and the official published version of record.

People interested in the research are advised to contact the author for the final version of the publication, or visit the DOI to the publisher's website.

- The final author version and the galley proof are versions of the publication after peer review.

- The final published version features the final layout of the paper including the volume, issue and page numbers.

Link to publication

\footnotetext{
General rights rights.

- You may freely distribute the URL identifying the publication in the public portal. please follow below link for the End User Agreement:

www.umlib.nl/taverne-license

Take down policy

If you believe that this document breaches copyright please contact us at:

repository@maastrichtuniversity.nl

providing details and we will investigate your claim.
}

Copyright and moral rights for the publications made accessible in the public portal are retained by the authors and/or other copyright owners and it is a condition of accessing publications that users recognise and abide by the legal requirements associated with these

- Users may download and print one copy of any publication from the public portal for the purpose of private study or research.

- You may not further distribute the material or use it for any profit-making activity or commercial gain

If the publication is distributed under the terms of Article $25 \mathrm{fa}$ of the Dutch Copyright Act, indicated by the "Taverne" license above, 
Dynamic Urinary Graciloplasty 
John Heesakkers, Maastricht 1997 ISBN 9090106928

Cover painting: Sahara, J. Heesakkers 1997, oil on canvas $35 \times 50 \mathrm{~cm}$ Cover design 8 figures: $J$. de Jonge

Printing: Datawyse | Universitaire Pers Maastricht 


\title{
Dynamic Urinary Graciloplasty
}

\author{
PROEFSCHRIFT
}

ter verkrijging van graad van doctor aan de Universiteit Maastricht, op gezag van de Rector Magnificus

Prof. mr. M.J. Cohen, volgens het besluit van het College van Decanen in het openbaar te verdedigen op vrijdag 4 juli 1997 om 12.00 uur precies

door

Johannes Petrus Franciscus Antonius Heesakkers geboren te Lieshout op 8 februari 1961 


\section{Promotor}

Prof. dr. R.A. Janknegt

\section{Co-promotor}

Dr. C.G.M.I. Baeten

\section{Beoordelingscommissie}

Prof. dr. G. Kootstra (voorzitter)

Prof. dr. J.W. Arends

Prof. dr. F.M.J. Debruyne (Katholieke Universiteit Nijmegen)

Prof. dr. med. R. Hohenfellner (Universiteit Mainz, Dld.)

Prof, dr. G.J. van der Vusse

The publication of this thesis was realised by major financial support of Bakken Research Center Maastricht, which is gratefully acknowledged.

Other financial support was generously provided by:

\author{
Abbott \\ Applied Medical Technics \\ Astra Meditec \\ Bard \\ Bayer \\ Bioplasty \\ Byk \\ Coloplast \\ Glaxo Wellcome \\ Hoechast Marion Roussel
}

Lorex Synthélabo

Medireva

MSD

Pie Medical

Schering Nederland

Stichting Urologie 1973

Stichting WAMU

Urologix

Yamanouchi Pharma

Zeneca Farma 
vooral voor mijn ouders 
. 


\section{Contents}

Outline of thesis on dynamic urinary graciloplasty 9

1. Urethral sphincter deficiency: prevalence and treatment modalities 13

2. Muscle plasticity $\quad 41$

3. Feasibility and side effects of dynamic urinary graciloplasty for treatment of intrinsic sphincter deficiency

4. Comparison of muscle histology and generated pressures of two types of dynamic graciloplasties in rabbits

5. Electrical stimulated graciloplasty in the male goat: an animal model for urethral pressure measurement

6. Acute effect of the electrically stimulated urinary graciloplasty on energy metabolism of the gracilis muscle in male goats

7. Dynamic urinary graciloplasty in male goats: a study on histology and urethral pressures

8. General discussion and scope of dynamic urinary graciloplasty

9. Summary and conclusions

Samenvarting

Dankwoord 

Outline of thesis on dynamic urinary graciloplasty 
The core contents of this booklet comprises the feasibility of the dynamic urinary graciloplasty as a treatment of intrinsic urethral sphincter deficiency, causing urinary incontinence. Graciloplasty as a treatment of incontinence originates decades ago. The gracilis muscle, one of the adductors of the upper leg, has a favorable neurowascular entry at the origin of the muscle. Therefore the distal part can be cut without the risk of innervation disturbances or the occurrence of muscle ischemia. Since the gracilis muscle is located close to the perineal part of the bladder outlet, it is technically possible to wrap the distal part around the urethra and even around the bladder neck.

Graciloplasty was already performed in the early twenties to treat children with primary incontinence due to epispadia. The latter is a urethral closing defect occurring during embryological development, resulting in the lack of or a rudimentary state of the urethral sphincter. The drawback of the procedure was that the gracilis muscle, being a skeletal muscle, is fast and strong but also fast fatiguing. 'Therefore it can not sustain longulasting contractions and patients can only keep up their continent state for a short period of time.

It has been known for about twenty years that tissue properties and especially the characteristics of muscles may change by chronic electrical stimulation. This means that skeletal muscles, originally depending on anaerobic metabolism and a limited glycogen pool, which is depleted after some time, can be changed into a muscle whose energy supply is based on aerobic metabolism. Consequently the changed muscle can continue its contraction for a long period with little fatigue. This process is reversible and tells us that a skeletal muscle is not a static unchangeable phenomenon but is in a dynamic state. The development of sophisticated pulse stimulators, of which some can have their electronic parameters changed on a remote basis, made it possible to change muscle characteristics after transposition of the muscle and after implantation of muscle electrodes and a pulse stimulator. After reprogramming the pulse stimulator step by step from outside, the muscle can be shaped phenotypically and genotypically into a muscle with sphincteric properties.

Dynamic urinary graciloplasty stands for the procedure of muscle transposition, implantation of muscle electrodes and a pulse stimulator, combined with the step by step change of the muscle characteristics.

The first chapter is about the epidemiology and current treatments of incontinence due to insufficient urinary sphincter closure. Some remarks are made first on the terminology used today and the difficulties in interpreting data on prevalence of urinary incontinence. The mentioned treatments are listed in increasing levels of invasiveness. The treatments described start with physical exercises like pelvic floor 
exercises, electrical muscle stimulation and biofeedback. Drug treatment for incontinence like oestrogens and alpha mimetics are dealt with next. Finally the main surgical options are described, ranging from anterior repairs, bladder neck and urethral suspension techniques, slings and injectables to the implant of the artificial urinary sphincter. The invasiveness of the described techniques parallel the grades of severity of the incontinence state. Pelvic floor exercises are most effective in cases of modest urine loss, whereas sling procedures and the artificial sphincter implant is used primarily for severe urine loss.

Chapter two is about the dynamic features of muscles with respect to adaptation to different activity patterns. Beginning with normal skeletal muscle anatomy, histochemistry and biochemical functioning, the adaptive changes are described. Muscle stimulation methods are mentioned as well as changes in the muscle physiology, changes in muscle histology and fibre composition. Afterwards changes in the regulatory system are listed followed by metabolic adaptations and changes in the energy metabolites. The chapter concludes with some clinical applications of electrical stimulation, especially electrical muscle stimulation.

Chapter three describes the operative technique of dynamic urinary graciloplasty which is used for the first feasibility study. The chapter describes the gracilis muscle anatomy, its innervation, blood supply and its function. In this feasibility study the bladder neck was chosen as the location for the gracilis muscle transposition. The used devices had to be switched on and off by a magnet. "The feasibility study in seven patients is presented as well as the results and an analysis of the failed patients. Based on the examination of the failures, animal experiments were started to investigate neosphincter location and neosphincter construction in order to have more successful results.

Chapter four is about a chronic rabbit experiment. In the animals a new construction of the neosphincter was tested. In order to have a more right-angled configuration of the muscle wrap in relation to the urethra, a pulled through graciloplasty construction was performed. The pulled through neosphincter construction was compared with the conventional gracilis muscle wrap. Muscle fibre transformation was analysed histologically for both types of graciloplasty. A comparison was made between the two types of graciloplasty with respect to muscle histology and generated pressures by the two graciloplasty techniques in order to have data on the assumed improvement of the sphincter construction.

Chapter five describes the investigation of the male goat as an animal model for 
performing urethral pressure measurements and testing of the neosphincter construction in the acute phase. First the choice for the male goat and the anatomy of gracilis muscles are described. Then the feasibility to use this animal for urethral pressure measurements is tested. Afterwards a comparison is made of the native urethral pressures, the resulting urethral pressures with a non-stimulated gracilis muscle transposition, and the pressures which occur after tetanic graciloplasty contraction by direct electrical muscle stimulation. A first reason for doing this experiment was to acquire data on the feasibility of the technique in male goats for a chronic study. A second reason was to investigate the differences between a sling-type graciloplasty, being the graciloplasty without muscle contraction and a sphincter like contracting graciloplasty.

In the sixth chapter an analysis is presented of the metabolism of high energy phosphates in the acute phase of chronic stimulation in untrained male goat gracilis muscles. The muscle biopsies for performing the analysis of high energy phosphates were taken before graciloplasty. They were compared to the muscle specimens which were talken after graciloplasty combined with tetanic stimulation for several minutes and a recovery period of five minutes. The lack in balance of energy demand and supply is demonstrated in the non-adapted muscle. The experiment also shows the differences in change of several metabolites of the energy supply system. "This chapter demonstrates once again the biochemical substrate of the energy supply, which causes skeletal muscle fatigue in non-adapted muscles.

In the seventh chapter the results of a chronic experiment in two male goats, with a dynamic urethral pulled-through graciloplasty, are listed. The primary reason for performing this study was to examine the behaviour of the bulbous urethra with respect to urethral stricturing. This was done because others had mentioned urethral stricturing as a cause of bulbous urethral graciloplasty failure. Since the bulbous urethra is easier to access for graciloplasty, a positive result from this study could imply that bulbous urethral graciloplasty is feasible and probably more successful than dynamic graciloplasty around the bladder neck. The changes in muscle histology and changes in urethral pressures in the non-adapted graciloplasty compared to the trained and adapted graciloplasty were studied.

In chapter 8 a synthesis of the results is presented. The results are discussed as well as implications for future graciloplasties. The scope and place of graciloplasty in urological practice are discussed as well. 


\section{Urethral sphincter deficiency: prevalence and treatment modalities}

Chapter 1 


\section{Introduction}

The exploration of the dynamic urinary graciloplasty as a new treatment of severe urinary incontinence due to an incompetent urethral closing mechanism, also known as urethral sphincter deficiency, intrinsic sphincter deficiency or intrinsic sphincter dysfunction is the main topic of this thesis. Urinary incontinence due to an incompetent urethral sphincter results in urine loss in a fashion which is labelled stress urinary incontinence. This implies that urine loss accurs when the intra-abdominal pressure rises, and the intravesical pressure transgresses the urethral closing pressure. Most patients, who suffer from this type of incontinence, complain of urine loss during laughing, coughing, sneezing, jumping, jogging, lifting etc.

When the urethral closing mechanism is severely damaged or totally absent, urine is lost continuously or nearly continuously. Clinically this grade of urinary incontinence is often labelled as grade III stress incontinence. It is caused functionally by urethral sphincter failure or intrinsic sphincter deficiency. The expression "intrinsic sphincter deficiency" is more precise than intrinsic sphincter dysfunction and is therefore to be preferred. Stress urinary incontinence and its grading most often refers to the clinical situation.

This chapter describes the prevalence and treatments of urinary incontinence caused by an incompetent urethral closing mechanism which nowadays exist. Since not all treatments are intended to deal with intrinsic sphincter deficiency, this chapter is titled "Urethral sphincter deficiency", including also the low and moderate grades. The mentioned treatments are in climbing onder of invasiveness, starting with drugs, followed by pelvic floor physical therapy and surgical therapies. Surgery starts with minor surgical therapies and ends with the major ones. The more severe the urethral sphincter deficiency is, the more invasive the treatment will be. Dynamic urinary graciloplasty is intended as a treatment for severe urinary incontinence or intrinsic sphincter deficiency. Therefore if one wishes to position the dynamic urinary graciloplasty among other treatments, this has to be done somewhere in the last part of this chapter, where treatments for the severe types of incontinence are described.

\section{Prevalence}

Urinary incontinence is a debulitating disorder affecting world wide millions of mostly older people. Many authors reported on the prevalence of incontinence in order to describe the magnitude of the problem. These reports vary substantially, probably due 
to the various definitions used for incontinence and the type of investigation. "Other factors also influence the reported data, like the recollection capacities of older people in surveys. ${ }^{2}$ Also the different ways in defining success or failure and the applied research methodology contribute to the differences in outcome.

Moreover the severity in which urinary incontinence bothers patients differs not only in incontinence grade but also in incontinence type and age of the patients. ${ }^{2}$ Of course there is also an individual variation in suffering with respect to grading. Urinary incontinence is defined by the International Continence Society as "Involuntary urine loss which is objectively demonstratable and a social or hygienic problem."

The prevalence of urinary incontinence has been investigated in community living people as well as in institutionalised people. The prevalence tends to be higher in women, older people and institutionalised populations. The percentages range from 9.2 to $53 \%$ in communities 3,4 and from 27 to $70 \%$ in institutions. ${ }^{5,6}$ 'The reported prevalences range from 5.7 to $64 \%$ in men $^{7.6}$ and from 12 to $79 \%$ in women. ${ }^{8,6}$ Ethnic differences in incontinence percentages are also reported."

Urethral sphincter deficiency consists of various degrees of severity. The mild category results in stress incontinence, the severe type causes total incontinence. Stress urinary incontinence as a subjective symptom is defined by the International Continence Saciety as the statement of a patient that urine is lost involuntarily during physical exercise. ${ }^{10}$ Stress urinary incontinence as an objective urodynamic diagnosis is the involuntary loss of urine during physical exertion in the absence of detrusor activity. This can be due to a low transmission ratio of sudden pressure rise or to an incompetent sphincter mechanism. ${ }^{10}$ The prevalence of stress incontinence as opposed to urge incontinence varies. An impression of the disparity in reported percentages is listed in table 1.

Harrison mentioned $46 \%$ women with symptomatic stress incontinence and $43 \%$ women with mixed incontinence (stress and urge). "This was in a general practice setting where $53 \%$ of women over 20 years reported to suffer from incontinence. Remmers reported $12 \%$ stress or mixed incontinence in males and $62 \%$ stress or mixed incontinence in women in an institutionalised community where $17 \%$ of males and $31 \%$ of women suffered from daily incontinence." In this study the prevalence of stress or mixed incontinence was $3 \%$ in men and $21 \%$ in women in total. Diokno found stress or mixed incontinence in $7 \%$ of men and $31 \%$ of women. ${ }^{12}$ Van Waalwijk van Doorn reported $65 \%$ symptomatic stress or mixed incontinence and $22 \%$ urge incontinence in a group of female patients suffering from micturition problems. ${ }^{13}$ 


\begin{tabular}{|c|c|c|c|c|}
\hline AUTHOR & SETTING & SEX & PREVALENCE & TYPE \\
\hline \multirow[t]{3}{*}{ Harrison } & general practice & women & 24 & stress \\
\hline & & & 23 & moxed \\
\hline & & & 6 & urge: \\
\hline \multirow[t]{2}{*}{ Remmers 1} & institutionalised & women & 62 & stress \& mixed \\
\hline & community & men & 12 & stress \& mixed \\
\hline \multirow[t]{3}{*}{ Diokno" } & non: & & & \\
\hline & institutionalised & women & 31 & stress \& mixed \\
\hline & community & men & 7 & stress \& mixed \\
\hline \multirow[t]{2}{*}{ van Waalwijk van Doorn ${ }^{19}$} & hospital patients & women & 65 & stress \& mixed \\
\hline & & & 22 & urge \\
\hline
\end{tabular}

Table 1. Prevalence (\%) of incontinence as reported by seweral authors.

Intrinsic sphincter deficiency (also labelled type III stress incontinence) as a cause of stress incontinence is reported in $3.4 \%$ male patients who underwent radical prostatectomy. ${ }^{14}$ In this series $45 \%$ stress incontinence was noted after 36 months follow up. Intrinsic sphincter deficiency is the most severe type of stress incontinence. In patients suffering from intrinsisc sphincter deficiency, the function of the urethral sphincter is lacking, which results in total incontinence. Causes of intrinsic sphincter deficiency are congenital like epispadia, bladder exstrophy or myelodysplasia. Frequent occurring iatrogenic causes are radical prostatectomy and oncological gynaecologic operations combined with radiotherapy. Accidental traumas like pelvic fractures may also cause intrinsic sphincter deficiency.

\section{Theraples}

Various therapies are applied nowadays to treat stress urinary incontinence. The goal of all therapies is to increase the bladder outlet resistance. Increasing outlet resistance without surgery can be done either pharmacologically, by alpha adrenergic agonists and oestrogens, or by physiotherapy.

\section{PHARMACOLOGICAL AGENTS}

\section{ALPHA ADRENERGICS}

Most alpha adrenergic receptors are located in the bladder neck and proximal urethra of the urinary tract. If these receptors are stimulated, contraction of smooth muscle 
occurs, which explains their working mechanism in urinary incontinence. The reported results with alpha adrenergics vary from good to disappointing. Diokno reported fairly good results with ephedrine in patients suffering from minimal to moderate urine loss. The benefit was minimal in severe incontinent patients. ${ }^{15}$ Phenylpropanolamine with equal peripheral properties but less central stimulation, gives significant subjective and objective improvement in the majority of patients, as reported by Awad. ${ }^{16}$ The reported analysis on phenylpropanolamine of the American Agency for Health Care Policy and Research on 8 randomised trials is however less optimistic, with cure rates of $0-14 \%$, and improvement rates ranging from $0-19 \%$. "The side effects ranging from $5-33 \%$ were also striking. ${ }^{17}$ Alpha adrenergic stimulators may have some effect on the bladder base and proximal urethra, however the reported improvements are mostly subjective and not very substantial.

\section{OESTROGENS}

These drugs have been used for many years in patients suffering from stress urinary incontinence. Especially in post menopausal women oestrogens drugs have a beneficial effect on urine storage. Urethral pressure parameters decrease to some extent in post menopausal women, which is probably due to a decreased oestrogen level. ${ }^{18}$ The working mechanism of these drug has not been definitely elicited. The beneficial effect might come from changes in autonomic innervation, changes in oestrogen receptors content of smooth muscle or changes in oestrogen binding sites. Changes in vascular or collagen elements of the urethra might also explain the oestrogen effect. ${ }^{19}$ The mucosal seal mechanism is also frequently mentioned as a cause of the positive changes. ${ }^{20}$ Double blinded studies of patients treated with oestrogens reveal that there is an objective, but especially a subjective improvement. The best results are obtained with the combined treatment with phenylpropanolamine. Beisland showed that oestrogens alone improved urodynamic parameters, but the combination with phenylpropanolamine cured 8 out of 20 patients and improved another $9 .{ }^{21}$ Hilton reported that topically applicated oestrogens had good subjective results, although he could not show any urodynamical improvement. He also combined oestrogens with phenylpropanolamine, with slightly better results than with oestrogens alone. ${ }^{22}$ Jackson did also find subjective but no objective improvement of oestradiol in women with proven urinary leakage. Use of oestrogens therefore was not recommended by them. ${ }^{23}$ The current common opinion is that oestrogens have a beneficial effect on oestrogen deprived incontinent patients, albeit that most patients are improved only subjectively. 


\section{PELVIC FLOOR PHYSICAL THERAPY}

Physical therapy with or without the use of electrical currents are applied to treat a vast array of diseases or clinical symptoms. Also in urology a substantial amount of symptoms and diseases are treated with this modality. Stress urinary incontinence due to weakness of the supporting pelvic muscles, and unawareness or misuse of the pelvic muscles are nowadays treated by physical therapy. The continence mechanism involves the relationship between pelvic support and the intrinsic sphincter mechanism. The pelvic support consists of the pelvic bone structures, the endopelvic fascia and the pelvic floor musculature. Physical therapy is used to improve the functional quality of the pelvic floor. The concept of this kind of training was developed by Kegel in 1948. ${ }^{24}$ By means of training, detrusor overactivity, which results in urgency or urge incontinence, is treated by activation of sensory receptors and the activating of reflex pathways.

\section{PELVIC FLOOR EXERCISES}

This technique consists of training patients in contracting specific muscles or muscle groups, or instructing patients how to use the pelvic floor musculature. Patients are taught to examine digitally the appropriate muscles, like the pubococcygeus muscle, in order to learn how to contract them separately. If they contract these muscles they have to relax the antagonistic muscles in the meantime. In this way patients can also be taught to use the muscles properly and to do not exactly the opposite, which is also labelled "reverse perineal command". ${ }^{25}$ The claimed outcome is either pelvic floor strengthening or coordinated use of the pelvic floor, and therefore regaining continence. Vaginal cones can be added to pelvic floor exercises to enhance the effect. They can also be used to test the pelvic floor muscle strength. This method was first described by Plewnik. ${ }^{26}$ Patients are asked to introduce tampon shaped cones of various weights, and try to retain them by contracting the proper muscles. Another advantage, apart from strengthening the proper muscles, is that the urethral sphincter contracts as well which has also a training effect.

Devreeze et al mentioned $36 \%$ cured patients and $22 \%$ improved patients after three months of exercise. ${ }^{27}$ The use of vaginal cones improved the effect of pelvic floor exercises from 68 to $79 \% .{ }^{28}$ Others reported cure rates of $44 \% .{ }^{29}$ However, patients have to be motivated for these exercises. The often observed lack of motivation is a drawback of the technique. ${ }^{27}$

\section{BIOFEEDBACK}

Biofeedback instruments are used to detect various physiological mechanisms of which patients are unaware in order to develop control over these mechanisms and to amplify 
them. ${ }^{30}$ In stress incontinence the goal of biofeedback is to give patients a tool which enables them to notice when the pelvic muscles contract or the urethral sphincter relaxes. Physiological information is available directly to the parient and provides the opportunity to respond in the proper way. Muscle contraction can be monitored by electromyography. ${ }^{31}$ By using multichannel feedback patients can learn to relax the antagonistic muscles while contracting the agonistic muscles. Good response rates in more than $50 \%$ of the patients have been reported, even after 6 months of cessation of the training. ${ }^{32}$

\section{FUNCTIONAL ELECTRICAL STIMULATION}

The application of electric currents to control continence is called functional electrical stimulation. By stimulation of efferent nerves, muscles can contract. Direct stimulation of the pudendal nerve or pelvic nerves increases the intraurethral pressures. Pudendal nerve stimulation evokes urethral sphincter contraction. Stimulation of the pelvic nerves gives a reflex contraction of the striated periurethral muscles. ${ }^{31}$ To induce this effect the peripheral innervation has to be intact. The electrical current is applied via anal or vaginal cones or surface electrodes. Fall reported improvement of $70 \%$ of patients with genuine stress incontinence, but no cures ${ }^{33}$ Others reported subjective improvement of $60 \%$. However, compared to sham treatment the urodynamic changes did not differ. ${ }^{34}$

Physical therapy is thought to have a positive effect on several voiding dysfunctions. It is however difficult to substantiate the effect objectively. Probably urodynamic tools used nowadays are not yet capable to quantify the exact result of these techniques. Also the durability of the techniques is under debate. Patient compliance and continuation of exercises after cessation of therapy are key to success.

\section{SURGICAL THERAPIES}

The most suitable surgical options to treat stress urinary incontinence depend on the underlying mechanism which causes incontinence. Two types of stress incontinence can be distinguished.

The first is the anatomical type in which the bladder outlet and proximal urethra are malpositioned during an increase in abdominal pressure rise. This may be due to a hypermobile bladder or a low positioned bladderbase in rest. ${ }^{35}$ The urethral sphincteric unit can be intact in this type of stress incontinence. The surgical therapy for the anatomical type of stress incontinence is the repositioning of the bladder neck and proximal urethra retropubically, preferably in its original position. If this is achieved the intraabdominal pressure rise (e.g. by coughing) is also transmitted upon the bladder 
neck and proximal wrethra, hence continence will be restored. This type of stress incontinence can be accompanied by a cystocele, which influences the chosen type of operation.

The other type is caused by intrinsic sphincter deficiency. In patients suffering from this type of incontinence, the urethral sphincter is not capable to close the bladder outlet appropriately. A cystoscopically confirmed open bladder neck and proximal urethra give an indication of intrinsic sphincter deficiency. Urodynamically the diagnosis can be established by a low maximal urethral closing pressure. A more active urodynamic parameter to diagnose intrinsic sphincter deficiency is a low leak point pressure. A normal position of the bladder can be found, without anatomical disturbances. The goals of surgical treatment of intrinsic sphincter deficiency are coaptation, support and compression of the lacking sphincteric unit. ${ }^{36}$ The combination of the anatomical type and intrinsic sphincter deficiency also exists. Classically the operation of choice for the anatomical type are suspension operations, either by an abdominal approach, (trans)vaginal approach or a minimal invasive approach, such as in needle suspensions. These operations can be combined with a concomitant treatment of the cystocele. The surgical possibilities for intrinsic sphincter deficiency are sling operations, injectables or implantation of the artificial urinary sphincter. It is difficult to distinguish the two types of incontinence, since there are no standard definitions and the combination of the two types is not rare. Moreover the classical treatments of anatomical incontinence also have a beneficial effect on intrinsic sphincter deficiency and vice versa. Therefore in practice suspension operations are also applied in patients suffering, at least partly, from intrinsic sphincter deficiency.

\section{OPERATYONS FOR THE ANATOMICAL TYPE OF INCONTINENCE}

The suspension operations consist of abdominal approaches, vaginal approaches and needle suspensions.

The best known abdominal operations are the Marshall Marchetti Krantz procedure and the Burch colposuspension. They both use a Pfannenstiel incision to have access to Retzius space. In the Marshall Marchetti Krantz procedure, developed in 1949, two or three absorbable or non-absorbable sutures are placed from the midurethra to the vesicourethral junction. The sutures are close to the urethra and fixed to the pubic periosteum. ${ }^{37}$ This close fixation causes the risk of obstruction. ${ }^{36}$ The description of the Burch colposuspension originates from 1961. ${ }^{38}$ Although numerous modifications are described, the original concept still holds. In this procedure six absorbable or nonabsorbable sutures are placed through the paravaginal fascia and fixed to the iliopectineal ligament, also named Cooper's ligament. The two most caudad sutures are placed at the level of the bladder neck, the other four are placed more proximally at the level of the bladderbase. The first pair is believed to restore continence whereas the 
other four are used to correct cystoceles. This is the claimed advantage of this procedure compared to the Marshall Marchetti Krantz operation.

The most famous representative of the vaginal approach is the anterior colporriaphy or Kelly plication, as described first in $1914 .{ }^{39}$ Here a midline incision is made in the vaginal wall and the pubocervical fascia is plicated and approximated in the midine by means of repeated sutures. Afterwards the vaginal wall is trimmed and closed. The technique is primarily used for correction of cystoceles, but some elevation of the urethra and bladder neck also occurs. ${ }^{40}$ This is the reason that it still is a widespread treatment for stress incontinence. The procedure is not capable to suspend the bladder neck to its original position or to correct hypermobility. Therefore it is not considered the optimal treatment for the anatomical type of incontinence.

The first description of needle suspensions by a transvaginal approach was by Pereyra in 1959. ${ }^{41}$ Stamey described the modified technique by cystoscopical control of needle placement in 1973. He also was the first to use dacron sleeves to support the suspending sutures. ${ }^{42}$ The resulting technique is known as the Stamey-Pereyra procedure. A transversal vaginal incision as well as two suprapubic incisions of $3-5 \mathrm{~cm}$ are made on both sides of the midline. After dissection of the underlying tissue a nylon suture, connected to a specially designed needle, is introduced from the suprapubic incision to the vaginal incision just lateral to the bladder neck. The second passage of the needle is laterally to the first passage in opposite direction after having put a $1 \mathrm{~cm}$ dacron tube on the suture. Under cystoscopical control the sutures are tight over the anterior rectus fascia. This procedure is repeated on the opposite side of the bladder neck. The goal is to suspend the internal vesical neck behind the symphysis pubis. This can be done more appropriately under endoscopical control. ${ }^{43}$

Other modifications on needle suspensions were introduced by Raz in $1981 .{ }^{44}$ In order to mobilise the urethra, an inverted $U$ incision in the anterior vaginal wall was developed. After dissection of the vaginal wall off the periurethral fascia, a nonabsorbable prolene suture is fixed on the right and left urethropelvic ligament together with the pubocervical fascia and the vaginal wall, except the vaginal epithelium. "The sutures are pulled by means of a suture carrier and tied onto the rectus fascia after having made a transverse 1-inch incision suprapubically on either side of the midline. In case of a cystocele the suspension part can be combined with a cystocele correction via the so called four corner approach. ${ }^{45}$ Three prolene sutures on each side of the urethra are used. One pair is placed at the level of the sacrouterine cardinal complex. A second incorporates the urethropelvic ligament together with the pubocervical fascia and the vaginal wall. The third pair of sutures incorporates the levator muscle and the urethropelvic ligament.

In 1987 Gittes and Loughlin described a no-incision modification of the Pereyra technique. ${ }^{46}$ In this technique two minor suprapubic perforations are made with a scalpel. The needle is introduced and popped through the vaginal wall guided by the 
intravaginal fingertip. A non-absorbable monofilament suture is connected and the needle is stabbed back out of the suprapubic wound. A second passage is made through the same suprapubic wound and a second perforation of the vaginal wall is created about $1.5 \mathrm{~cm}$ from the other one. After a few extra helical bites the needle is once again pulled back. In the small scalpel incision they are tied over the anterior rectus fascia. The advantage of this procedure is that it is simple to perform. The drawback however is that it is more difficult to control suture placement.

The results of the above described procedures to treat the anatomical type of incontinence vary substantially which may partly be due to the used analytical methodology. ${ }^{47}$ The results are summarised in table 2.

\begin{tabular}{lllll} 
TECHNIQUE & $\begin{array}{l}\text { NUMBER OF } \\
\text { PATIENTS }\end{array}$ & $\begin{array}{l}\text { SUBJECITVE } \\
\text { SUCCESS }(\%)\end{array}$ & $\begin{array}{l}\text { OBJECTIVE } \\
\text { SUCCESS (\%) }\end{array}$ & $\begin{array}{l}\text { FOLLOW UP } \\
\text { TIME(MONTYS) }\end{array}$ \\
\hline
\end{tabular}

\section{Marshall Marchetti Krantz}

Krantz $^{48}$
Stritumatter
Colombo

Burch colposuspension

Colombo ${ }^{50}$

Bergman ${ }^{\text {st }}$

Ki. ${ }^{52}$

Alcalay ${ }^{5 * 1}$

Feyereisl ${ }^{55}$

Enzelsberger ${ }^{83}$

Kelly anterior colporraphy

Bergman $^{51} \quad 30$

Gittes suspension

$\mathrm{Kil}^{52} \quad 18$

Raz suspension

$\begin{array}{lr}\operatorname{Ramon}^{6.5} & 18 \\ \operatorname{Raz}^{6 x_{5}} & 206\end{array}$

Stamey-Pereyra suspension

34
40
40
33
29
109
87
26
30

96

$\begin{array}{llr}85 & 97.4 & 24 \\ & 65 & 24-84\end{array}$

18

18

206

Bergman ${ }^{51}$

Kil ${ }^{52}$

Ramon ${ }^{65}$

Walker

Trockman" ${ }^{69}$

O'Sullivan ${ }^{70}$

O'Sullivan ${ }^{* 0}$
30
92

72.5

83

90.3

80

82

86

75

81.6

85

37

44

$24-84$

60

30.5

120

$60-120$

15

60

14.7

10

15

$43 \quad 60$

$69 \quad 34.6$

$78 \quad 37$

$70 \quad 60$

$49 \quad 117$

55 60

Table 2. Reported snccess percentages of various suspewsion operations. 
For the Marshall Marchetti Krantz procedure Krantz reported a success rate of $96 \%$ withour giving further details. ${ }^{48}$ Strittmatter mentioned a $97.4 \%$ objective improvement in 34 women after 2 years follow up. "In a prospective randomised trial in 80 women, Colombo et al reported a subjective cure rate of $85 \%$ and a urodynamically defined objective cure rate of $65 \%$ after a follow up of 2 to 7 years. For the Burch colposuspension these percentages were 92 and $80 \%$ respectively. Moreover the Marshall Marchetti Krantz procedure implied a longer hospital stay and more complications. ${ }^{50}$

The Burch colposuspension is regarded as one of the best treatments for stress urinary incontinence. As mentioned above in one of the few comparative studies the Burch came out better than the Marshall Marchetti Krantz. ${ }^{50}$ Bergman and Elia reported in a prospective randomised study among 93 women an objective success rate of $82 \%$ after 5 years follow-up. For the Kelly plication and Pereyra needle suspension this was 37 and $43 \%$ respectively. ${ }^{51}$ In a comparative study Kil et al reported that the initial results were comparable but that the long-term results of the Burch procedure was better ( $86 \%$ continent) compared to the Stamey ( $69 \%$ continent) or Gittes ( $44 \%$ continent). ${ }^{52}$ The results improved when the descent of the bladder neck during stress was minimal. This was also reported by Wall et al who found this to be the most important predictor for success. ${ }^{53}$ The outcome in their series was also dependent on the number of previous urethral operations. Apart from the same finding Alcalay et al also mentioned heavy weight, intraoperative blood loss and de novo detrusor instability as a negative predictor for successful outcome of the Burch colposuspension. ${ }^{54}$ They observed a $75 \%$ cure rate after 10 years with $14 \%$ de novo detrusor instability in 109 women. Feyereisl had the same success percentage after $5-10$ years follow up but did not find a correlation between body weight or previous incontinence operations and outcome. ${ }^{55}$

One of the reported drawbacks of suspension operations which give a negative outcome is the occurrence of de novo detrusor instability. ${ }^{56}$ As mentioned above $14 \%$ was mentioned by Alcalay. ${ }^{54}$ Vierhout and Mulder found de novo detrusor instability in $68(17 \%)$ of 396 women who underwent a Burch procedure. ${ }^{57}$ Virseda-Chamorro et al also reported that de novo detrusor instability still occurred more often in a group of women suffering from both urge and stress incontinence after suspension operation, than in women suffering from stress incontinence alone. ${ }^{58}$ They also concluded that the Kelly plication induced the lowest rate of detrusor instability after operation.

Surprisingly they also observed that in $30 \%$ of the women, operated because of mixed incontinence, the detrusor instability disappeared. Weinberger also reported remittance of detrusor instabilities in $50 \%$ of women who had this phenomenon before a sling operation. ${ }^{59}$ At the same time he had de novo instabilities in $33 \%$ of cases. Nitti et al reported de novo detrusor instabilities in $24 \%$ of 92 women of 65 years and older who 
underwent a Raz suspension. ${ }^{60}$ They also observed that instabilities resolved in $60 \%$ of patients who had instabilities beforehand.

Compared to needle suspensions the Burch colposuspension is more invasive, resulting among others in a longer postoperative recovery and a longer hospital stay. Therefore the less invasive laparoscopic Burch procedure is under attention. The laparoscopic procedure gives comparable results as the open Burch whereas the hospital stay is shorter. The operation time however is much longer. ${ }^{61}$ This can probably be improved because of the steep learning curve. ${ }^{6: 2}$ Compared to transvaginal suspensions the shortterm results are the same, and the postoperative recovery probably is quicker. ${ }^{6.3}$ From the data, which are nowadays available, it can be concluded that the Burch colposuspension is a successful procedure for the anatomical type of incontinence. If randomised studies are performed, the Burch is superior to other procedures. One side effect is the occurrence of de nowo detrusor instability. However preexisting detrusor instabilities also may disappear. This phenomenon resulted in an opportunistic treatment for detrusor instability, which has been described as: "A Burch for urge". The reported results of needle suspensions also vary a lot, however they all have in common that the success percentages decrease with longer follow-up time. As mentioned above in comparative studies the results of transvaginal approaches are not as good as the retropubic Burch procedure. When the transvaginal operations are compared the Gittes procedure is the least successful, probably because one has only limited control..$^{53,64}$ 'The Stamey-Pereyra suspension has long-term results which are comparable to the Raz procedure. Ramon et al had a cure rate of 78 and $83 \%$ respectively. ${ }^{65} \mathrm{He}$ also recommended suspensions for a hypermobile urethra with low urethral pressures. Raz et al reported a success rate (cure or minimal incontinence) of $90.3 \%$ in 206 women after 15 months follow up. ${ }^{66}$ Others however reported a low subjective long-term success rate, despite the high short-term success rate. ${ }^{67}$ Walker and T'exter reported 70\% subjective long-term improvement after a Stamey-Pereyra procedure. Half of the patients were totally dry. ${ }^{68}$ "T'rockman et al reported a continence rate of $49 \%$ after 10 years for the modified Pereyra procedure. Of his patients $73 \%$ were satisfied. ${ }^{69} \mathrm{O}^{\prime}$ Sullivan et al also had a good short-term success rate with $55 \%$ dry patients and $21 \%$ improved patients after the Stamey-Pereyra procedure. After five years however only $18 \%$ were dry. ${ }^{20}$ One can conclude that the long-term continence rates of transvaginal suspension procedures are not $100 \%$, although this does not mean that patients are not satisfied. Probably a moderate improvement already changes patients acceptability of incontinence in a positive way. In this respect one has to keep in mind that micturition control can be more important than total dryness. ${ }^{74}$ 


\section{Slings}

Pubovaginal slings have been used for stress incontinence since the beginning of this century. ${ }^{72}$ Slings are used for intrinsic sphincter deficiency of any origin. It is also a frequent applied operation when other anti-incontinence treatments, including suspensions, have failed. Slings always have been used for complicated cases of stress incontinence. Moreover, a sling operation is regarded as a difficult procedure. "Various native or artificial materials have been used for slings. The first described material used for a sling was the pyramidalis muscle. ${ }^{72}$ Later Frangenheim used the fascia of the pyramidalis muscle together with the muscle. ${ }^{74}$ Deming was the first to use the gracilis muscle for a sling procedure to treat incontinence caused by epispadias. ${ }^{75}$ Other muscles and fascia like the fascia lata also have been used until Aldridge used the rectus fascia. ${ }^{76}$ Because of its favourable anatomy, the rectus fascia has become number one for slings good results were described already in $1953 .^{77}$ Afterwards other materials have been tried for slings, like dacron, polypropylene (Marlex and Prolene), polytetrafluoroethylene (Goretex and Tellon), silastic, lyodura, porcine derma and bovine fascia. Raz introduced the vaginal wall sling. With this technique an in situ sling of anterior vaginal wall, excluding the epithelium is constructed around the vaginal side of the proximal urethra. ${ }^{36}$ Actually this is a combination of a suspension as well as a sling procedure, as can be seen by the published results. Raz and cowrorkers found a failure rate of $7 \%$ in 160 women with eirher anatomical incontinence or intrinsic. sphincter deficiency. The results were the same in the anatomical group $(n=65)$ and the group with intrinsic sphincter deficiency $(n=95) .^{78}$

For the pubovaginal rectus fascia sling procedure a Pfannenstiel incision is made above the pubic bone. The rectus fascia is identified and a fascia strip of approximatelly $1.5 \mathrm{~cm}$ width and $10 \mathrm{~cm}$ long is taken from the lower leaf of the incised transverse rectus fascia. The rectus muscles are split and the retropubic space is entered, pushing the bladder and proximal urethra dorsally. An incision is made in the anterior vaginal wall from the bladder neck to the proximal urethra. Dissection is done laterally to the retropubic space in order to make a tunnel around the proximal urethra. The sling is passed as a free graft retropubically to the vaginal incision, and guided back to the contralateral retropubic side. Endoscopic control can be done to rule out bladder perforation. The sling passes the belly of the rectus muscle and the rectus fascia on both sides, and is tied together with non-absorbable material. The sutures are tied in such a fashion that urethral motion stops. ${ }^{36,73}$ Patients are instructed to perform intermittent selfcatheterisation beforehand or afterwards if necessary.

The complications of slings are woiding difficulty which implies that the patient has to perform self catheterisation. If this is not feasible and urine retention occurs, it is possible to remove the sling or to perform a suburethral sling release ${ }^{79}$ or urethrolysis. ${ }^{89}$ 
De novo detrusor instability has been reported as well as postoperative settled instability. ${ }^{73}$ Infection and erosion of the sling is a major issue in synthetic sling procedures. The reported results of slings are good, also if the sling procedure is performed as a last rescue treatment. Some reported results are listed in table 3.

\begin{tabular}{|c|c|c|c|c|}
\hline TECHNIQUE & $\begin{array}{l}\text { SLING } \\
\text { TYPE }\end{array}$ & $\begin{array}{l}\text { NUMBER OF } \\
\text { PATIENTS }\end{array}$ & $\begin{array}{l}\text { SUCCESS } \\
(\%)\end{array}$ & $\begin{array}{l}\text { FOLLOWW UP } \\
\text { TTME (MONTHS) }\end{array}$ \\
\hline Gromley & rectus fascia & 13 & 93 & 6 \\
\hline Blaivas $^{82}$ & rectus fascia & 67 & 82 & 42 \\
\hline Enzelsberger ${ }^{83}$ & lyodura & 26 & 88 & 30 \\
\hline Herschorn ${ }^{84}$ & $\begin{array}{l}\text { polytetrafluoro } \\
\text { ethylene (2) } \\
\text { rectus fascia (11) }\end{array}$ & 13 & 69 & 34.3 \\
\hline Decter ${ }^{85}$ & $\begin{array}{l}\text { rectus fascia (5) } \\
\text { fascia lata (5) }\end{array}$ & 10 & 40 & 25 \\
\hline Swierzewski ${ }^{8 k}$ & $\begin{array}{l}\text { periurethral } \\
\text { inuscular tissue }\end{array}$ & 7 & 100 & 17 \\
\hline Morgan $^{8 \mathrm{~A}}$ & $\begin{array}{l}\text { polytetrafluoro } \\
\text { ethylene }\end{array}$ & 88 & 85 & 50 \\
\hline Weinberger ${ }^{59}$ & $\begin{array}{l}\text { pollytetrafluoro } \\
\text { ethylene }\end{array}$ & 62 & 61 & 12 \\
\hline
\end{tabular}

Table 3. Reported success percentages of voariows kinds of sling procedure.

Gromley et al had $93 \%$ overall continence rates in 13 patients with type III stress incontinence after six months. ${ }^{81}$ Blaivas and Jacobs reported $82 \%$ continence rate after 3.5 years in 67 women with complicated stress incontinence. ${ }^{82}$ In one of the few comparative studies Enzelsberger compared 26 women who underwent a Burch colposuspension with 26 women who had a lyodura suburethral sling. ${ }^{83}$ After 2.5 years of surgery the success rate in the Burch group was $85 \%$ and in the lyodura group $88 \%$. In patients with neurogenic bladders sling procedures have been applied together with bladder augmentation in order to increase urethral resistance, bladder capacity and bladder compliance. Herschorn reported in this difficult group a continence rate of $69 \%$. He combined the sling with bladder neck tapering in this series of 13 men. ${ }^{84}$ Decter had in 4 out of 10 patients long-term success in a similar patient group if the sling procedure was combined with bladder augmentation. ${ }^{85}$ If this was not done the 
long-term success rate was only $25 \%$. Swierzewski and McGuire reported a $100 \%$ success in 7 women suffering from stress incontinence after 17 months, even if the incontinence was complicated by an urethral diverticulum. ${ }^{* 6}$ The results as well as complications of artificial slings are extensively documented. In a comparative study Goretex slings were regarded as well as fascia lata slings. ${ }^{87}$ The results were comparable whereas the Goretex group tended to cause more postoperative complications. Morgan and coworkers mentioned a $85 \%$ cure rate in 88 women with a Marlex sling ${ }^{88}$ Weinberger and Ostergard reported a satisfying $73 \%$ subjective and $61 \%$ objective cure rate after one year in 62 women treated with polytetrafluoroethylene slings, ${ }^{59}$ However $40 \%$ of the patients developed wound complications and $22 \%$ of the slings were removed. Bent et al reported that 23 of 115 slings had to be removed because of tissue reaction. ${ }^{89}$ The sling procedure is an effective and successful treatment of stress urinary incontinence, especially for incontinence caused by intrinsic sphincter deficiency. Slings can be regarded as the procedure of choice for complicated cases of incontinence, e.g in cases of earlier operative procedures. Autologous sling material has minimal documented complications compared to artificial material and therefore is highly preferable.

\section{Injectables}

Collagen, polytetrafluoroethylene (Teflon), silicone microimplants (Macroplastique ${ }^{\mathrm{TM}}$ ) or fat can be injected periurethrally to increase the mechanical resistance of the bladder outlet. The indication for injectables is intrinsic sphincter deficiency. The treatment is less suited for patients with intrinsic sphincter deficiency concomitant with a hypermobile urethra. ${ }^{90}$ These procedures can be done on an outpatient basis under local anaesthesia. Repeated injections in the same patient is also feasible and easy. Teflon was used already years ago for treatment of stress incontinence. However reports on teflon particle migration, granulomatous reactions like foreign body giant cell response or urethral abscesses make it a less suitable application. ${ }^{91.92 .93}$ The reported results as well as complications vary substantially. Results are listed in table 4. Lopez and coworkers reported a success rate of $73 \%$ in 128 women with moderate to severe stress incontinence at a mean follow up of 31 months. There were minimal side effects. ${ }^{93}$ Kabalin found the effect after prostatic surgery not very substantial. ${ }^{94} \mathrm{He}$ performed 20 injections in 13 patients suffering from incontinence after prostatic surgery. Of the patients $77 \%$ did not perceive any improvement of the treatment, whereas $23 \%$ improved but were not cured. Fortunately, no side effects were found in this study. Kiilholma et al had an $18 \%$ cure rate in female patients after 5 years follow up. However after one year only 2 out of 8 men maintained improvement. ${ }^{92}$ They also observed in 4 out of 30 patients complications caused by teflon. The general opinion is that Teflon is suitablle in patients suffering from a lesser degree of stress incontinence but that the drawbacks can't cope with the advantages. 
TECHNIQUE

NUMBER OF
PATENTS

SUCCESS

FOLLOW UP

$(\%)$

TIME (MONTHS)

Teflon (polytetrafluoroethylene)

$\begin{array}{lrrr}\text { Lopez }^{93} & 128 & 73 & 31 \\ \text { Kabalin }^{94} & 13 & 23 & 11-36 \\ \text { Kuilholmat }^{92} & \text { women: } 22 & 18 & 60 \\ & \text { men: } 8 & 25 & 12\end{array}$

Glutaraldehyde X-linked collagen

Goldenberg $^{98} \quad 190$

Appell

Bomalski ${ }^{100}$

$190 \quad 82$

Silicone microimplants

Harris 104

Autologous fat

Buckley $^{105} \quad 144$

Cervigni ${ }^{106}$

Santarosa ${ }^{\text {so }} \quad 15$

Trockman "

$14 \quad 86$

$32 \quad 56$

3

14

$66-9.7$

$66-11$

31

60

2

.5

5

$56-6$

Table 4. Results of injectables with warious types of material

To overcome the disadvantage of the observed particle migration by Teflon, bovine dermal collagen has been processed for periurethral injections. ${ }^{95}$ It is cross linked with glutaraldehyde and dispersed in phosphate-buffered physiologic saline. The final result improves the integrity for injection. ${ }^{96}$ "The product is biodegradable and biocompatible and causes no foreign-body response. ${ }^{97}$ Degradation of the material starts after 12 weeks. Neovascularisation, deposition of fibroblasts and autologous collagen occur at the injection site. ${ }^{95}$ This reaction is thought to secure the long-term beneficial effect. The product is marketed as Contigen (CR Bard Co, Covington, GA). Goldenberg reported a cure rate of $30 \%$ and a significantly improvement rate in $52 \%$. This lasted on average 5.4 months in a group of 190 women, suffering from all types of stress incontinence. ${ }^{98}$ Appell reported $34 \%$ improved and $46 \%$ cured patients after one year follow up, in a group of 372 women suffering from intrinsic sphincter deficiency. In the improved group after two years the improvement rate was $77 \%$. The leak point pressure improved with $39,5 \mathrm{~cm}$ water after two years. T'wo patients developed a hypersensitivity response. ${ }^{99}$ Cross linked collagen has been used successfully in children with stress incontinence because of spina bifida or epispadias. The reported short-term results are $22 \%$ cure and $54 \%$ improvement. ${ }^{100}$ So far at least the short-term results of cross linked bovine collagen are promising and the side effects minimal. Allergic reactions occur in $3 \%$ of patients, the other side effects are minimal. ${ }^{101}$ Silicone microimplants (Macroplastique ${ }^{\mathrm{TM}}$ ) have been introduced lately. The material 
consists of solid textured polydimethylsiloxane particles suspended in a non-silicone carrier gel. After injection, the gel is processed by the reticuloendothelial system and excreted unchanged in the urine. The polydimethylsiloxane particles stay behind and are capsulated in fibrin. The biggest part of the particles have a size over $100 \mu \mathrm{m}$. (mean size $163 \mu \mathrm{m}$ ). They are too large to be phagocytosed and therefore it is unlikely that they will migrate. ${ }^{102}$ Animal studies showed that the particles stayed at the injection site for at least 9 months. ${ }^{103}$ However, since a minor part of the particles is less than 100 $\mu \mathrm{m}$, these particles might migrate. Since no long-term experience exist so far, the possible risks of migration are not yet known. Harris et al recently reported the results of Macroplastique ${ }^{\mathrm{TM}}$ in 40 women with genuine stress incontinence. ${ }^{10 .}$ Three months after injection $40 \%$ were dry, 33\% were improved and $27 \%$ were unchanged. Four improved patients underwent a second treatment with Macroplastique ${ }^{\mathrm{TM}}$. After three years the $40 \%$ had remained dry, $18 \%$ were still improved and $42 \%$ required another treatment for incontinence. No migration was observed. These results are similar of those reported by Buckley et al. ${ }^{105}$

Autologous fat injections is been used recently as a cheap alternative for "Teflon, collagen or silicone particles. The advantages are the biocompatibility, the price and the availability. Fat tissue is harvested from the lower abdominal subcutis and injected periurethrally. The technique is safe and is a potential treatment for intrinsic sphincter deficiency. Sofar the long-term effect remains unclear. Cervigni et al reported 8 cured women, 4 improved and 2 failures at a mean follow-up of 9.7 months. ${ }^{106}$ Santarosa and Blaivas found the technique useful in women with stress incontinence. ${ }^{90}$ Of 12 women with intrinsic sphincter deficiency, 7 were improved with repeated injections with persisting success. The technique failed however in post radical prostatectomy patients. Trockman reported 4 cured patients, 14 improved patients and 14 failures after a mean follow-up of 6 months. ${ }^{101}$ The average improvement was $60 \%$ although it was not mentioned how this was measured. All patients were women suffering from intrinsic sphincter deficiency.

\section{Artificial urinary spbincter}

Nowadays the most applied artificial urinary sphincter is the current model from American Medical Systems; the AS 800. The concept of this artificial sphincter is an inflatable cuff encircling the urethra. When the cuff is inflated, circular compression of the urethra is effected, the urethra is closed and continence is obtained. In 1947 it was Foley who developed this concept and designed the first urethral cuff which could be inflated by a sort of syringe. ${ }^{107}$ Because of a lack of acceptance it was not generally applied. In 1973 Scott et al conceived the idea of the AS 721, one of the first artificial sphincters preceding the AS $800 .{ }^{108}$ 'The development from the AS 721 to the AMS 800 comprised the introduction of the pressure regulation balloon (AS 761), automatic reflation sphincter (AS 742, AS 791/792) and controlled activation and deactivation 
(AS 800). The AS 800 consists of a urethral cuff of silicone elastomer. This cuff is placed around the bulbous urethra in men or around the bladder neck in women. The cuff is connected to a control pump which is placed in the male scrotum or the female labium. The pump is connected to a pressure-regulating balloon, which is placed in the prevesical space. The cuff size is selected after having measured the urethral circumference. The balloon pressure reservoir varies with respect to the reservoir pressure. If the chosen reservoir has a too low pressure, no closure will be achieved, whereas erosion of the urethra occurs if the pressure is too high. After implantation of the device, several weeks are waited before activation of the artificial sphincter, in order to let the wounds heal. If the patient wishes to activate the sphincter he can push the pump control, which contains a valve to deflate the balloon and inflate the cuff. The urethra is now closed. If the patient pushes the pump control once again, the cuff is deflated and the balloon is filled with the fluid coming from the cuff. The urethra is open in order to void. After approximately two minutes the fluid is running gradually from the balloon and inflates the cuff in order to close the urethra gently. The main associated complications of this device are mechanical dysfunctioning, infection because of the foreign body material, erosion of the urethra dute to too high cuff pressures and urethral obstruction.

Scott reported an overall success rate of the AS 721 of $68 \% .{ }^{110}$ Donovan, Barrett and Furlow reported in 21 out of $31(68 \%)$ women cure or improvement, two years after implantation. ${ }^{11}$ Fifty-two procedures were necessary for the 21 successes. One of the main problems was that most of the women had had previous surgery. Webster reported in 24 of 25 women improvement and no revisions. ${ }^{112}$ Gundiau et al reported $22 \%$ complications after prostatectomy. ${ }^{13}$ Martins and Boyd reported infection-erosion in $9 \%$ of 145 men. ${ }^{114}$ Especially men who had radiotherapy were prone to infectionerosion. In another manuscript they mentioned in $38 \%$ of 81 men surgical revisions, mainly because of urethral atrophy. ${ }^{115}$ Ghoniem and coworkers analysed persisting incontinence implant of the AS $800 .^{116}$ Infection and erosion occurred in 7 of 30 patients, detrusor instability in 9 patients and bladder outlet obstruction in 2 patients. Because not all patients are continent with an artificial sphincter, Brito et al used a double cuff AS 800 with success in $80 \%$ of patients who were still incontinent with one artificial sphincter. ${ }^{117}$

To summarise, the artificial sphincter has good results in a group of patients who are difficult to treat because of the severeness of their incontinence. The treatment however is with substantial risk of infection-erosion because of the intrinsic qualities of the implantable device, but also because of former treatments or the underlying cause of incontinence. Therefore the need for optimising the device or seeking for other treatment modalities is still mandatory. 
Two robust ultimate options remain when the above mentioned treatments are considered not to be eligible. The first is to leave the incontinence and give support and comfort by means of absorbent products, condom-catheters etc. The other one is to perform a urinary diversion like an incontinent Bricker ileal conduic, a continent Cock pouch or a wet stoma. It is obvious that these options are mostly negative choices, which are selected when patients do not wish to be operated upon, the operation risk is unacceptable or when all other treatments failed. 


\section{References}

1. Remmers $\mathrm{A}$

Prevalence of urinary incontinence in elderly people

In:Urinary incontinence and woiding disorders in the elderly, towards acceptable and applicablile diagnostic eval wation. Universinaire Pers Maastrich 1994:13-27.

2. Branch $\mathrm{LG}_{3}$ Walker $\mathrm{LA}$, Wetle "TT, DuBeau $C E_{1}$ Resnick NM

Urinary incontinence knowledge among community-dwelling people 65 years of age and older

J Am Geriatr Soc 1994;42:1257-1262.

3. Jagger $\mathrm{C}$, Clarke $\mathrm{M}$, Davies RA The elderly at home: indices of disability J Epid Comm Health 1986:40:139-142.

4. Noelker LS

Incontinence in elderly cared for by family Gerontologist 1987;27:194-200.

5. Ekelund P, Rundgren $\mathrm{A}$

Urinary incontinence in the elderly with implications for hospital care consumption and social disability

Arch Gerontology Geriatr 1987;6:11-18.

6. Ifoshi 'T, Nakahara T, Hashimoto S, Hayashi M, Takabnyashi K, Miki K, Takigawa Y, Kitagawa 5

Prevalence of urinary incontinence among institutionalized persons aged 60 and over in Japan

Nippon Koshu Eise: Zasshi 1995;42:482-490.

7. Feneley RCL, Shepherd AM, Powell PH, Blannin J

Urinary incoutinence: prevalence and needs

Br. Urol 1979;51:493-496.

8. McGrother $\mathrm{CW}$, Castleden $\mathrm{CM}$, Duffin $\mathrm{H}$, Clarke M

Provision of services for incontinent elderly people at home

J Epid Comm Health 1986;40:134-138.
9. Lara C, Nacey J

Ethnic differences between Maori, Pacific Island and European New Zealand women in prevalence and attitudes to urinary incontinence N Z Med J 1994;107:374-376.

10. International Continence Society; Standardisation Committee The Standardisation of Terminology of lower urinary tract function Scand J Urol Nephrol 1988;114:5-19 (suppl).

11. Harrison GL, Memel DS

Urinary incontinence in women: its prevalence and its management in a health promotion clinic

BrJ Gen Pract 1994;44:149-152.

12. Diokno AC, Brock BM, Brown MB, Iferzog AR

Prevalence of urinary incontinence and other urological symptorns in the noninstitutionalized elderly J Urol 1986;136:1022-1025.

13. Van Waalwijk wan Doorn ESC Sensitivity and specificity of conventional urodymamics with respect to urinary incontinence In:Ambulatory urodynamics.ASKA lekst + druk bv Alphen ad Rijn, NL 1993: $15-47$.

14. Hautman RE, Sauter TW, Wenderoth AU Radical retropubic prostatectomy: morbidity and urinary continence in 418 consecutive cases Urology 1994;43:47.51.

15. Diokno AC, Taub $M$ Ephedrine in treatment of urinary incontinence Urology 1975;5:624-625. 
16. A wad $\mathrm{S}$, Downie J, Kiruluta $\mathrm{H}$ Alphaladrenergic agents in urinary disordes of the proximal urethra: part $I$. sphincteric incontinence Br J Urol 1978,50,332-335.

17. Agency for Health Care Policy and Research Urinary incontinence Guideline Panel: urinary incontinence in adults: Clinical Practice Guideline AHCPR 1992:publication 92-0038.

18. Rud I

Urethral pressure profile in continent women from childhood to old age Act Obstet Gynaecol Scan 1980,59:331-335.

19. Jackson $\$$, Avery $N$, Shepherd A, Abrams P, Bailey $A$

The effect of oestradiol on vaginal collagen in postmenopausal women with stress urinary incontinence

Neurourol Urodynam 1996,15;327-328.

20. Raz $S$, Ziegler $\mathbb{M}$, Cane $\mathbf{M}$

The role of female hormones in stress incontinence

In:Proceedings of 16 th congress of Societe International d" Urologie 1973;1:397.

21. Beisland $\mathrm{H}$, Fossberg $\mathrm{E}$, Moer A, Sander $\mathrm{S}$ Urethral sphincter insufficiency in postmenopausal females: treatment with phenylpropanolamine and estriol separately and in combination Urol Int 1984;39.211-216.

22. Hilion ${ }^{2}$, Tweddel A, Mayne C Oral and intrayaginal estrogews alone and in combination with alpha adienergic stimulation in genuine stress incontinence Int Urogynecol 1990;:1:80 86 .

23. Jackson $S$, Shepherd A, Abrams The effect of oestradiol on objective urinary leakage in postmenopausal stress incontinence; a dowble blind placebo controlled tritill Neurourol Urodynam 1996;15:322-323.
24. Kegel A

Progressive resistance tercise in the functional restoration of the perineal muscles

Am J Gynecol 1948;56:238248.

25. Bump R, Hurt W, Fand J, Wyman JF Assessment of Kegel pelvic muscle exarcisc performance after brief verbal instruction An I Obstet Gynecol 1991;165:322-329.

26. Plevmik $S$

New method for testing and strengthening of pelvic floor muscles

In: Proceedings of the International

Comtinence Society 1985:267:268.

27. Devieeze M. Verecken $R$, wan Assche I: Perineal pllysiotherapy in the treatment of fenule urinary incontinence as an allernative to surgery Int Urogynaecol 1992;3:33.

28. Peatie A, Plevnik S, Stanton S Vaginal cones: a conservative method of treating genuine stress incontinence Br J Obstet Gynaecol 1988;95:1049-1053.

29. Dellas A. Drewe J

Conserwative therapy of fenvalle genuine stress incontinence with vaginal cones Eur J Obstet Gyn R B 1995;62:213-215.

30. Ellia $G$, Bergman $A$

Pelvic muscle exercises: when do they worte?

Obstet Gynecol 1993:81:283-286.

31. Bouchier $A$, Juras J

Nonsurgical therapy for stress incontinence Urol Clin North Am 1995;22:616-619

32. Burns 1 , Pranilueff $\mathrm{K}$, Nochajski" Hadley $\mathbb{E}_{\text {, Lewy }} \mathrm{K}$, Ory $\mathrm{M}$

A comparision of effectiveness of biofeedback and pelvic musele exercise treatment of stress incontinence in older community-dwelling women J Gerontol 1993;48:167-174. 
33. Fall $M$, Ahlstrom $K$, Carlsson $C_{\text {, EK }} A_{\text {" }}$ Entandson $B$, Frankentberg 5 , Mattiason $A$ Contelle: pelvic flo or stimulator for female stress-urge incontinerice Urology 1986:27:282-287.

34. Yasuda K, Hattor T, Suda S, Hosaka H Pelvic floor electrical stimulation in the treatment of stress incontinence: a placebo controlled double-blind trial Neurourol Urodyn 1996;15:397-398.

35. Weil E, van Walwijk wan Doorn E, Heesakkers J, Meguid "T, Janknegt R Transvaginal ultrasonography: a study with healthy volunteers and women with genuine stress incontinence Eur Urol 1993;24:226-230.

36. Raz S, Litule $\mathbb{N}_{2}$ Juma $S$ Female urology; surgery for stress incontinence

In: Campbell's Urology 6rh edition. Editor Walsh PC. WB Saunders \& Cie 1992:27942806.

37. Marshall V'T, Marchetti AA, Krantz KE The correction of stress incontinence by simplle vesicourethral stuspension Surg Gynecol Obstet 1949;88:509-518.

38. Burch J

Urethrovaginal fixation to Cooper's ligament for correction of stress incontinence, cystocele and prolapse AmJ Obstet Gynecol 1961;81:281-290.

39. Kelly HA, Dumm WM

Urinary incontinence in women, without manifest injury to the bladder Sung Gynecol Obstet 1914:18:444-450.

40. Warrell A

Anterior repair

In: Surgery for fernale incontinence 2 nd edirion. Editors Stanton SL. Tanagho EA. Springer Verlag 1986:77-85.
41. Pereyra Al

Simplified surgical procedure for the correction for stress incontinence in women

West J Surg 1959;67:223-22\%.

42. Stamey $T A$

Endoscopic suspension of the vesical neck for urinary incontinence Surg Gynecol Obster 1973;136:547-554,

43. Stamey $[\mathrm{A}$

Endoscopic suspension of the vesical neck In: Surgery for fermale incontinence 2nd edition. Editors Stanton SL, Tanagho EA. Springer Verlag 1986:115-132.

44. Raz S

Modified bladderneck suspension for female stress incontinence Urology 1981;17:82-84.

45. Stothers $\mathrm{I}$, Chopra A, Raz S Vaginal reconstructive surgery for female incontinence and anterior vaginal-wall prolapse

Urol Clin North Am 1995;22:641-655.

46. Girtes RF, Loughlin KR

No-incision pubovaginal suspension for stress incontinence

J Urol 1987:138:568-570.

47. Sirls LT, Keoleian CM, Korman HJ, Kirkemo AK

The effect of study methodology on reported success rates of the modified Pereyra bladder neck suspension J Urol 1995;154:1732 1735.

48. Kranta KE

The Marshall Marchetti Krantz procedure In: Surgery for female incontinence 2 nd edition. Editors Stanton SL, Tamagho EA. Springer Verlag 19:86:87-93. 
49. Sirittmatter H], Neises M, Wischnik A, Melchert F

Marshall-Marchetti-Krantz Operation oder Faszienzügelplastik zur Therapie der rezidivharninkontinenz der Fraus Gebursh u Fratuenheilk 1993;53:630-634.

50. Colombo $\mathrm{M}$, Scalambrino S, Maggioni $\mathrm{A}$, Milani $R$

Burch colposuspension versus modified Marshall-Marchetti-Krantz urethropexy for primary stress urinary incontinence: a prospective, randomized clinical trial An J Obstet Gynecol 1994:171:1573-1579.

51. Bergman A, Elia $G$ Three surgical procedures for genuine stress incontinence: five-year follow-up of a prospective randomized study Am J Obstet Gynecol 1995;173:66-71.

52. Kil PJ, Hoekstra JW, van der Meijden AP, Smans AJ, Theeuwes AG, Schreinemachers LM Transvaginal ultrasonograpliy and urodynamic evaluation after suspension operations: comparison among Gittes, Stamey and Burch suspensions JUrol 1991;146:132-136.

53. Wall LL, Helms M., Peatrie AB, Pearce M, Stanton SL

Bladdler neck mobility and the outcome of surgery for genuine stress urinary incontinence. A logistic regression analysis of lateral bead-chain cystourethrogranss J Reprod Med 1994;39:429-435.

54. Alcallay M, Monga A, Stanton SL

Burch colposuspension: a 10-20 year follow up

BrJ Obstet Gynaecol 1995;102:740-745.

55. Feyereisl J, Dreher E, Haenggi $W$, Zikmund J, Schneider $H$ Long-term results after Burch colposuspension Am J Obstet Gynecol 1994;171:647-652.
56. Kelly MJ, Knialsen $\mathbb{K}$, Bruskewiti $\mathbb{R}$, Roskamp D, Leach GE Symptom analysis of patients undergoing modified Pereyra bladder neck suspension for stress wirinary incontinence. Pre- and postoperative findings Urology 1991,37:213:219.

57. Vierhout ME, Mulder AF

De nowo detrusor instabilicy after Burch colposuspension

Acta Obster Gynecol Scand 1992,71:414416.

58. Virsedi-Chamorro M, Salinas-Casado J, Ramirez-Fermandez. JC, Rapariz-Gonzalez $M$, Esteban-Fuertes M, Nacarino Corbacho L, Resel-Estevez L

Repercusion de los sintomas irritativos vesicales e inestabilidad dell detrusor en los resultados de la uretropexia Arch Esp de Urol 1995;48:595-601.

59. Weinberger MW, Ostergard DR Long-term clinical and urodynamic evaluation of the polytetraffuoroethylene suburethral sling for treatment of genuine stress incontinence

Obstet Gynecol 1995;86:92-96.

60. Nitri WM, Bregg KJ, Sussman EMM, Raz S The Raz bladder neck suspension in patients 65 years old and older J Urol 1993;149:802-807.

61. Polascik TJ, Moore RG, Rosenberg MT, Kavoussi LR.

Comparison of laparoscopic and open retropubic urethropexy for treatment of stress urinary incontinence Urology 1995;45:647-652.

62. Radomski $\mathrm{SB}_{0}$ Herschthorn $\mathrm{S}$ Laparoscopic Burch bladder neck suspension: early results J Urol 1996:155:515-518.

63. McDougall EM, Kilutke CG, Cornell "I" Comparison of transwaginal versus: laparoscopic bladder neck suspension for stress urinary incontinence Urology 1995; 45:641-646. 
64. Narshima M, Kondo $A$ Needle suspension of the bladder neck for stresy urinary incontinence surgical results of 394 patients operated on with quanticative procedures

Nippon Hinyokika Gakkai Zasshi 1995;36:1051-1059.

65. Ramon J, Mekras J, Webster GD Transvaginal needle suspension procedures for recurrent stress incontinence Urology 1991;38:519-522.

66. Raz $\$$, Sussman EM, Erickson DB, Bregg KJ, Nitri VW

The Raz bladder neck suspension: results in 206 patients

J Urol 1992:148;845-850.

67. Bosman $G$, Vierhout ME, Huikeshoven FJ A modified Raz bladder neck stuspension operation. Results of a one to three years follow-up investigation

Acta Obstet Gynecol Scand 1993;72:47-49.

68. Walker GT, Texter JH

Success and patient satisfaction following the Stamey procedure for stress urimary incontinence

J Urol 1992;147:1521*1523.

69. Trockman BA, Leach GE, Hamilton T, Sakamoto M, Santiago L, Zimmern PE Modified Pereyra bladder neck suspension: 10 year followup using outcomes analysis ind 125 patients

Urol 1995:154:1841-1847.

70. O'Sullivan DC, Chilton CP, Munson KW Should Stamey colposuspension be our primary surgery for stress incontinence? BrJUrol 1995:75:457-460.

71. Groeneweg JM, Vierhout ME, Mulder AF Subjectief en objectief succes wan colposuspensic volgens Burch ten aanzien van continentie, tevredenheid en mictiepatroon

Ned Tijdschr Geneeskund 1994;138; $1277-1280$.
72. Gaebbell $\mathrm{R}$

Zur operativen beseitigung der Angeboremen incontinentia Urinae Ztschr Gynaek 1910;2:187.

73. McGuire EJ Surgical treatment of intrinsic wrethral dysfucntion: slings: Urol Clin North Am 1995;22:657-664.

74. Frangenheim $P$

Zur operativen Behandlung der Inkontinenze der mannlichen harnrohe Verth Deutsch Ges F Chir 1914:43:49.

75. Deming $\mathrm{CL}$

Transplantation of the gracilis muscle for incontinence of urine JAMA 1926:86:822-825.

76. Aldridge AH

Transplantation of fascia for relief of urinary stress incontinence Am J Obstet Gynecol 1942;44:398-411.

77. Jeffcoate TNA

The results of the Aldridge sling operation for stress incontinence J Obstet Gynaecol Brit Emp 1953;63:36-39.

78. Raz S, Stothers L, Young GP, Short J, Marks B, Chopra A, Wahle GR Vaginal wall sling for anatomical incontinence and intrinsic sphincter dysfunction: efficacy and outcome analysis IU Urol 1996;156:166-170.

79. Brubatker L

Suburethral sling release

Obstet Gynecol 1995;86:686-688.

80. Foster $\mathrm{HE}$, McGuire EJ

Management of urethral obstruction with transwaginal urethrolysis J Urol $1993 ; 150: 1448-1451$.

81. Gormley EA, Bloom DA, McGuire EJ, Ritchey ML

Pubovaginal slings for the management of urinary incontinence in female adolescents J Urol 1994:152:822-825. 
82. Blaivas $J G$, Jacobs $B Z$

Pubovaginal fascial sling for the treatment of complicated stress urinary incontinence J Urol 1991; 145:121*-1218.

83. Enzelsberger $H$, Kurz $C$, Seifert $M$,

Raimann $\mathrm{H}$, Schatten $\mathrm{C}$

Zur operativen Behandlung der

Rezidivstressinkontinenz: Burch-versus

Lyoduraschlingenoperation - eine

prospektive Studie

Geburtsh u Fravenhellk 1993;53:467-471.

84. Herschorn $S$, Radomski SB

Fascial slings and bladder neck tapering in the treatment of male neurogenic incontinence

J Urol 1992;147:1073-1075.

85. Decter RM

Use of the fascial sling for neurogenic incontinencellessons learned

J Urol 1993;150:683-686.

86. Swierzewski SI, McGuire EJ

Pubovaginal sling for treatment of female stress urinary incontinence complicated by urethral diverticulum

J Urol 1993;149:1012-1014.

87. Ogundipe A, Rosenzweig BA, Karram MM, Bilumenfeld $D_{n}$ Bhatia NN

Modified suburethral sling procedure for treatment of recurrent or severe stress urinary incont inence

Surg Gynecol Obstet 1992;175:173-176.

88. Morgan JE, Heritz DM, Stewart FE,

Connolly JC, Farrow GA

The polypropylene pubovaginal sling for the treatment of recurrent stress urinary incontinence

J Urol 1995;154:1013-1014.

89. Bent $A E$, Ostergard DR, Zwick-Zaffuto $M$ Tissue reaction to expanded polytetrafluoroethylene suburethral sling for urinary incontinence: clinical and histologic study Am J Obster Gynecol 1993;169:1198-1204.
90. Santarosa $\mathbb{R}_{y}$ Bhaivas J

Periurethral injection of autologous fat for the treatment of sphincteric incontinence J Urol 1994;151:607-611.

91. McKinney $C D, G a f f e y$ M], Gillenwater $M$ Bladder outlet obstruction after multiple periurethral polytetrafiuoroethylene injections J Urol 1995;153:149-151.

92. Kiilholma $\mathrm{P}$, Chancellor $\mathrm{M}_{8}$ Makinen $\mathrm{J}$, Hirsch I, Klemi P

Complications of Teflon injection for stress urinary incontinence

Neurourol Urodyn $1993 ; 12: 131-137$.

93. Lopez A, Padion O, Patsias G, Politano V Transurethral polytetrafluoroethylene injection in fermale patients with urinary continence

J Urol 1993;150:856-858.

94. Kabalin J

Treatment of post-prostatectomy stress urinary incontinence with periurethral polytetrafluoroethylene paste injection J Urol 1994:152;1463-1466.

95. Winters J, Appell R

Periurethral injection of collagen in the treatment of intrinsic sphincter deficiency in the female patient

Urol Clin North Am 1995:22:6734678.

96. MePherson J, Wallace D, Pier K

Development and biomechanical characterization of injectable collagen J Dermatol Surg Oncol 198:;14:13.

97. Leonard M, Canning D, Epstuin J, Gearhart J, Jeffs $\mathbb{R}$

Local tissue reaction to the subureteral injection of glutaraldehyde cross-linked bowine collagen in humarns J Urol 1990;143:1209-1212.

98. Goldenberg $S$, Warkentin $M$ Periurethiral collagen injection for patients with stress urinary incontinence J Urol 1994;151:479 A (suppl). 
99. Appell $\mathrm{R}$, McGuire $\mathrm{E}$, DeRiduder $P$, Bennet $A$, Webster $\mathrm{C}_{3}$ Badlani $\mathrm{G}$, Bennat $J$, Creen $B$ Summary of effectiveness and safety in the prospective, opien, multicenter investigation of contigen implant for incontinence due to incrinsie sphincter deficiency in females

J Uro 1994;151:418A (suppl).

100. Bomalaski M, Bloon D, MoGuire E, Fanzl A

Glutaraldetyde cross-linked collagen in the treatment of urinary incontinence in children

J Urol 1996; 155:699-702.

101. Trockman, Leach $\mathrm{G}$ Surgical treatment of intrinsic urethral dysfunction: injectables (fat)

Urol Clin North Am 1995;22:665-671.

102. Athanastou $\$$, Cardozo L

Silicone implants for stress incontinence $\mathrm{Br}$ J Unol 1996;78:726-728.

103. Henly DR, Barrett DM, Weiland TL Particulate silicone for use in periurethral injection: local tissue effects and search for migration

J Urol 1995;153:2039-2043.

104. Harris DR, Incovon JW, Lemberger RJ Peri-urethiral sificone microimplants (Matroplastique ${ }^{\text {TM }}$ ) for the tieatment of genuine stress incontinence Brj Urol 1996;78:722-725.

105. Buckley $\sqrt{ } \mathrm{F}$, Lingam $\mathrm{K}$, bloyd $\mathrm{SN}$, Meddings $\mathbb{R}_{y}$ Scott R, Kirk D, Deane R, Kyle K Injectable silicone macroparticles for fernale urinary incontinence JUrol 1993;1:49:759A (suppl).

106. Cervigni $M, P$ anei $M$

Periurethral autologous fat injection for type III stress urinary incontinence J Urol 1993;149:403A (suppl).
107. Foley FEB

An artificial sphincter: a new dewice and operation for control of enuresis and urinary incontinence

J Urol 1947;58:250-259.

108. Scott FB, Bradley WE, Timm GW Treatment of urinary incontinence by implantable prosthetic sphincter Urology $1973 ; 1: 252-259$.

109. Furlow wiL

Artificial Sphincter

In: Surgery for female incontinence 2 nd edition. Editors Stanton SL, Tanagho EA. Springer Verlag 1986:155-173.

110. Scot FB

The artificial sphincter in the management of incontinence in the male

Urol Clin North Am 1978;5:375-391.

111. Donovan MG, Barrett DM, Furlow WL Use of the artificial urinary sphincter in the management of severe incontinence in females

Surg Gynecol Obstet 1985;161:17-20.

112. Webster GD, Perz LM, Khaury JM, Timmons $\mathrm{Sl}$

Management of type III stress urinary incontinence wsing artificial urinary sphincter

Urology 1992;39:499-503.

113. Gund hau JC, Barrett DM, Parulkar BG Mayo Clinic experience with the AS 800 artificial urinary sphincter for urinary incontinence after transurethral resection of prostate or open prostatectomy Urology 1993; 41:318-321.

114. Martins FE, Boyd SD

Postoperative risk factors associated with artificial urinary sphincter infectionerosion

Br J Urol 1995;75:354-358. 
115. Martins FE, Boyd SD

Artificial arinary sphincter in patients following major pelvic surgery and/or radiotherapy:are they less favourable candidates?

JUrol 1995;153:1188-1193.

116. Ghoniem GM, Lapeyrolerie J, Saod OP, Thomas $\mathbf{R}$

Tulane experience with management of urinary incontinence after placement of an artificial urinary sphincter World J Urol 1994;12:333-336.

117. Brito CG, Mulcahy JJ, Mitchell ME, Adams MC Use of a double cuff AMS 800 urinary sphincter for severe stress incontinence J Urol 1993;149:283-285. 

Muscle plasticity

Chapter 2 


\section{Introduction}

Deming was the first to describe the graciloplasty for urinary incontinence in JAMA in 1926.' In a population of children suffering from total incontinence because of epispadia, he detached the gracilis muscle at its insertion under the knee and wrapped it around the urethra. While pressing the knees tightly against each other by activating the adductors, including the gracilis muscle, the patients could actively evoke continence. The drawback of this technique was and is that it is not possible to maintain continence for a long time, because a skeletal muscles is used. The reason is that most skeletal muscles, including the gracilis muscle, are prone to fatigue because they act on anaerobic glycolysis. When the energy pool of glycogen is depleted it is not possible to sustain longlasting contractions. For this reason the urinary graciloplasty was not a widespread used technique and was finally abandoned, although some successful short term results have been reported. ${ }^{2,3}$

Since the last decades it is known that by chronical electrical stimulation it is possible to change the properties of muscles. Skeletal muscles can be changed from fast, strong and fatigable muscles into muscles which are slower and able to sustain longlasting contractions. The advantage of electrical stimulation compared to muscle exercise is the possibility to activate a single muscle even continuously and that stimulation parameters can be tailored to individual muscle specifications. Muscle exercise comprises groups of muscles, it can not be repeated infinitely and presupposes patients cooperation. Therefore electrical stimulation is better suited for changing muscle characteristics. The development of implantable devices with muscle electrodes or nerve electrodes can be implanted in animals or humans. With adjustment of the stimuli characteristics on a remote basis, it is possible to change muscles properties gradually, taking advantage of muscle plasticity capabilities. This means that in a dynamic way the muscle is moulded into an intended shape, e.g. into a muscle with sphincter like properties.

\section{Skeletal muscle anatomy}

Striated skeletal muscle consists of muscle bundles or muscle fasciculi. One muscle fasciculus consists of several muscle fibres. These are long multinucleated cells of 10-100 microns. The muscle fibres are enveloped by a layer of connective tissue, the endomysium. The muscle fibres consists of cross striated myofibrils, which are present parallel to one another in the sarcoplasma. The striated pattern of the myofibrils is caused by the strict arrangement of actin and myosin, the main muscle proteins. These 
proteins are positioned parallel to one another in contractile elements, the sarcomeres. The myofibrils are surrounded by the sarcoplasmatic reticulum, a close meshed network which serves to transmit the excitary impulse into the interior of the muscle. It also has an important function in transport of nutrients and metabolites.

\section{Musclle contraction}

Actin and myosin are responsible for muscle contraction. The proteins are arranged parallel and alternated to one another in such a way that they can slide into each other. When the muscle is activated, myosin slides parallel to actin thereby shortening the length of the sarcomere (fig. 1). The result of shortening of a number of sarcomeres is an isotonic muscle contraction.

A muscle contraction is started when a nerve impulse reaches the neuromuscular junction and releases $\mathrm{Ca}^{2+}$ via the sarcoplasmatic reticulum in the sarcomere. The

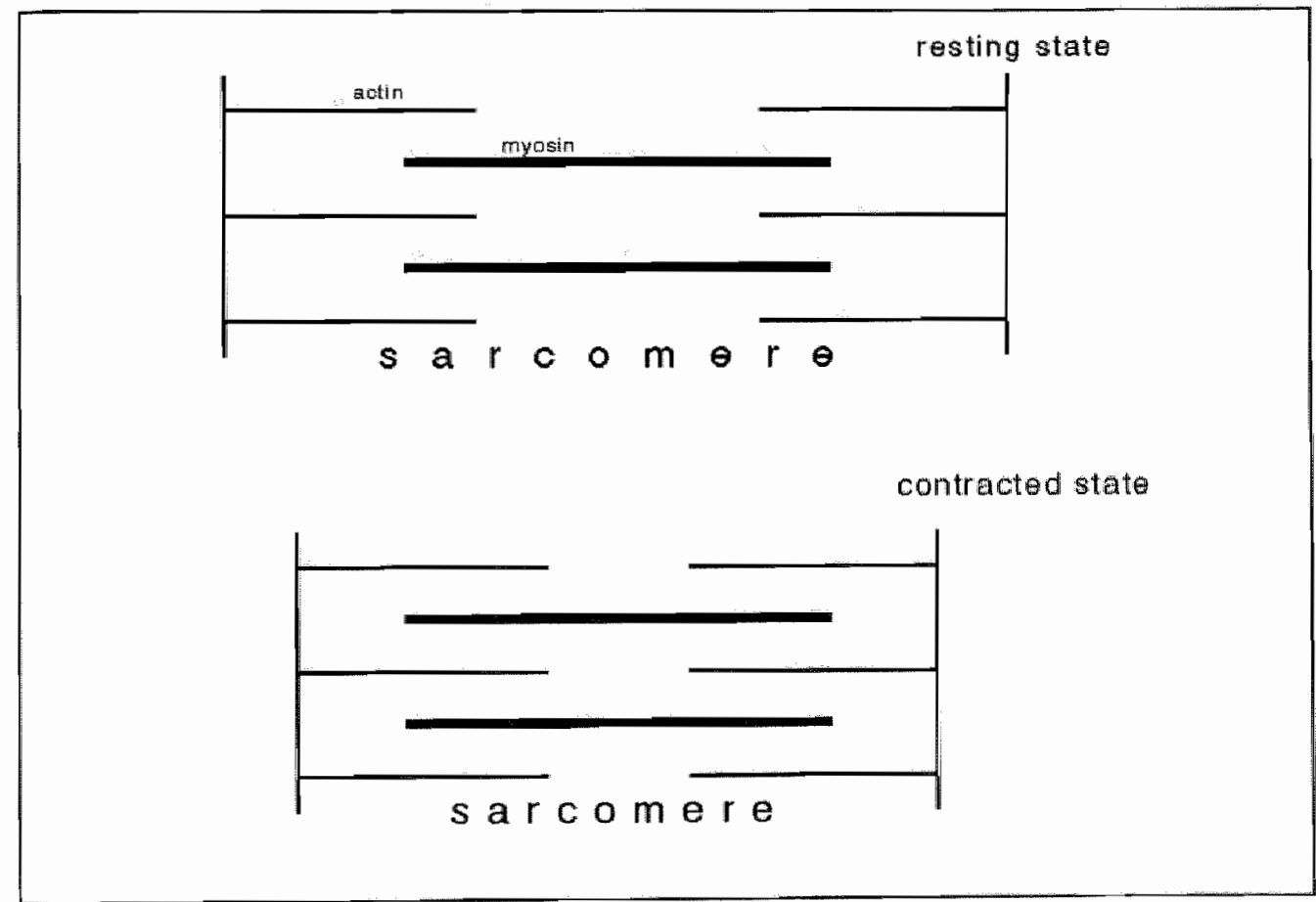

Figure 1. Schematic representation of sarcomere with actin and myosin in resting state and contracted state. 
uptake of $\mathrm{Ca}^{2+}$ into the sarcoplasmatic reticulum is facilitated by $\mathrm{Ca}^{2+} \mathrm{ATPase}$. $\mathrm{Ca}^{2+}$ binds to troporin, a protein which is associated with the actin molecule. This causes a configurational change leading to exposure of the myosin binding sites on the actin molecule. One molecule of myosin and one molecule of actin have several binding sites which can be bound at different moments. The myosin binds to actin in such a fashion that the actin molecule is pulled towards the middle of the sarcomere. The actinmyosin complex allows for binding of A TP, which facilitates the dissociation of the myosin from actin. Because of this dissociation the myosin molecule is capable of binding to anorher actin binding site, situated more to the lateral border of the sarcomere. With this second binding the actin is pulled step by step to the centre of the sarcomere; the myosin more or less walks on the actin. This action is equivalent to the sliding of the filaments past each other. After the neuronal stimulation has stopped, $\mathrm{Ca}^{2+}$ is pumped out, which causes the configuration of the troponin molecule to change again. Now the myosin binding sites are functionally blocked. This implies that the muscle is in rest once again. ${ }^{4}$

\section{Muscle fibre typing}

One molecule of myosin consists of two heavy chains and two light chains. The distinction between different types of muscle fibres is based on subtypes or isoforms of the myosin heavy chain (MHC). The MHC isoforms are of the slow-contracting type or the fast-contracting type, which determines their behaviour. Fibre types can be identified by histochemically differences in MHC isoform stability to myofibrillar adenosine triphosphatase (mATPase). ${ }^{5}$ It is also possible to stain immunocytochemically the slow-type myosin, e.g. by $\mathrm{R}_{11} \mathrm{D}_{10}$ staining, which gives a dark brown colouring, and makes it possible to distinguish the slow type I muscle fibres from the fast type II muscle fibres. ${ }^{6}$

Another way to classify the fibre types is the combination of the key enzymes of the anaerobic and aerobic-oxidative metabolic pathways with a mATPase method which distinguishes fast-twitch and slow-twitch fibres. This results in a classification in three groups of fibre types: fast glycolytic, fast oxidative and slow oxidative?

\section{Stimulation pattern}

In dynamic urinary graciloplasty pulse-trains of $25 \mathrm{~Hz}$ and $210 \mu \mathrm{s}, 0.125 \mathrm{~s}$ "on" and $2.0 \mathrm{~s}$ "off" are used to start of muscle conversion. The gracilis muscle is trained by increasing the duty cycle of the pulse-trains. The stimulation time is gradually 
increased up to continuous stimulation.

Most experience however of muscle fibre conversion by electrical stimulation has come from low frequency continuous stimulation at $10 \mathrm{~Hz}$. It is likely that 8 hours a day of stimulation gives different results than 24 hours stimulation. Since quite some variation exist in the operation technique, in the used animal of the same species, in tissue reaction to the implanted devices and in animal behaviour, even the same stimulation pattern may give different results when inter-individual comparisons are made.

In contrast to the continuous low frequency stimulation of $10 \mathrm{~Hz}$, studies have been perfomed with high frequency stimulation of $40-60 \mathrm{~Hz}$, given in pulse-trains followed by a resting period of some seconds. ${ }^{910}$ The results show that the fast-to-slow conversion does not differ substantially from chronic low frequency stimulation." Also the alterations towards the aerobic-oxidative enzymes, capillary density and fatigue resistance resemble much that of chronic low frequency stimulation. ${ }^{10}$ These and other experiences indicate that the total amount of activity applied to a muscle, is probably more important for the conversion from fast-twitch muscle fibres to low-twitch muscle fibres, than the stimulation pattern."

The above mentioned observations make it plausible that similarities exist between the changes induced by chronic low-frequency stimulation and changes induced by highfrequency stimulation when using pulse-trains. Therefore the following changes based primarily on low-frequency stimulation, also account to a high extent for highfrequency stimulation.

\section{Changes in stimulated skeletal muscle}

Salmons and Vrbova were the first to report that in rabbits low-frequency stimulation changes the fast-twitch muscle into a slow-twitch muscle. ${ }^{12}$ This is caused by a fundamental phenotype conversion of the stimulated muscle. The adaptive capability of the muscle is due to the variation in isoform expression of most of the muscle protein, like myosin heavy chain, myosin light chain and troponin. "When a fasttwitch muscle is stimulated in a fashion, that resembles a stimulus pattern delivered to a slow-twitch muscle, the muscle characteristics change with regard to its native phenotype. The changes include the functional elements of the muscle fibre, changes in fuel supply and changes in fatigue resistance. The result is that the muscle contracts and relaxes slower and is more resistant to fatigue. ${ }^{13}$ 


\section{PHYSIOLOGICAL CHANGES}

Increase in time to peak twitch tension, increase in half-relaxation time and decrease in tetanic tension frequency were the first noticed effects of low-frequency stimularion. ${ }^{12}$ This means that the muscle is getting slower and needs a lower frequency to reach the state of tetanic contraction.

From a clinical point of view one of the most interesting findings is that chronic low frequency stimulation increases the resistance to fatigue, as was first described by Peckham for the cat. ${ }^{14}$ The increased fatigue resistance is related to the elevated aerobicaxidative potential and the increase in capillary density. ${ }^{13}$ Stimulated fast-twitch muscle of the rabbit has a reddish colour, whereas unstimulated rabbit muscle has a whitish appearance. This change in colour is attributed to the increased capillar density, ${ }^{15}$ but also to the higher concentration of myoglobin, an oxygen carrying protein in muscle cells. ${ }^{16}$ "The increase in the number of capillaries per area is the result not only from a true increase of the number of capillaries, but also from a decrease in muscle fibre diameter, which has been reported by several authors. ${ }^{8,17,18}$ With respect to clinical applicability it is noteworthy that in general muscle fatigue depends on the used stimulation frequency: the higher the frequency, the quicker fatigue occurs. ${ }^{19}$

\section{HISTOCHEMICAL CHANGES IN MUSCLE FIBRES AND MYOFRBRILLAR PROTEINS}

A review of fibre and protein changes in stimulated muscle was given by Pette and Vrbova in $1992 .{ }^{13}$ Much of the following is based on their work. As mentioned above the classification of muscle fibre types is based on the existence of isoforms of the myosin heavy chain (MHC). In general one can say that type II fibres are fast-twitch fibres and type I fibres are slow-twitch fibres. With improvement of electrophoretic techniques subtypes have been identified. ${ }^{20}$ Nowadays muscle fibres are classified in IIB, IID, IIA, IIC, IC and I fibres. IIB, IID, IIA are fast-twitch fibres which express the MHC isoforms HCIIb, HCIId, HCIa respectively. Type I is a slow-twitch fibre which expresses the isoform $\mathrm{HCI}$. The fibres IIC and IC are hybrid fibres who have expression of HCIIa and HCI isoforms in different ratios. Stimulation of muscle fibres gives a shift in the order IIB $->$ IID $->$ IIA $->$ IIC - $>$ IC $->$ I. ${ }^{13}$ One has to bear in mind that there is species-specific response and variation in fibre transformation to stimulation. ${ }^{21}$ Low-frequency stimulation induces changes in the myofibrillar proteins, especially in the major protein of the thick myosin filament, but also in the proteins of the thin filament, tropomyosin and troponin. Partial alterations in the fast myosin light chain (LC) to slow LC was first mentioned by Sreter. ${ }^{22}$ The transformation of fast LC to slow LC takes several months. Afterwards considerable amounts of fast myosin LC can be detected, implying that this may coexist together with slow myosin LC and slow MHC. ${ }^{23}$ The proteins of the light filament follow the decline of fast MHC. The 
diminishing of fast $\mathrm{MHC}$ is accompanied by a decline in fast troponin- $\mathrm{T}$ which is exchanged by slow troponin- $T$ isoforms. ${ }^{24}$ To a lesser extent this also accounts for other troponin subunits, troponin-I and troponin-C. ${ }^{25}$

Reduction of the $\alpha$ tropomyosin/ $\beta$ tropomyosin ratio, another light filament protein involved in the relaxation phase of muscle contraction, indicates the transformation to slow-twitch like muscles. ${ }^{26}$

\section{REGULATORY CHANGES}

The regulatory system for muscle contraction also changes partly by the conversion of enzymatic isoforms. With stimulation a reduced capacity and maximum rate of $\mathrm{Ca}^{2+}$ uptake by the sarcoplasmatic reticulum is observed. This occurs already after one to two days of stimulation and is due to a decrease in activity of sarcoplasmatic reticular Ca-ATPase. Finally the Ca-ATPase activity equals the activity of this enzyme in slowtwitch muscle, ${ }^{28}$ because the fast-twitch Ca-ATPase isoform is exchanged with its slowtwitch counterpart. ${ }^{29}$ This change is accompanied by a decrease in parvalbumin, a protein for binding $\mathrm{Ca}^{2+}$ in the cytosol of fast-twitch muscles. ${ }^{30}$ At the same time the expression of phospholamban, needed for the regulation of Ca-ATPase in slow-twitch muscle, increases. ${ }^{29}$

Structural changes of the sarcoplasmatic reticulum occur already 6 hours after the onset of stimulation. The profile alters in such a way that after a some weeks the sarcoplasmatic reticulum resembles that of slow-twitch muscles. ${ }^{31}$

\section{METABOLIC CHANGES}

Fast-twitch skeletal muscles, like the gracilis muscle, normally contract for locomotive activities during short periods of the day. In these periods they have to generate substantial energy in a short period of time in order to contract, e.g. for lifting a leg against gravity. The metabolic pathway which delivers the demanded energy in this type of action is that of anaerobic glycolysis. Energy-rich products like glycogen are stored in fast-twitch skeletal muscles. These products will be used when the muscle contracts, without the use of oxygen. Muscle activity is therefore primarily based on anaerobic glycogen breakdown. The glycogen stores are limited. In non-trained fasttwitch skeletal muscles no compensatory metabolic system exists to take over energy delivery after depletion of glycogen. The result is that the muscle fatigues and is not able to sustain contraction. When low-frequency stimuli are imposed on a fast-twitch muscle, the enhanced demand for energy must come from the aerobic-oxidative energy metabolism. Therefore the observed metabolic changes in the transformation from fasttwitch to slow-twitch muscles deal with changes in isoforms and activity levels of enzymes involved in energy supply. 
Directly after low-frequency stimulation has started, an important disbalance in energy demand and energy supply occurs after the glycogen stores have been used. This causes a large part of the fast-twitch fibres to degenerate within a few days after the start of stimulation. ${ }^{32}$ Since the aerobic-oxidative metabolism is active now, the increased demand for energy and oxygen causes the maximal blood flow and oxygen extraction from the blood to increase as well as the capillary density. ${ }^{33}$ The enhanced blood flow and oxygen extraction is seen in rest as well as during activity. Increase in oxygen extraction probably is due to the increase in myoglobin content. ${ }^{16}$ In muscles which are subjected to chronic stimulation the use of free fatty acids is observed, combined with proteins needed for fatty acid transport. ${ }^{36,37}$ This phenomenon implies an increase of the aerobic oxidation by using fatty acids. ${ }^{21,35}$ In order to enhance the transportation of the needed metabolites adaptation of the extracellular space and the level of transport, proteins like albumin are also observed. ${ }^{36,37}$

The enzymatic changes induced by low-frequency stimulation comprise increases in the activities of those enzymes involved in the aerobic-oxidative pathways. ${ }^{13}$ These are enzymes involved in the citric acid cycle, like citrate synthase, which may increase to levels above those of heart muscle. ${ }^{38}$ Other pathways involved in aerobic oxidation are fatty acid oxidation, ketone body utilisation and the respiratory chain. The enzymes involved in these pathways express increased activity levels. ${ }^{13}$ At the same time the activity levels of enzymes involved in glycolysis, glycogenolysis and transfer of energyrich phosphates are reduced. The level of increase is related to the basal level of activity of these enzymes in unstimulated animals. The lower the base level of activity is, the higher it may rise. ${ }^{21}$ This can be noticed in studies where bigger animals were studied with a high level of basic activities of the aerobic-oxidative pathways, like dogs. Chronic stimulation imposed on these animals induces a more moderate increase in the activity levels of the enzymes involved in aerobic-oxidative pathways. ${ }^{39}$ The expression of isozyme patterns is changed by chronic low-frequency stimulation as well. A shift from the LDH subunit is observed. LDH-4 and LDH-5 decrease whereas LDH-1, LDH-2 and LDH-3 increase. ${ }^{10,21,38,40}$ This means that the LDH spectrum changes, and resembles that of cardiac muscle. The LDH changes are more pronounced in muscles which have originally a low level of aerobic-oxidation. ${ }^{13,21}$

A profound increase in the level of hexokinase and its isozyme hexokinase II has been noticed. ${ }^{16.41}$ 'This enzyme is needed for glucose phosphorylation in the pathway of glucose catabolism. "The steep increase of this enzyme at the start of stimulation when the muscle still tries to generate energy by glucose catabolism, might indicate that glucose phosphorylation is the limiting step in unstimulated muscle to sustain longlasting contractions. ${ }^{13}$ The decrease in hexokinase activity, starting 4 weeks after stimulation, indicates that energy supply now is provided by fatty acid oxidation as a result of the enhanced aerobic-oxidative potential. Therefore the need for glucose catabolism and thus the higher hexokinase activity is less essential after that time. 


\section{CHANGES IN METABOLTTES OF ENERGY METABOUISM}

The changes in the concentrations of metabolites of the energy metabolism are most impressive directly after the start of low-frequency muscle stimulation. ${ }^{13}$ According to Green the changes occur in three phases. ${ }^{42}$ During the first 15 minutes ATP concentration is reduced by $50 \%$, phosphocreatine by $60 \%$ and glycogen stores by 70 $80 \%$. In the same period glucose increases threefold, and lactate tenfold. The second phase lasts up to 4 days and is characterised by recovery of the ATP and phosphocreatine level, the drop of lactate levels and recovery of glycogen to supranormal levels. The third phase lasts approximately 7 weeks. This phase is characterised by low activity of anaerobic glycolysis, indicated by low lactate levels. At the same time slightly reduced concentrations of ATP, phosphocreatine and glycogen are measured. The energy profile now resembles that of a slow-twitch muscle. Since the ATP utilisation is high, due to continuous muscle contraction, and the ATP demand cannor be met by the anaerobic parhway, a series of profound adaptations occur to ensure ATP supply. The restoration of ATP, PC and lactate towards the metabolic resting state of the muscle, occur already early in the continuous contraction phase, whereas the restoration of the contractile performance is not associated with the metabolites. ${ }^{43}$

The potential for the fast-twitch skeletal muscle to adapt to the increased inflow of metabolites of the energy metabolism by changing from anaerobic glycolytic metabolism to aerobic-oxidative metabolism is very important. If this would not be possible, the clinical consequences would rather belimited, and no major applications would be possible. With ongoing continuous contractions the muscle would not survive its changed behaviour pattern and necrosis would occur. Therefore the existence of the adaptive potential of the fuel supply systems made it possible to have muscle plasticity implemented in clinical practice.

\section{Clinical applications}

Since programmable pulse stimulators and electrodes for various applications have been developed, modulation of organic activities by means of electrical currents has been widely applied. Among these applications are cardiac pacing, direct nerve stimulation in hemiplegic patients, respiratory assistance, direct nerve stimulation for modulating micturition behaviour, or direct nerve stimulation for evoking micturition in patients with spinal cord injuries. ${ }^{44,45,46,47,48}$ Lately new efforts have been made to examine the possibility to influence bowel movements or to influence pancreatic activity..$^{49}$ Apart from dynamic urinary graciloplasty nowadays three major clinical fields exist where chronical muscle stimulation is applied. 
RESTORATION OF MUSCLE FUNCTION, PREVENTION OF MUSCLE WASTE IN DISEASED MUSCLE OR INACTIVE MUSCLE DUE TO NERVE DAMAGE

In tetraplegic patients upper extremity functions have been partially restored by multichannel stimulation. Control is obtained by shoulder implants and adjustment of muscle force by varying the pulse width or pulse interval. The lack of sensory feedback is one of the drawbacks. ${ }^{30}$ For lower extremity motion restoration good results have been reported as well, although the stimulation pattern is more complex. ${ }^{51}$ In order to prevent quadriceps muscle waste, due to immobilisation because of knee joint surgery, electrical stimulation is successfully applied during the immobilisation phase. ${ }^{52}$ Low frequency stimulation also appears to slow down the deterioration of Duchenne"s disease..$^{53}$

\section{CARDIOMYOPLASTY}

In 1985 the first article was published about the use of the skeletal latissimus dorsi muscle to assist the heart with an impaired function. ${ }^{54}$ Before that time the fatigability of skeletal muscle hampered the use of skeletal muscles in clinical cardiothoracic surgical practice. With this technique the left latissimus dorsi is wrapped around the heart while neurovascular pedicle is left intact. Muscular electrodes are implanted and connected to a burst pulse stimulator. Increasing stimulation periods are imposed upon the muscle, in order to train the muscle and make it fatigue-resistant. After transformation of the muscle fibres, the muscle can contribute to the contraction capacity of the heart. The latissimus dorsi can contract synchronously with the heart, by using a sensing electrode located in the myocard. In a reported series of 20 patients, of whom 13 survived and could be analysed, 12 patients improved on functional classification and returned to almost normal social life. ${ }^{5.5}$

\section{DYNAMIC ANAL GRACILOPLASTY}

In order to restore continence in patients with faecal incontinence due to a lacking anal sphincter, the dynamic anal graciloplasty was developed. ${ }^{56,57}$ With this technique the distal part of the gracilis muscle. Two electrodes are implanted in the muscle and connected to a burst pulse stimulator. The muscle is subjected to a training program in order to become farigue-resistant. After 10 weeks, muscle fibre conversion from type II to type $I$ is realised and the muscle can contract continuously, a necessity in maintaining faecal continence. With the use of a magnet or an external programmer the implanted pulse stimulator can be switched off and the trained gracilis muscle relaxes in order to defaecate. Konsten et al reported that 17 out of 26 patients achieved complete faecal continence, whereas the anal pressure parameters improved as well. ${ }^{58,59}$ 
Quality of life assessments also showed improvements in 9 out of 15 successfully operated patients. ${ }^{60}$

Based on the concept of muscle plasticity, the experiences in cardiomyoplasty and especially anal dynamic graciloplasty, plans for dynamic urinary graciloplasty were developed and implemented in clinical practice. The following chapters deal with these first developments. 


\section{References}

1. Deming Cl

Transplaxutation of the gracilis muscle for incontinence of urine

JAMA $1926 ; 62 ; 822-824$.

2. Loughnane $\mathrm{FM}$

Transplantation of the gracilis muscle to cure stress incontinence in women BrJ Urol 1939;11:142-146.

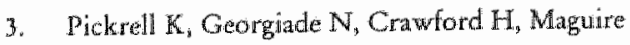
C, Boone A Gracilis muscle transplant for correction of urinary incontinence in male children Ann Surg 1956;14:7647779.

4. Smith TE

Molecular Cell Biology

In: Textbook of Biochemistry, 3rd edition.

Editor T Dewlin. Wiley Liss, New York 1992: 927.980 .

5. Guth $L$, Samaha FH

Qualitative differences between actomyosin A T'Pase of slow and fast mammalian muscle Exp Neurol 1969; 25:138-152.

6. Haverith $M G_{3}$ Visser $R$, Schrijvers van Schendel JMC, Bosman ET

Muscle fibre typing in routinely processed skeletal muscle with monoclonal antibodies Histochemistry 1990;93:497-499.

7. Parnatrd RJ, Edgerton VR, Furukawa T, Peterja

Histochemical, biochenical and contractile properties of red, white, and intermediate fibres

Am J Physiol 1971:220:410 414.

8. Pente D, Muller W, Leisner E, Vrbova $G$ Time dependent effects on contractile properties, fibre population, myosin chains and enzymes of energy metabolism in intermittently and continuously stinulated fast twitch muscle of the rabbit Pllugers Arch 1976;36*:102-112.

9. Mabuchi $\mathrm{K}$, Sreter FA, Gergely J

Myosin and sarcoplasmatic reticalum $\mathrm{Ca}^{26} \mathrm{ATP}$ ase isoforms in electrically stimulated rabbit fast muscle

In: The dynamic state of muscle fibres. Editor

D Pette. De Gruyter, Berlin 1990:445-462.

10. Hudicka O, Tyler KR

The effect of long-term high-frequency stimulation on capillary density and fibre types in rabbit fast muscles

J Physiol(London) 1984;353:435-445.

11. Pette D

Changes in phenotype expression of stionulated skeletal muscle

In: Cardiomyoplasty. Editors A Carpentier, IC Chachques, P Grandiean. Futura Publishing Inc., Mount Kisco 1991:19-29.

12. Salmons $S$, Vrbova $G$

The influence of activity on some contractile characteristics of mammalian fast and slow muscle

J Physioll(London) 1969;201:535-549.

13. Pette D, Vibova $G$

Adaptation of mammalian skeletal musde

fibres to chronic electrical stimulation

Rev Physiol Biochem Pharmacol 1992;120:

116-202.

14. Peckham PH, Mortimer JT, van der Meulen IT Physiologic and metabolic changes in white muscle of cat following induced exercise Brain Res 1973;50:424-429.

15. Brown JMC, Hendriksson I, Salmons $S$ Restoration of fast muscle characteristics following cessation of chronic stimulation: physiological, histochemical and metabolic changes during slow-to-fast transformation Proc $\mathbb{R}$ Soc Lond (Bioll) 1989;235:321-346.

16. Pette D, Smich ME, Staudte HW, Vrbova G Effects of long-term electrical stimulation on some contractile and metabolic characteristics of fast rabbit muscles Pflugers Arch 1973;338:257-272. 
17. Salmons $S_{\text {, Hendriksson J }}$

The adaptive response of skeletal muscle to increased use

Muscle Nerve 1981:4;94-105.

18. Mannion JD, Bicto T, Hammond RL, Rubinstein NA, Stephenson I.w Histochemical and fatigue characteristics of conditioned canine latissimus dorsi muscle Circ Res 1986;58:298-304.

19. Grandjean P

Electrical stimulation of skeletal muscles

In: Cardiomyoplasty. Editors A Carpentier, JC Chachques, P Grandjean. Futura Publishing Inc., Mount Kisco 1991; 39-62.

20. Termin A, Staron RS, Pette D Myosin heavy chain isoforms in histochemically defined fibre types of rat muscle

Histochemistry 1989;92:453-457.

21. Simoneau JA, Pette $D$

Species-specific responses of musclle lactate dehydrogenase isozymes to increased contractile activity

Pflugers Arch 1989;413:679\%681.

22. Sreter FA, Gergely J, Salmons S, Romanul F Synthesis by fast muscle of myosin light chains characteristic of slow muscle in response to long-term stimulation Nature New Biol 1973;241:17-19.

23. Staron RS, Gohlsch B, Pette D Myosin polymorphism in single fibres of chronically stimulated rabbit fast-twitch minsele

Plugers Arcla 19:87;408:444-450.

24. Schmitt TL, Pette D

Correlations between troponin- $\mathrm{T}$ and myosin heavy chain isoforms in normal and transforming rabbit muscle fibres In: The dynamic state of muscle fibres. Editor D Pette. De Gruyter, Berlin 1990:293-302.
25. Hartner KT, Pette D

Effects of chronic low-frequency stimulation on troponin I and troponin $C$ isoforms in rabbit fast-twitch muscle Eur J Biochem 1990;188:261-267.

26. Roy RKK, Mabuchi K, Sarkar 5 , Mis $C_{\text {, }}$ Sreter FA

Changes in troponyosin subunit pattern in chronic electrically stimulated rabbit fast muscles

Biophys Res Commun 1979;89:181-187.

27. Leberer $\mathrm{E}$, Hartner $\mathrm{K} T$, Petce $\mathrm{D}$

Reversible inhibition of sarcoplasmatic reticulum Ca-ATPase by altered neuromuscular activity in rabbit fast-twitch muscle

Eur J Biochem 1987;162:555-561.

28. Pette D, Heilman C

Transformation of morphological, functional and metabolic properties of fast-twitch muscle as induced by long-term electrical stimulation

Basic Res Cardiol 1977;72:247-253.

29. Leberer $\mathrm{E}_{\mathrm{x}}$ Hartner KT, Brandl GJ, Fuji J, Tada M, MacLennan DH, Pette D Slow/cardinc sarcoplasmatic teticulum CaATPase and phospholamban mRNAs are expressed in chronically stimulated rabbit fast-twitch muscle Eur J Biochen 1989;185:51-54.

30. Klug $G A$, Leberer $E_{*}$ Leisner E, Simoneau JA, Pette D

Relationship between parwalbumin content and the speed of relaxation in chronically stimulated rabbit fast-twitch muscle Pflugers Arch 1988; $411: 126-131$.

31. Eisenberg BR, Salmons 5

The reorganization of subcellular structure in muscle undergoing fast-to-slow type transformation. A stereological study Cell 'Tissue Res $1981 ; 220-449-471$. 
32. Maier A, Gambke B, Petre D

Degeneration-regeneration as a mechanism contributing to the fast to slow conversion of chronically stimulated fast-twitch rabbit muscle

Cell Tisue Res 1986;244:635-643.

33. Hoppeler H, Hudlicka O, Uhimann E Relationship between mitochondria and oxygen consumption in isclated cat miscle $\mathrm{J}$ Physiol(Lond) $198 \% ; 385: 661-665$.

34. Hudlicka $O$, Tyler $\mathbb{K} R$, Airman $T$ The effect of long-term electrical stimulation on fuel uptake and performance in fast: skeletal muscles

In: Plasticity of muscle. Editor D Pette De Gruyter, Berlin 1980:401-408.

35. Kaufmann M, Simoneau JA, Veerkamp JH, Pette D

Electrostimulation-induced increases in fatty acid-binding protein and myoglobin in rat fast-twitch muscle and comparison with tissue levels at heart FEBS Letr 1989;245:181-184.

36. Henriksson J, Chi MMY, Hintz CS, Young DA, Kaiser KK, Salmons S, Lowry OH Chronic stimulation of mammalian muscle: changes in enzymes of six metabolic pathways

Am J Physiol 1986;251:C614-C632.

37. Heilig A, Pette D

Albumin in rabbit skeletal muscle. Origin, distribution and regulation by contractile activity

Eur J Biochem 1988;171:211-214.

38. Hood DA, Pette D

Chronic longuterm stimulation creates a unique metabolic enzyme profile in rabbit fast-twitch muscle FEBS Let 1989;247:471-474.
39. Acker AM, Mannion ID, Brown WE, Salmon S, Herriksson I, Bitto T, Gale DR, Hammond R, Stephenson LW Canine diaphragm muscle after 1 yr of continuous electrical stimulation: its potential as a myocardial substitute J Appl Physiol 1987;62:1264-1270.

40. Seedor: U, Leberer E, Kirschbaum BJ, Perte D Neural control of gene expression in skeleta muscle. Effects of chromic stimulation on lactate dehydrogenase isoenzymes and citrat synthase

Biochem J 1986;239:1150-120.

41. Pette D, Staudte HW, Vrbova G Physiological and biochemical changes induced by long-term stimulation of fast muscle

Naturwissenschaften 1972:59:469-470.

42. Green HJ, Dusterhoft S, Dux L, Pette D Metabolite patterns related to exhaustion, recovery, and transformation of chronically stimulated rabbit fast-twitch muscle Pflugers Arch 1992; 420:359-366.

43. Hood DA, Parent G Metabolic and contractile responses of rat fast-twitch muscle to $10-\mathrm{Hz}$ stimulation Am J Physiol 19;260;832-840.

44. McNeal DR, Waters RL

Rehabilitation Engineering Centre Grant on Functional Electrical Stimulation Reparts of progress 1988.

45. Glenn Ww

Diaphragm pacing by electrical stimulation of the phrenic nerve

Neurosurgery 1985;17:974.

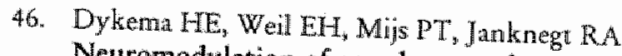
Neuromodulation of sacral nerves for incontinence and voiding dysfunctions. Clinical results and complications Eur Urol 1993;24:72. 
47. Bosch JL, Groen J

Sacral (\$3) segmental nerve stimulation as a treatment for urge incontinence in patients with detrusor instability: results of chronic electrical stinulation using an implantable neuroprosthesis

J Urol 1995; 154:504-507.

48. Van Kerrebroeck PhEV, Koldewrin EL,

Wijksitra $\mathrm{H}$, Debruyne FM]

Intradural sacral rhizotomies and implantation of an anterior sacral root stimulator in the treatment of neurogenic bladder dysfunction after spinal cord injury. Surgical techniques and complications World J Urol 1991:126:132.

49. Pacemaker activity and intercellullar communication.

Editor JD Huizinga. CRC press, Boca Ration 1995.

50. Peckham $\mathrm{PH}$, Marsolais EB, Mortimer JT

Restoration of key grip and release in the $\mathrm{C} 6$ tetraplegic patient through functional electrical stimulation

$J$ Hand Surg 1980;5:5.

51. Marsolais EB, Kobetic $R$ 4th Annual Applied Netural Control Research Day

Case Western Reserve University , Cleveland 1989.

52. Gould $N_{x}$ Donnermeyer $D$, Pope $M$, Ashigaka I

Transcutaneous muscle stimulation as a method to retard disuse atrophy

Clin Orthop 1982;164:215-220.

53. Scotr OM, Hyde SA, Vrbova G, Dubowitz V Therapeutic possibilities of low frequency electrical stimulation in children with Duchenne muscular dystrophy J Neurol Sci 1990;95:171-182.

54. Carpentier A, Chachques JC

Myocardial substitution with a skeletal muscle: first successful clinical case Lancet $1985 ; 1: 1267$.
55. Carpentier $A, A b r y ~ B$. Milaieanu $S_{0}$

Chachques JC

Hopital Broussais Clinical Experience

In: Cardiomyoplasty. Editors A Carpentier JC Chachques, $\mathbb{P}$ Grandjean. Futura Publishing Inc., Mount Kisco 1991;147-157.

56. Baeten C, Spaans F, Fluks A

An implanted neuromuscular stimulator for faecal incontinence following previously implanted gracilis muscle. Report of a case Dis Colon Rectum 1988:134-137.

57. Williams NS, Hallan R, Koeze TH, Watkins ES Construction of a neorectum and neoanal sphincter following previous proctocolectomy Br J Surg 1989;76:1191-1194.

58. Konsten J, Baeten CGMI, Spaans F, Havenith MG, Soeters PB

Follow-up of anal dynamic graciloplasty for faccal incontinence

World J Surg 1993; 17:404-409.

59. Baeten CGMI, Geerdes BP, Adang EMM, Heineman E, Konsten J, Engel GL, Kester ADM, Spanns F, Soeters $\mathbb{P} B$ Anal dynamic graciloplasty in the treatment of intractable faecal incontinence NEngJ Med 1995;332:1600-1605.

60. Adang EMM, Engel GL, Konsten J, Baten CGMI

Quallity of life after dynanic graciloplasty for faecal incontinence: first results Theor Surg 1993:8:122-124. 
Feasibility and side effects of dynamic urinary graciloplasty for treatment of intrinsic sphincter deficiency

\section{Chapter 3}

The main part of this chapter was published as:

ELECTRICALLYY STIMULATED GRACILIS SPHINCTER (DYNAMIC GRACILOPLASTY) FOR TREATMENT OF INTRINSIC SPHINCTER DEFICIENCY: A PILOTT STUDY ON FEASIBILITY AND SIDE EFEECTS.

Janknegt RA, Heesakkers JPFA, Weil EHJ, Baeten CGMI. Journal of Urology 1995;154:1830-1833. 


\section{Introduction}

The causes of intrinsic sphincter deficiency are of congenital, traumatic or iatrogenic origin. The most frequent occurring congenital causes are total epispadias', bladder exstrophy ${ }^{2}$ and myelodysplasia. ${ }^{3}$ Traumatic causes consists of mostly blunt external forces to the pelvic area. The most frequent iatrogenic cause are sphincter damage aft transurethral resection of the prostate or radical prostatectomy and oncologic operations combined with radiotherapy. Significant incontinence was reported in 0.5 to $1 \%$ of the 400,000 transwrethral prostatectomies performed in the United States annually. An intrinsic sphincter deficiency rate up to $3.4 \%$ is reported after radical prostatectomy."

Urinary diversion and implantation of an artificial sphincter are the conventional surgical treatments for severe incontinence. A $12 \%$ complication rate requiring reintervention are reported after urinary diversions ${ }^{6}$ and an $8-22 \%$ complication rate requiring intervention was demonstrated with the artificial sphincter. ${ }^{7.8}$

A new surgical technique for treating intrinsic sphincter deficiency is the dynamic graciloplasty. With this technique the gracilis muscle is transposed around the bladder neck. Afterwards the skeletal muscle is converted into a functional sphincter by electrical stimulation. During an increasing stimulation protocol the fatigable type II fibres, the main fibres in skeletal muscles, are replaced by type I fibres, which can sustain long-lasting contractions.

A preliminary report has been published on the dynamic graciloplasty for urinary incontinence in humans. 'We describe the operation technique of the dynamic graciloplasty and its results and complications in seven patients.

\section{Anatomy}

The gracilis muscle is a superficial muscle in the upper leg, which belongs to the adductor muscle group together with the adductor longus muscle and the adductor brevis muscle. The gracilis muscle originates at the outer inferior ramus of the pubic bone and ischium. The insertion is at the medial condyle of the tibia via the pes anserinus (fig 1). The pes anserinus is a goose foot shaped joint tendon of the sartorius muscle, the semitendinosus muscle and the gracilis muscle. The gracilis muscle is a lean and long muscle which is located superficially at the inner side of the thigh. Its function is adduction of the hip and endorotation of the knee. ${ }^{10}$ Since the other adducting muscles are more voluminous and stronger, the gracilis muscle has no important function and can easily be used for other purposes. 
The innervation of the gracilis muscle is by an anterior branch of the obturator nerve, which has its offspring at L2-I4. After having given off nerve branches to the pectineus muscle, the adductor brevis muscle and the adductor longus muscle, the remaining branch penetrates the gracilis muscle proximally at its lateroposterior side. Before entering the muscle, the nerve divides into four branches. ${ }^{11}$

The arterial supply of the gracilis muscle originates from the principal pedicle of the first profunda femoris perforator. Most patients have three arterial pedicles to the muscle. The arteries enter the muscle at the lateroposterior level close to the anterior border. The principal pedicle enters the muscle at the upper thirds of the muscle.

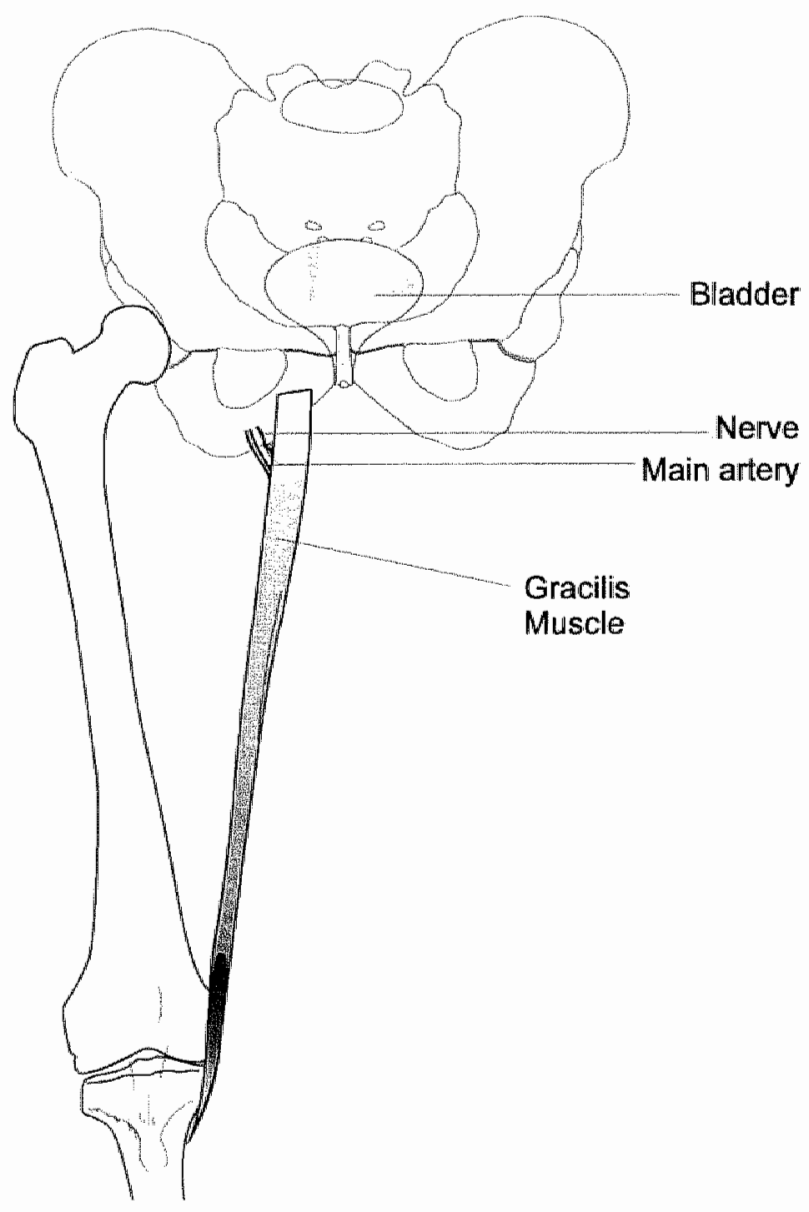

Afterwards 3-4 four large branches descend to the distal part of the muscle. ${ }^{12}$ Since the main pedicle enters at the upper thirds of the muscle and the branch of the obturator nerve also enters proximally, it is possible to detach the muscle at its tendon, without jeopardising innervation nor arterial blood supply.

'Therefore, the distal part can be used for other purposes. Because the origin of the gracilis muscle is located close to the urethra, the distal part of the muscle can be used for a urethral wrap.

Figure 1. Diagram of gracilis muscle anatony and its related topography with the bladder. The entrance of the principal arteries and the nerve is also indicated. 


\section{Operation}

\section{FIRST STAGE}

This part comprises the transposition of the gracilis muscle. The patient is in lithotomy position and a transurethral catheter is inserted. An incision is made parallel with the long axis of the muscle through the cutis and subcutis. A second incision is made at the medial tibial condyle. The muscle is transected at the tendinous portion before its insertion at the tibial bone. The distal part of the muscle is pulled out of the upper leg through the incision in the leg. Minor arterial branches to the distal parts of the muscle are cur. A subcutaneous tunnel is made digitally to transpose the gracilis to the perineum. An opening in the urogenital diaphragm is created. Via a Pfannenstiel incision the periurethral region is prepared in order to wrap the muscle around the bladderneck. The gracilis is brought in Retzius space and threaded around the urethra, starting ventrally. The wrap is performed in such a fashion that there is close contact between urethra and gracilis but without closing the urethra. The tendinous end is sutured to the contralateral pubic bone. The indwelling catheter is removed after approximately one week (figure 2).

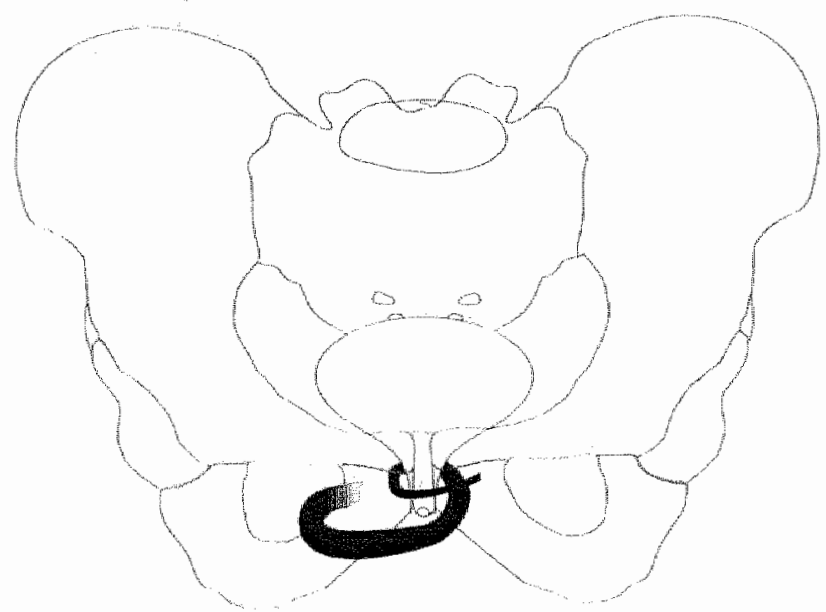

Figure 2. Gracilis muscle after transposition around bladder neck

\section{SECOND STAGE}

The second stage is done at least six weeks later in order to secure a tight connection between the tendinous part and the pubic bone. During this operation, two muscle electrodes and a pulse stimulator are implanted. The implant is started after having 
checked the function of the gracilis with external stimulation. An incision is made over the gracilis where it can be felt at the medial side of the leg. Two electrodes (SP 5528, Medtronic, Kerkrade, the Netherlands) are placed in the muscle. The cathode is placed near the nerve-entry zone. During operation, the optimal place for positioning of the cathode is tested with the electrode and an external screener. The electrode is put against the muscle at various places near the nerve-entry zone. With the screener the spot with the lowest threshold for muscle contraction is located. At that place the cathode is sutured into the gracilis muscle. The anode is placed five $\mathrm{cm}$ more distally. Insulation sheaths are secured and the electrodes are tunnelled to the lower abdomen where they are connected to a subcutaneously positioned pulse stimulator (Itrel II ${ }^{\mathrm{TM}}$, Medtronic, Kerkrade, the Netherlands). The stimulator and the electrodes are immersed in aminoglycosides. Antibiotics are administered for three days (figure 3).

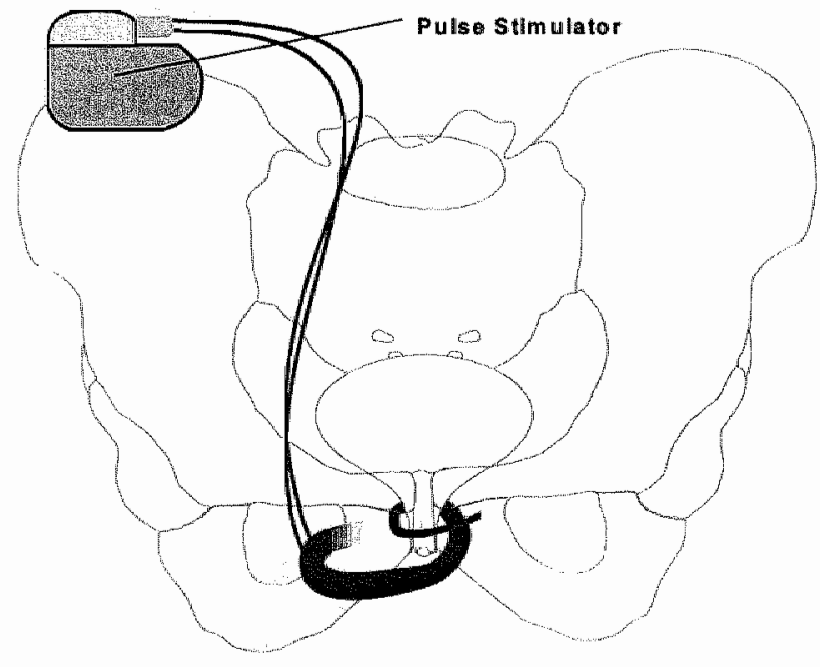

Figure 3. Graciloplasily werpped around bladder neck witb wascle electrodes and stimulatot.

\section{Stimulation}

After implantation a stimulation program is started to transform the gracilis from a fatigable skeletal muscle into a non-fatigable sphincter. "The stimulation parameters are derived from successful experiments in faecal incontinence and cardiomyoplasty. ${ }^{13}$ Muscle fibre conversion can be done by low frequency continuous stimulation, for example with $10 \mathrm{~Hz} .^{14}$ To achieve maximal contraction force and maximal muscle fibre conversion, other stimulation protocols have been developed. Latissimus dorsi stimulation in dogs pointed out that higher frequencies give higher maximal tetanic 
muscle forces. ${ }^{15}$ Others showed that the use of pulse trains instead of single pulses, results in a higher percentage slow-twitch fibres. ${ }^{16}$ Therefore a protocol was developed which uses an increasing duty cycle with pulse trains of 6 pulses of $210 \mu \mathrm{s}$ and a train frequency of $25 \mathrm{~Hz}$. Intermittent stimulation is started with a duty cycle of 0.125 seconds "on" and 2 seconds "off". The voltage is adjusted at the level of contraction perception to a maximum of 4.0 volts. The duty cycle is increased every two weeks with an external programmer (Model 7432, Medtronic, Kerkrade, NL). After 8 weeks the duty cycle is $100 \%$ " on". At that time a large part of the fast twitch farigable muscle fibres are replaced by slow twitch non-fatigable muscle fibres. At this moment the frequency is decreased to $15 \mathrm{~Hz}$, because in a slow twitch muscle a fused contraction is obtained with a lower frequency. In order to void, patients can switch the stimulator "off" by using an external magnet. The stimulation scheme is listed in table 1.

\begin{tabular}{|c|c|c|c|c|c|}
\hline Time (weeks) & 0 & 2 & 4 & 6 & 8 \\
\hline On time (s) & 0.125 & 0.2 & 0.4 & 1.0 & 1.0 \\
\hline Off rime (s) & 2 & 1.2 & 0.7 & 0.5 & 0.0 \\
\hline Duty cycle (\%) & 4 & 14 & 36 & 67 & 100 \\
\hline Frequency (Hz) & 25 & 25 & 25 & 25 & 15 \\
\hline
\end{tabular}

Table 1. Characteristics of stimulation protocol of transposed gracilis muscle.

\section{Pre-operative screening}

The diagnostic procedure for the operation exists of patient history " physical examination and laboratory findings. Sphincter function is analysed cystoscopically. Urodynamic investigation is performed to test bladder stability, bladder capacity and urethral pressures.

\section{Patients}

At the moment of analysis 7 patients ( 5 men and 2 women, age range 22-72 years) were available who had been treated with the above described dynamic graciloplasty technique. The preoperative characteristics of the seven evaluable patients are listed in table 2. Cause of incontinence was congenital in 2 men, traumatic in 2 men, iatrogenic in one man and oncologic operations combined with radiotherapy in 2 women. 
Table 2. Patient characteristics before treatment. The origin of incontinence, prevous treatnents, urodynamic characteristics and findings at cystoscopy are mentioned". MUCP means maximal urethral closing pressure. PTFE is polytetraf horoetbylene.

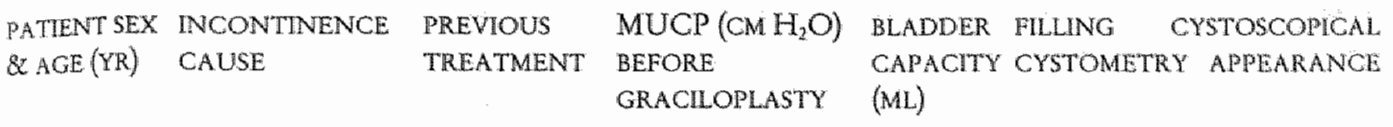

\begin{tabular}{|c|c|c|c|c|c|c|}
\hline 1 male 25 & $\begin{array}{l}\text { pelvic fracture } \\
\text { with bladder } \\
\text { \& urethral rupture }\end{array}$ & $\begin{array}{l}\text { 1. railroad procedure } \\
\text { 2. artificial sphincter }\end{array}$ & 21 & 100 & $\begin{array}{l}\text { no open } \\
\text { instabilities }\end{array}$ & $\begin{array}{l}\text { internal } 8 \\
\text { external } \\
\text { sphuncter }\end{array}$ \\
\hline 2 male 22 & extrophia vesicae & $\begin{array}{l}\text { 1. twice epispadia } \\
\text { correction } \\
\text { 2. urethrocutaneous } \\
\text { fistula correction }\end{array}$ & 52 & 120 & $\begin{array}{l}\text { unstable } \\
\text { contractions }\end{array}$ & $\begin{array}{l}\text { open } \\
\text { bladder neck }\end{array}$ \\
\hline 3 male 65 & $\begin{array}{l}\text { pelwic fracture } \\
\text { with urethral } \\
\text { rupture }\end{array}$ & $\begin{array}{l}\text { 1. four times Sachse } \\
\text { urethrotomy } \\
\text { 2. urethroplasty }\end{array}$ & $\ldots$ & 100 & $\begin{array}{l}\text { no } \\
\text { instabilitives }\end{array}$ & $\begin{array}{l}\text { open intermal } \\
\text { \&external } \\
\text { sphuncter }\end{array}$ \\
\hline 4 male 63 & $\begin{array}{l}\text { congenital atonia } \\
\text { of } \\
\text { bladder \& sphincter }\end{array}$ & conservative & 40 & 520 & $\begin{array}{l}\text { no } \\
\text { instabilities }\end{array}$ & $\begin{array}{l}\text { insufficient } \\
\text { dlosing internak } \\
8 x \text { external } \\
\text { sphincter }\end{array}$ \\
\hline 5 male 72 & $\begin{array}{l}\text { Turner Warwick } \\
\text { bladder neck } \\
\text { incision }\end{array}$ & conservative & - & 200 & $\begin{array}{l}\text { no } \\
\text { instabilitives }\end{array}$ & $\begin{array}{l}\text { non dosing } \\
\text { external } \\
\text { sphincter }\end{array}$ \\
\hline 6 temale 49 & $\begin{array}{l}\text { abdominovaginal } \\
\text { hysterectomy \& } \\
\text { lymphadenectomy } \\
\text { radiotherapy }\end{array}$ & $\begin{array}{l}\text { 1. PTFE } \\
\text { injections } \\
\text { 2. twice Raz } \\
\text { colposuspension }\end{array}$ & 37 & 120 & $\begin{array}{l}\text { low complianct } \\
\text { no instabilities }\end{array}$ & $\begin{array}{l}\text { open } \\
\text { bladder neck } \\
\text { \& antonic } \\
\text { wrethra }\end{array}$ \\
\hline 7 female 58 & $\begin{array}{l}\text { abdominovaginal } \\
\text { hysterectomy\& } \\
\text { lymphadenectorny } \\
\text { radiotherapy }\end{array}$ & $\begin{array}{l}\text { PTFE } \\
\text { injections }\end{array}$ & 12 & 300 & $\begin{array}{l}\text { low compliance } \\
\text { unstable } \\
\text { contractions }\end{array}$ & $\begin{array}{l}\text { open } \\
\text { bladder neck } \\
\text { or atomic } \\
\text { urethrin }\end{array}$ \\
\hline
\end{tabular}

All but patient 4 had had previous surgery in the pelvic region. They all had an extensive history of incontinence treatments and they all were totally incontinent. Urodynamic investigation, when performed, showed a maximal urethral closing pressure (MUCP) ranging from $12 \mathrm{~cm} \mathrm{H}_{2} \mathrm{O}$ to $52 \mathrm{~cm} \mathrm{H}_{2} \mathrm{O}$. Cystoscopy revealed a nonclosing sphincter mechanism in all patients, while 2 patients had bladder instabilities. 


\section{Patient control between the two stages and at follow up}

Patients are followed intensively after operation and stimulation. After gracilis muscle transposition before the second operation, an urethral pressure profile is performed with the gracilis muscle contracting and relaxing by an external stimulator. This is alsc done after the second operation within three months if possible. Cystoscopy is repeated when the patient does not respond to the treatment.

\section{Results}

The procedures and results are listed in table 3. Patients 2,6 and 7 also underwent illeocystoplasty, because of the Politano Leadbetter procedure (patient 2) or because of the low capacity and low compliant bladder (patient 6 and 7). Operation time was approximately 2,5 hours for stage 1 and approximately 1,5 hours for stage 2 . Complications other than those related to graciloplasty functioning occurred in 4 patients. Patient 2 had a vesicocutaneous fistula that was closed. Patients 4 and 7 had strictures and patient 6 had an urinary tract infection that was treated with antibiotics. Subjectively 4 patient are satisfied with the treatment. Patients 1, $2 \& 4$ had good results and one patient is dry at night.

The graciloplasty failed in patient 3,5 and 7. Cystoscopy was performed for analysis. It revealed in patient 3 that the bladder neck was not closed but pulled dorsally during contraction. In patient 5 cystoscopy showed a only contractile gracilis at the ventral side of the bladder neck. Biopsies showed normal muscle fibres at the graciloplasty site. These two patients had an artificial sphincter implant. Cystoscopy performed in patient 7 showed that there was no contraction during stimulation at all. This patient had a urinary diversion. During this operation, electromyographic recordings showed muscular activity in the groin but no activity around the bladder neck. There were no indications for nerve damage. Biopsies taken at the site of the graciloplasty around the bladder neck showed fibrotic tissue. 


\begin{tabular}{|c|c|c|c|c|c|c|c|}
\hline \multirow[t]{2}{*}{$\begin{array}{l}\text { PATTENT } \\
\text { NUMBER }\end{array}$} & \multirow[t]{2}{*}{ PROCEDURE } & \multicolumn{3}{|c|}{$\operatorname{MUCP}\left(\mathrm{CH} \mathrm{H}_{2} \mathrm{O}\right)$} & \multirow[t]{2}{*}{ COMPLCATIONS } & \multirow[t]{2}{*}{$\begin{array}{l}\text { SUEJECTNE } \\
\text { OUTCOME }\end{array}$} & \multirow[t]{2}{*}{$\begin{array}{l}\text { OBjectwE } \\
\text { oUTCOME }\end{array}$} \\
\hline & & $\begin{array}{l}\text { AFTER STAGE } 1 \\
\text { STMMULATION: } \\
\text { OFF }\end{array}$ & ON & $\begin{array}{l}\text { AFTER STAGE } 2 \\
\text { STIMULATOR } \\
\text { ON }\end{array}$ & & & \\
\hline 1. & DUG & 27 & 135 & 38 & none & satisfied & $\begin{array}{l}3 \text { times } \\
\text { per month } \\
\text { incontinent: }\end{array}$ \\
\hline 2. & $\begin{array}{l}\text { 1. Politano Leadbetter } \\
\text { 2. Young Dees } \\
\text { 3. chorda correction } \\
\text { 4. DUG }\end{array}$ & - & 73 & 80 & $\begin{array}{l}\text { fistulat which } \\
\text { was closed }\end{array}$ & satisfied & $\begin{array}{l}\text { twice a week } \\
\text { incontinent }\end{array}$ \\
\hline 3 & DUG & - & - & $-\ldots$ & $\begin{array}{l}\text { graciloplasty } \\
\text { pulled dorsally } \\
\text { therefore no } \\
\text { closure }\end{array}$ & $\begin{array}{l}\text { not } \\
\text { satisfied }\end{array}$ & faled \\
\hline 4. & DUG & - & 31 & 90 & $\begin{array}{l}\text { twice urethral } \\
\text { stricure treated } \\
\text { with wall stent }\end{array}$ & satisfied & $\begin{array}{l}\text { dry withour } \\
\text { retention }\end{array}$ \\
\hline 5. & DUG & - & 23 & 26 & $\begin{array}{l}\text { incomplete } \\
\text { closure }\end{array}$ & $\begin{array}{l}\text { not } \\
\text { satisfied }\end{array}$ & failed \\
\hline 6. & $\begin{array}{l}\text { 1. ileocystoplasty } \\
\text { 2. DUG }\end{array}$ & 34 & 33 & 12 & $\begin{array}{l}\text { urinary tract } \\
\text { infection }\end{array}$ & satisfied & dry at night \\
\hline 7 & $\begin{array}{l}\text { 1. ileocystoplasty } \\
\text { 2. DUG }\end{array}$ & 41 & 100 & - & $\begin{array}{l}\text { 1. migration of } \\
\text { stimulator } \\
\text { 2. urethral strictu } \\
\text { 3. no gracilis } \\
\text { contractions }\end{array}$ & $\begin{array}{l}\text { not } \\
\text { satisfied } \\
\text { lire }\end{array}$ & failed \\
\hline
\end{tabular}

Table 3. Summary of post-procedure wrodynamic findings, complications, subjective and objective outcome. MUCP is maximal uretbral closing pressure. DUG is dynamic urinary graciloplasty. 
The urethral pressure of patient 2 after the second operation is depicted in figure 4 . It clearly staw the increase in urethral pressure when the stimulator is switched on.

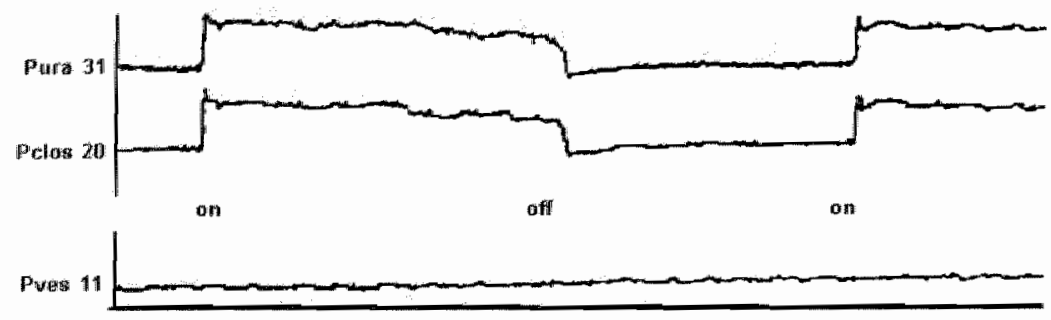

Figure 4. Increase in uretbral pressure rise in patient 2 when stimulator is switched on as seen during urodynamic inwestigation. The pressures are in cm $\mathrm{H}_{2} \mathrm{O}$. Pura is urethral pressure, Pclos is urethral closing pressare, Pves is vesical pressure. The figures indicate the recorded pressures at the start of the investigation.

\section{Discussion}

In the past various attempts have been made to use the gracilis muscle for restoring faecal or urinary continence. ${ }^{17,18,19,20}$ Due to the fatigability of the skeletal gracilis muscle, prolonged success was never described. Modern techniques demonstrated that it is possible to convert skeletal muscles into non-fatigable sphincteric muscles. Skeletal muscles consist mainly of anaerobe fibres. With electrical stimulation the activity of the enzymes of the aerobic metabolism increases, and the anaerobic enzyme activity decreases. Aerobic mitochondrial enzymes increase and the anaerobic calcium-activated myosin ATP-ase activity decreases. An acquisition of the myosin light chains of the slow type can be observed, as well as a loss of the myosin light chains of the fast type. ${ }^{21}$ This mechanism results in a change from skeletal, fast anaerobe muscle fibres to an increasing amount of slow, aerobe muscle fibres, which are able to sustain long-lasting contraction and, therefore, can mimic sphincteric activity. ${ }^{22}$

This technique is applied for faecal incontinence, resulting in good restoration of continence. ${ }^{23,24}$ Encouraged by the success of the dynamic anal graciloplasty, in which continence was restored in $64 \%$ of the patients ${ }^{25}$, graciloplasty with electrical remodelling in patients with intrinsic sphincter deficiency was begun at our clinic. The advantages of this technique are the orthotopic location of the bladder and the use of autologous material, which is less prone to infection or erosion.

The main differences of urinary graciloplasty compared to anal graciloplasty are that 
leakage of urine occurs more easily than stool leakage, and that the gracilis muscle is wrapped around the bladder neck for stability and to avoid stricture formation. This implies that the muscle must pass the urogenital diaphragm and requires more length than the subcutaneously wrapped anal gracilis.

Since the experience had to start from scratch the first results are promising, but many questions remain. The gracilis muscle was chosen because it has no essential function in humans, the main bloodvessels and nerves enter at the origin and it is close to the pelvis. ${ }^{12}$ This implies that the gracilis can be dissected from its insertion and swung around the bladder neck. This procedure, however requires a u-turn in the medial upper leg which might cause damage to the gracilis. The gracilis is wrapped around the bladder neck and not around the urethra to prevent urethral strictures. ${ }^{26}$ However, patients 4 and 7 did have strictures, although in patient 4 this could have been due to selfcatheterisation. Strictures priobably are not caused by the location around the bladder neck or the urethra, but by the tension with which the gracilis is wrapped. This condition cannot be avoided in all cases because the gracilis length is critical. These difficulties make it compulsory to investigate other muscles for the wrap, for example the rectus abdominis or gluteus muscle. The sphincter location also may be questioned. The bulbous urethra may be a better location because of the critical gracilis length and need to pass the urogenital diaphragm, which can cause ischemia, as happened in patient 7 .

The usual method of creating the wrap is for the gracilis to cross the bladder neck ventrally and swing back dorsally to the ipsilateral side. The distal part of the gracilis crosses the proximal part underneath and is fixed to the pubic bone contralaterally. In this way the gracilis provides circumferential support to the bladder neck. It is preferable that only the muscle portion of the gracilis is swung and that the tendinous part is used for fixation. If the tendinous portion must be used it may cause kinking leading to outflow obstruction. This problem probably cannot be avoided because muscle transformation results in diameter reduction and a relative increase of collagen in the transposed gracilis, leading to a more tendinous-like gracilis. ${ }^{27}$

A stable, low pressure bladder with good capacity is important. However in some patients the opposite is found, which can be corrected by an ileocystoplasty, combined with the first stage of the dynamic graciloplasty. Any leakage or infection that occurs can be treated conservatively without removal of the muscle because of the autologous material (patient 2). Cystoscopy is an important tool to analyse the sphincter function. Before transposition direct visualisation shows no sphincter closure. Gracilis behaviour after transposition with and without stimulation can be demonstrated by cystoscopy.

Urodynamic studies demonstrate that maximal urethral closure pressure after stimulation increases in patients with good results (like patients 1 and 2). However the lower maximal urethral closure pressure before stimulation in patient 4 is remarkable 
because of the good subjective result. The maximal urethral closure pressure increase in patient 7 also is surprising. Stricture formation made it impossible to perform urethral pressure profilometry after completion. We find that urodynamics are not very reliable in these patients. The gracilis wrap around the bladder neck causes a change in the urethral configuration, making insertion of a catheter difficult. Artifacts can occur due to urethral kinking or deviation from the normal urethral curvature. "Therefore, a reliable profile often is not possible.

It is evident that these patients have complaints that impact significantly on daily life. Therefore it is not amazing that a partial successful operation gives subjective satisfaction, as in patient 6 .

Because our initial patients did so well, we extended our feasibility study to 9 parients. Due to the difficulties encountered in some patients, new efforts are being made to define the ideal patient population. From our study it is difficult to tell which patients will benefit from graciloplasty. Intuitively we believe that patients who underwent radiotherapy are not ideal candidates. New initiatives for improvement of sphincter design and sphincter location are also in progress. 


\section{References}

1. Dees JE

Congenital epispadias with incontinence

JUrol 1949;6:2:513-522.

\section{Lancaster PAL}

Epidemiology of bladder exstrophy: a communication from the international clearing house for birth defects monitoring systems

Teratology 1987;36:221-227.

3. Steir $\mathrm{SC}$, Feldman JG, Friedlander $\mathrm{M}$, Klein RJ

Is myellomeningocele a disappearing

disease?

Pediatrics 1982;69:511-514.

4. Cocken ATK

Does transurethral resection of the prostate adversely effect long-term survival in the elderly male patients?

Probl Urol 1991;5:407-411.

5. Hautmann RE, Sauter TW, Wenderorh UK

Radical retropubic prostatectomy:

morbidity and urinary continence in 418

consecutive cases:

Urology $1994 ; 43: 47-51$.

6. Wilson TG, Moreno JG, Weinberg A, Ablering $T \mathrm{TE}$

Late complications of the modified Indiana potsch

J Urol 1994;151:331-334.

7. Fishman IJ, Shabsigh R, Scont FB

Experience with the artificial urinary sphincter model AS 800 in 148 patients J Urol 1989; 141:307-310.

8. Gundiau JG, Barret DM, Parulkar BG Mayo Clinic experience with the AS 800 artificial urinary sphincter for urinary incontinence after transurethral resection of prostate or open prostatectomy Urology 1993;41:318-321.
9. Janknegt RA, Baten CGMI, Weil EHJ, Spans F

Electrically stimulated gracilis sphincter for treatment of bladder sphincter incontinence Lancet 1992;340:1129-1130.

10. Rumpf fwand und extremitäten: membrum inferius

In: Lehrbuch der gesamten Anatomie des Menschen. Editor TH Schiebler

Springer Verlag Berlin Heidelberg New York $1977: 245-299$.

11. Parel J, Shanahan $\mathrm{D}$, Williams NS, Sinnatamby CS, George B, Watkins ES The anatomy of the anterior division of the obturator nerve in relation to the electrically stimulated gracilis neoanal sphincter

Clinical Anatomy $1991 ; 4: 385$.

12. Shamahan $D$, Riches DJ, Sinnatamby CS, Williams NS, Watkins ES

The arterial anatomy and surgical relevance of the human gracilis muscie I Anat 1991:175:270-272.

13. Chachques JC, Grandjean PA, Carpentier A Dynannic cardiomyoplasty: experimental cardiac wall replacement with a stimulated skeletal muscle

In: Biomechanical Cardiac Assist. Editor RC] Chiu. Mount Kisco, New York, Futura Publishing Co. 1986:59-84.

14. Pette D, Vrbova $G$

Adaptation of mammalian skeletal musele fibres to chronic electrical stimulation Rev Physiol Biochem Pharmacol 1992:120:116-118.

15. Lucas CMHB, varn der Veen FH, Grandjean PA, Pene OCKM, Wellens HJJ What is the idieal pulse frequency for skeletal muscle stimulation after cardionyoplasty? PACE 1991:14:778.782. 
16. Chacquess $] C$, Carpentier $A$

Experimental basis of cardiomyoplasty

In: Cardionyoplasty. Editors A Carpentier,

JC Chachques, P Grandjean. Mount Kisco,

New York, Futura Publishing Co. 1991:77-96.

17. Deming CL

Transplantation of the gracilis muscle for incontinence of urine.

JAMA 1926:82:822-824.

18. Loughnane FM

Transplantation of the gracilis muscle to cure stress incontinence in women

Br J Urol 1939;11:142:146.

19. Pickrell $\mathrm{K}$, Georgiade $\mathrm{N}$, Crawford $\mathrm{H}_{\text {, }}$ Maguire C, Boone A

Gracilis muscle transplant for correction of urinary incontinence in male children

Ann Surg 1956:14:764:779.

20. Pickrell $\mathrm{K}$, Masters $\mathrm{F}$, Georgiade $\mathrm{N}$,

Horton $C$

Rectal sphincter reconstruction twing

gracilis muscle transplant

Plast Reconstruc Surg 1954;13:46-55.

21. Salmons $S$, Teariksson J

The adaptive response of skeletal muscle to increased usse

Muscle Nerve 1981;4:94-105.

22. Pette $D$, Müller W, Leisner $E$, Vrbova $G$

Time dependent effects on contractile properties, fibre population, myosin light chains and enzymes of emergy metabolism in intermittently and continuously stimulated fast twitch musclles of the rabbit Pfligers Arch 1976:364:103-112.

23. Haeten CGMI, Konsten J, Spans F, Visser $\mathbb{R}$, Habets $A M$, Bourgeois IM, Wagenmakers $A$, Soeters DB

Dynamic graciloplasty for treatment of faecal incontinence

Lancet 1991;38:1163 1165.
24. Cavina $E$, Seccia $M$, Evangelista $G$, Chiarugi $M$, Buccianti $P$, Tortora $A_{*}$ Chirico A

Perineall colostomy and electrostimulated gracilis "meosphincter" after abdomino-perineal resection of the colon and anorectum: a surgical experience and follow-up of 47 cases

Int J Colorect Dis 1990;5:6-11.

25. Konsten J

Dynamic musculoplasty, a new perspective for treatment of faecal incontinence Maastriche 1993, UPM:65-83.

26. Williams NS, Fowler $C G$, George BD, Blandy JP, Badenoch DF, Patel J

Electrically stimulated gracilis sphincter for bladder incontinence

Lancet 1993;341:115-116.

27. Konsten I. Baten CGMI, Havenith MG, Oei TK

Evaluation of gracilis muscle transposition for faecal incontinence with magnetic resonance imaging

Eur J Radioll 1993;16:190-194. 


\section{Comparison of muscle histology and generated pressures of two types of dynamic graciloplasties in rabbits}

\section{Chapter 4}

This chapter will be published as:

COMPARISON OF MUSCLE HISTOLOGY AND GENERATED PRESSURES OF TWO TYPES OF DYNAMTC GRACLOPLASTIES IN RABBITS.

Heesakkers JPFA, Geerdes BP, Freling G, Baeten CGMI, Janknegt RA. European Urology, in press. 


\section{Introduction}

The first report on graciloplasty to restore urinary incontinence dates from $1926 .{ }^{1}$ No successfull long-term results of graciloplasty are reported, particularly because of the fatigability of skeletal muscles. By electrical stimulation periods of increasing duration, the percentage of aerobic, fatigue-resistant type I fibres increases in skeletal muscles. ${ }^{2}$ In this way a muscle is able to sustain long-lasting contraction. Graciloplasty, combined with electrical stimulation resulted in long-term success in patients with faecal incontinence. ${ }^{3}$

'The first results of the electrical stimulated graciloplasty for urinary incontinence were promising, but not as good as in anal graciloplasty. 4.5 One of the reasons is that, in contrast to stool, urine is liquid which implies that the closing capacity of the sphincter has to be higher. Normally the graciloplasty, done around a tubular organ, is performed by a straightforward wrap causing a spiral wrap instead of a pure circular wrap. Compared to this conventional wrap, higher pressures could probably be achieved by the split sling graciloplasty (SSG). The drawback of this technique might be that the blood perfusion of the pulled-through muscle part is jeopardised by strangulation of the contracting proximal part. In order to investigate how the SSG affects muscle histology in the distal part of the graciloplasty, a comparison was made of gracilis muscle histology between the conventional graciloplasty and the SSG. Additionally, a comparison was made of generated pressures for both types of graciloplasty.

\section{Material and methods}

\section{ANIMALS}

Ten adult crossbred giant Flemish rabbits of each sex were used with a mean weight of 4.3 (range $4.0-4.7) \mathrm{kg}$.

\section{SURGERY}

The rabbits were anaesthetised with xylazine and ketamine. A longitudinal skin incision on the medial upper side of both legs was made, and the gracilis tendon was detached distally from its insertion at the tibia. A muscle biopsy was taken and placed in formalin. An intramuscular electrode (SP 5528, Medtronic, Kerkrade, the Netherlands) was implanted near the nerve entry zone of both muscles. The left as well as the right gracilis were wrapped tightly around a flexible polyurethane tube of 2.9 mm in diameter and a wall thickness of $0.13 \mathrm{~mm}$. To stiffen this tube, another polyurethane tube with a diameter of $2.2 \mathrm{~mm}$ was put into the outer tube. With these 
tubes the urethra was simulated. In the right leg a conventional graciloplasty was performed. In the left leg a SSG was performed as described by Rosen et al..$^{6}$ With this technique a longitudinal split is made parallel to the fibre direction in the proximal part of the muscle. After having circled the muscle around the polyurethane tube, the distal part is pulled through the proximal part. The distal parts of the graciloplasty were sutured to the inguinal ligament. The tubes with the graciloplasties were buried subcutaneously. The two techniques are depicted in figure 1.

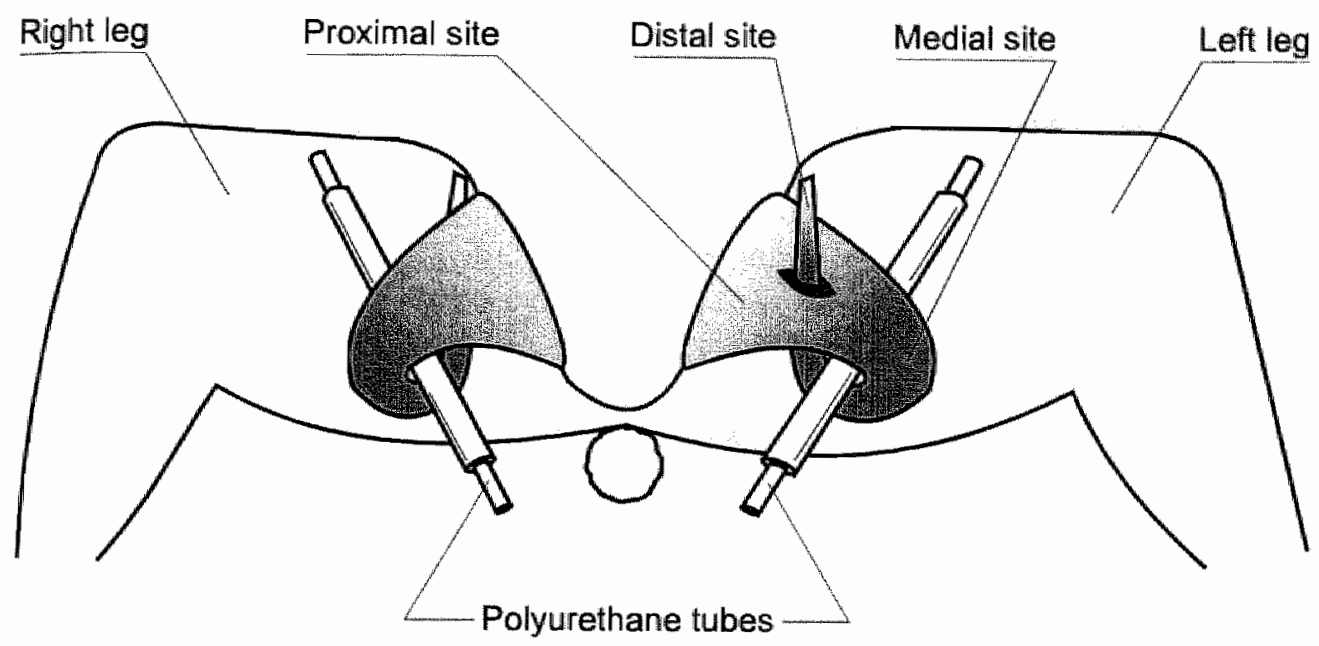

Figure 1. Conventional spiral graciloplasty and split sling graciloplasty situated awound polywethane tubes. In the right leg a conventional graciloplasty is performed, aplit sling gracilophasty is perfomed in the left leg. The location of the proximal medial and distal biopsy places is also indicated.

Afterwards the two electrodes were tunnelled subcutaneously to the abdominal cavity and unipolarily attached to a programmable implantable pulse generator (Itrel ${ }^{\mathrm{TM}} 7424$, Medtronic, Kerkrade, the Netherlands).

\section{ELECTRICAL STMULATION}

After a one week recovery period, a stimulation program was started. The amplitude was determined by palpable contractions of the transposed gracilis muscle. The pulse duration was $210 \mu \mathrm{sec}$ at $25 \mathrm{~Hz}$. Every two weeks the duty cycle was telemetrically changed according to the scheme presented in table 1 : 


\begin{tabular}{|c|c|c|c|c|c|}
\hline Time (weeks) & 0 & 2 & 4 & 6 & 8 \\
\hline On time (s) & 0.1 & 0.2 & 0.4 & 1.0 & 1.0 \\
\hline Off time (s) & 1.2 & 1.2 & 0.7 & 0.5 & 0.0 \\
\hline Duty Cycle (\%) & 8 & 14 & 36 & 67 & 100 \\
\hline Frequency (Hz) & 25 & 25 & 25 & 25 & 15 \\
\hline
\end{tabular}

Table 1. Characteristics of stimulation protocol of tranzposed gracilis muscle.

\section{MUSCLE HISTOLOGY}

After 2 weeks of continuous stimulation, muscle biopsy specimens were taken from the origin, the graciloplasty site and in the distal part of the gracilis muscle and routinely fixed in formalin and paraffin embedded. The specimens underwent haematoxylin-eosin staining for global assessment and Sirius red staining for calculating the amount of connective tissue. Monoclonal antibody $R_{11} D_{10}$ (Centocor, Leiden, the Netherlands) staining was used for distinguishing type I and type II fibres. The following parameters were analysed:

A. Global muscle change was assessed by examination and scoring of the biopsy specimens by an independent experienced pathologist as follows:
score 1:
$0-25 \%$ change
score 2:
25- $50 \%$ change
score 3:
$50-75 \%$ change
score 4:
$75-100 \%$ change.

B. The percentage of type I and type II fibres was calculated by counting approximately 200 fibres in every biopsy specimen.

C. The maximum minor diameter of type I and type II fibres was calculated by using the Quantimet 570C (Leica).

D. The area percentage of connective tissue was determined by using Quantimet $570 \mathrm{C}$ (Leica).

\section{GENERATED PRESSURES}

Pressure measurement was done at the same moment as the biopsy specimens were taken. The animals were anaesthetised again. The skin of the inner sides of both legs was opened and the inner tubes were removed, leaving the thin outer tubes intact. One end of the outer tubes was connected to luer-lock water catheters whereas the other end was closed. The system was subsequently filled with saline. All air bubbles were 
removed from the system before the pressure measurements. The water catheter first was zeroed on air. The pressures were measured in $\mathrm{cm} \mathrm{H}_{2} \mathrm{O}$. The maximal pressure was recorded at rest $(R)$ and during the stimulation phase (S) during which the stimulator was switched "on". After having activated the stimulator the pressure went in most cases down to a steady state pressure. The time $\left(t_{p}\right)$ to reach this steady state and the measured pressure $(\mathbb{P})$ at this point were recorded. The pressure difference divided by the time to reach the steady state phase was calculated as an indicator $\mathbb{I}: I=(\mathrm{S} \cdot \mathrm{P}) / \tau_{\mathrm{p}}$. The stimulation frequency was varied and the maximum pressure was recorded in order to find the optimum frequency with regard to the highest pressure.

\section{STATISTICS}

The Wilcoxon paired rank test was used for histological as well as pressure analysis in all individual rabbits. For histology the following were compared: BEFORE versus AFTER stimulation: the mean of the proximal, medial and distal biopsy specimen was regarded as the AFTER result; PROXIMAL vs MEDIAL vs DISTAL score for the left as well as the right side; LEFT vs RIGH'T scores.

\section{ETHTCS}

The study was approved by the Institutional Animal Care and Use Committee of the University of Maastricht, the Netherlands.

\section{Results}

\section{ANIMALS}

One rabbit died because of infection. Two rabbits had an electrode break-down. A fourth rabbit developed an infection in one leg. Therefore six rabbits were suitable for analysis. In total 48 biopsies were ayailable for analysis in these six rabbits.

\section{HISTOLOGY}

\section{Histological change}

Five biopsy specimens were considered not representative of muscle tissue, one specimen got lost during staining. The mean values $\pm \mathrm{SD}$ of the biopsy scores at the various biopsy sites are listed in table 2 . 
Table 2. Histological results of the tef split shing graciloplasty (L) and the right conventiond graciloplasty (R). The biopsy taken before graciloplasty is indicated with B. P. M and D indicate the proxinal, medial and distal biopsy site (mean $\pm S D, n=6$ ). Asterisk indicates statistical significance $(p<0.05)$ of the medn (Lmean and Rmean) after graciloplasty compared tot we biopsies taken before graciloplasty ( $L B$ and $R B$ ).

LEPT SPLIT SLINO GRACHLORASTY

\begin{tabular}{|c|c|c|c|c|c|c|c|c|c|c|c|}
\hline & 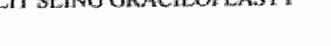 & $\mathbb{L B}$ & & LP & & LM & & $\mathbb{L D}$ & & Lme & \\
\hline A. & Clobal muscle change & 1.0 & $(0)$ & 2.5 & $(1.3)$ & 2.8 & $(1.0)$ & 2.0 & $(1.0)$ & $2.4^{*}$ & $(0.4)$ \\
\hline B. & $\%$ Type I fibres & 3 & (4) & 46 & (37) & 66 & (13) & 54 & $(17)$ & $55 *$ & $(17)$ \\
\hline C. & Type I fibre diameter, $\mu \mathrm{m}$ & 41 & $(7)$ & 43 & $(10)$ & 38 & (6) & 36 & (6) & 39 & (4) \\
\hline D. & Type II fibre diameter, $\mu \mathrm{m}$ & 36 & (5) & 48 & (5) & 40 & (5) & 36 & (6) & $42 *$ & (4) \\
\hline E. & \% Connective tissue & 2.7 & $(1.4)$ & 11 & (13) & 8 & $(5)$ & 10 & (4) & $10^{*}$ & (7) \\
\hline
\end{tabular}

RIOHT CONWENTIONAL GRACLLPLASTY

RB RP RM R R R R

\begin{tabular}{llcccccccccc}
\hline A. & Global muscle change & $\mathbf{1 . 0}$ & $(0)$ & $\mathbf{2 . 0}$ & $(0.8)$ & $\mathbf{1 . 8}$ & $(0.8)$ & $\mathbf{2 . 8}$ & $(0.4)$ & $\mathbf{2 . 2 *}$ & $(0.6)$ \\
B. & $\%$ Type If fibres & 3 & $(4)$ & 66 & $(20)$ & 54 & $(38)$ & 85 & $(6)$ & $70 *$ & $(16)$ \\
C. & Type I fibre diameter, $\mu \mathrm{m}$ & 42 & $(10)$ & 34 & $(3)$ & $\mathbf{3 6}$ & $(3)$ & $\mathbf{4 2}$ & $(8)$ & $\mathbf{3 9}$ & $(6)$ \\
D. Type II fibre diameter, $\mu \mathrm{m}$ & 36 & $(3)$ & $\mathbf{4 7}$ & $(8)$ & $\mathbf{4 0}$ & $(5)$ & $\mathbf{4 1}$ & $(3)$ & $\mathbf{4 3} *$ & $(4)$ \\
E. & \% Connective tissue & $\mathbf{2 . 3}$ & $(2.0)$ & 8 & $(3)$ & $\mathbf{8}$ & $(6)$ & 8 & $(5)$ & $8 *$ & $(4)$ \\
\hline
\end{tabular}

A significant change was found after stimulated graciloplasty as compared with before graciloplasty. This change was significant for the conventional right leg graciloplasty $(p=0.027)$ as well as the left-leg SSG $(p=0.027)$. The mean change for the right- and leftgraciloplasty leg was about $50 \%$. The histological changes in the right-leg graciloplasty were not different from the left SSG. No significant differences could be observed between the proximal, medial or distal site of the right graciloplasty or the left SSG.

\section{Cbange in type I and type II fibres}

The mean percentages of type I fibres as compared with the total of type I and type II fibres are listed in table 2. There was successful conversion with electrical stimulation in both gracilis muscles, as can be seen by the increase in type I fibres. A difference for the right and the left leg before versus after stimulated graciloplasty was observed: $p=0.043$ in both legs. The large standard deviation indicates a substantial variation of type I fibres after graciloplasty between the rabbits as well as the different biopsy sites. Statistically there is no difference in type I fibres in the right graciloplasty compared with the left SSG. No differences were found in the proximal versus medial versus distal site of both legs. 


\section{Variations in type I and type II fibre diameter}

The muscle fibre diameters of type I fibres and type II fibres are listed in table 2. In every biopsy specimen the diameter of approximately 20 type I fibres and 20 type II fibres were measured. Although some decrease was observed, the mean diameter of type I fibres did not change with stimulation. "The mean diameter of type II fibres increased with stimulation from $36 \mu \mathrm{m}$ to $42 \mu \mathrm{m}$ in the left gracilis and from $36 \mu \mathrm{m}$ to $43 \mu \mathrm{m}$ in the right leg ( $\mathrm{p}=0.046$ for left as well as right). No differences were observed in the diameters of biopsy specimens taken at the proximal, medial or distal sites of the left as well as the right graciloplasty.

\section{Change in connective tissue}

The results are listed in table 2 . The percentage connective tissue was significantly less before as compared with after stimulation of the graciloplasty in the left as well as the right leg $(p=0.028)$. Although the connective tissue was less at the proximal, medial and distal site in the right stimulated graciloplasty, as compared with the connective tissue in the left graciloplasty the difference was not significant. Especially no difference could be found in the amount of connective tissue in the distal biopsy specimen as compared to the proximal or medial biopsy specimen of the left stimulated graciloplasty.

\section{PRESSURES}

The recorded pressures in the individual rabbits are listed in table 3 . The spread in pressure measurement was substantial as can be seen by the standard deviation. The pressure in rest was comparable for the left as well as for the right leg. During stimulation, the mean pressure rise was $24 \%$ in the conventional graciloplasty and $58 \%$ in the SSG. Although the mean pressure rise was higher in the SSG no statistical differences were observed ( $R R$ vs $L R: p=0.249 ; R S$ vs $L S: p=0.249$; RR vs RS : $p$ $=0.173 ;$ LR vs LS $: p=0.173$ ).

The recorded pressures at the steady pressure phase $(\mathrm{P})$ together with the time to reach this steady state $\left(t_{\mathrm{p}}\right)$ are also listed in table 3 . A pressure drop was observed in all cases except in two right graciloplasties with low pressures. The drop in mean pressures in the right conventional graciloplasty was from 52 to $40 \mathrm{~cm} \mathrm{H}_{2} \mathrm{O}$ (23\%). This drop was from 76 to $51 \mathrm{~cm} \mathrm{H}{ }_{2} \mathrm{O}(33 \%)$ in the split sling graciloplasty. However, no significant differences could be observed between the two techniques.

The indicator $I$ in the right graciloplasty was 0.19 and in the left graciloplasty 0.21 . These figures do not differ $(p=0.463)$ which implies that both graciloplasties are equally capable to sustain longlasting contraction. 
Table 3. Maximum recorded pressures in $\mathrm{cm} \mathrm{H}_{2} \mathrm{O}$ in the left split sling graciloplasty (L) and he conventional right graciloplasty (R). Maximum pressures are recorded without stimulation in rest $(R)$ and with stimulation (S). The pressure change is listed in percentages. Steady state pressure ( $P$ ) in stimulated left split sling graciloplasty (L) and conventional graciloplasty (R). Time (to ) tattain this steady state is mentioned in reconds. The indicator I is mentioned as well (see text).

LFET SPDLIT SLLAMG GRACHLORLASTY

\begin{tabular}{|c|c|c|c|c|c|c|}
\hline RABBIT & $L R$ & $\mathrm{LS}$ & $\%$ change & LP & $t_{p}$ & $I=(S-P) A_{p} R R$ \\
\hline$i$ & 11 & 33 & +200 & 17 & 120 & 0.13 \\
\hline 2 & 12 & 106 & +780 & 42 & 120 & 0.53 \\
\hline 3 & 144 & 112 & -22 & 98 & 42 & 0.33 \\
\hline 4 & 48 & 64 & +33 & 55 & 80 & 0.11 \\
\hline 5 & 63 & 126 & +100 & 82 & 110 & 0.40 \\
\hline 6 & 12 & 117 & +42 & 12 & 30 & 0.17 \\
\hline
\end{tabular}

RIOHT CONVENTIONAL GRACHOPLASTY

\begin{tabular}{|c|c|c|c|c|c|c|}
\hline RABBIT & $\mathrm{RR}$ & RS & \% change & $\mathrm{RP}$ & $t_{p}$ & $\mathrm{I}=(\mathrm{S}-\mathrm{P}) / \mathrm{t}_{\mathrm{p}}$ \\
\hline$\|$ & 6 & 8 & +33 & 8 & - & 0.00 \\
\hline 2 & 11 & 12 & +9 & 12 & n. & 0.00 \\
\hline 3 & 88 & 70 & -20 & 35 & 80 & 0.44 \\
\hline 4 & 43 & 52 & +26 & 46 & 110 & 0.05 \\
\hline 5 & 41 & 88 & +115 & 70 & 35 & 0.51 \\
\hline 6 & 6.1 & 83 & +36 & 67 & 140 & 0.11 \\
\hline
\end{tabular}

Table 4 lists the generated pressures at different stimulation frequencies. The results of the first rabbit were not available for analysis. The mean maximall pressure was $47 \mathrm{~cm}$ $\mathrm{H}_{2} \mathrm{O}$ in the right graciloplasty and $60 \mathrm{~cm} \mathrm{H}_{2} \mathrm{O}$ in the left graciloplasty at $25 \mathrm{~Hz}$.

Table 4. Maximal pressures ( $\mathrm{cm} \mathrm{H}_{2} \mathrm{O}$ ) at 10, 15, 20,25, 33, 50 and $85 \mathrm{~Hz}$ in the left split sling graciloplasty (L) and right conventional graciloplasty (R) (mean $\pm S D$ ).

\begin{tabular}{|c|c|c|c|c|c|c|c|}
\hline FREQUIENCY & $10 \mathrm{~Hz}$ & $15 \mathrm{~Hz}$ & $20 \mathrm{HZ}$ & $25 \mathrm{~Hz}$ & $33 \mathrm{~Hz}$ & $50 \mathrm{~Hz}$ & $85 \mathrm{~Hz}$ \\
\hline $\begin{array}{l}\text { LEP" } \\
\text { SPLI" SLING GRACILOPLASTY }\end{array}$ & $46(34)$ & $53(32)$ & $58(31)$ & $60(30)$ & $58(29)$ & $57(29)$ & $56(33)$ \\
\hline $\begin{array}{l}\text { RIGH"I CONVENTIONAL } \\
\text { GRACLIOPLASTY }\end{array}$ & $42(17)$ & $46(19)$ & $47(20)$ & $47(19)$ & $46(19)$ & $47(21)$ & $37(22)$ \\
\hline
\end{tabular}




\section{Discussion}

Dynamic graciloplasty is nowadays applied in people suffering from faecal or urinary incontinence. In urinary incontimence efforts are made to improve the closing capabilities of the graciloplasty. In the conventional spiral shaped wrap more skewed forces are generated which pull the urethra aside. In theory the SSG could be an improvement. With this construction the muscle wrap is situated more rectangular to the urethra. When the muscle contracts a more circumferential compression of the urethra is obtained. However, in the SSG the distal part of the gracilis muscle has to be pulled through the longitudinal split in the proximal muscle part. This might imply that during contraction of the graciloplasty the blood supply of the pulled-through part is challenged because of strangulation by the proximal part. This would lead to severe histological changes in the long-term. It is essential to know whether more histological changes can be observed because a continuous contracting muscle is the final stage of the training period. Another reason for investigating graciloplasty histology is that in urinary incontinence the graciloplasty has been wrapped around the bladder neck. In order to get there the stiff urogenital diaphragm has to be passed. In two patients a fibrotic gracilis was found around the bladder neck, most likely caused by strangulation by the urogenital diaphragm during contraction. ${ }^{5}$ This means that the viability of the gracilis muscle is in delicate balance and histological changes quickly occur.

The global assessment of the biopsy specimens, as done routinely by pathologists, shows that a conventional graciloplasty as well as a SSG combined with stimulation gives significant histological changes. However no differences are observed between the mean changes in the SSG compared with the conventional graciloplasty. Moreover, as compared with the left proximal and left medial location, significant changes did not occur in the left distal graciloplasty location. This means that during global biopsy inspection the pulled through part of the gracilis muscle is as vital as other parts of the transposed muscle.

The conversion into type I fibres has been successful. The mean percentages are 55 and $70 \%$ for the left and right leg, respectively. These values are abtained after 8 weeks of stimulation and did not differ $(p=0.12)$. The observed percentages are in accordance with those reported inother publications. The same as well as higher percentages of type I fibres have been reported, although other stimulation frequencies were applied. 8.910

The diameter of type II fibres increased from 36 to $42 \mu \mathrm{m}$ whereas the mean type I fibre diameter decreased somewhat, although this was not significant. It is suggested that the decrease of fibre diameter increases the fatigue resistance because the diffusion distance between capillaries and fibre centre is reduced. "This indicates the functional importance of the type II fibres before stimulation because of the smaller diameter. It 
also seems consistent that there is a non significant decrease in diameter of type I fibres with stimulation, which was observed by others. ${ }^{2}$

The Sirius red staining gives a red colouring of connective tissue. This was done to see the effect of the stimulated graciloplasty on the amount of connective tissue in the muscle. Before the procedure, the proportion of connective tissue is 2.7 and $2.3 \%$ for the left and right leg respectively After stimulation the value in the SSG is $10 \%$ $(p=0.028)$. In the conventional stimulated graciloplasty the connective tissue has increased from $3 \%$ to $8 \%(\mathrm{p}=0.028)$. The percentages after graciloplasty are equal $(p=0.600)$. The increase in connective tissue is in concordance with other publications. ${ }^{15}$ No difference could be observed in the percentage of connective tissue in the proximal, medial or distal biopsy sites in the left or the right leg. Especially the amount of connective tissue in the distal biopsy of the left stimulated SSG was not different from the proximal or medial location, or the percentages of the right leg. This means that the change at this location was equal to other locations.

The major goal of this study was to investigate the differences between the SSG and the conventional graciloplasty with regard to urethral pressures. Rosen et al reported that the anal SSG was superior in terms of pressure and configuration. ${ }^{6}$ In our rabbit study we used a very easily compressible $0.13 \mathrm{~mm}$ polyurethane tube as an artificial urethra. The advantage of this technique is that urologic complications (urinary tract infection, bladder retention, fistulas) which jeopardise the graciloplasty and the stimulation device, occur less frequently. Table 3 shows (although not significant) that the mean maximum pressure in the SSG in rest as well as during stimulation is higher than in the conventional graciloplasty. 'The standard deviation indicates that a substantial disparity in recorded pressures is registered. This can be explained by the way the pressure is recorded. It is easy to disturb the configuration of the graciloplasties and the tubes which are not as tight positioned in their location as a native urethra. When putting a clamp at the end of the tube, kinking of the artificial urethra may occur, causing a change in different recorded pressure. We found that handling of the model was delicate and had to be done very carefully. This is also the reason why we think that comparison of the relative pressure change is preferable over the absolute pressures. Therefore, an increase of $58 \%$ in the stimulated SSG compared to $24 \%$ in the conventional graciloplasty is striking.

The indicator I represents the ability to sustain longlasting contractions. If no pressure drop is observed the time to reach the steady state phase is infinite and the indicator is 0. If a fast pressure drop occurs the time is limited to reach the plateau and the indicator high. One has to take into account that the pressure difference has to be within certain limits because a high pressure drop in a long time will also increase the indicator. 'There is no substantial difference in the left SSG as compared with the right 
conventional graciloplasty ( $0.19 \mathrm{vs} 0.21)$. This implies that both graciloplasties are equally capable of sustaining longlasting contractions. This finding is compatible with the finding that no difference in percentage type I fibres, which are more fatigueresistant, could be found between the SSG and the conventional graciloplasty. The control of the stimulation frequency shows that the applied $25 \mathrm{~Hz}$ was ideal. By looking at the generated pressures at various frequencies, it is possible to determine the optimal stimulation frequency which delivers the highest pressure within the tubes by fused graciloplasty contractions. In individual cases the highest pressure was obtained with different frequencies. It is important to note that a substantially lower frequency like $10 \mathrm{~Hz}$ does not result in higher pressures. This would imply that a lower frequency which is less energy consuming would have been superior because of the longer stimulator lifespan. On the other hand a higher stimulation frequency, which is more energy-consuming, does not lead to higher pressures. This result is comparable with the finding of Lucas et al who reported $30 \mathrm{~Hz}$ as compared to higher as the ideal frequency for muscle stimulation in cardiomyoplasty in dogs. ${ }^{14}$

\section{Conclusion}

The dynamic graciloplasty causes histological changes in the rabbit gracilis muscle. These changes are comparable for the conventional spiral graciloplasty and for the SSG. The histology changes as much in the proximal, medial and distal part of the muscle. The percentage fibre conversion from type II into type I fibres is comparable for the right as well as the left graciloplasty. Graciloplasty combined with electrical stimulation leads to an increase of connective tissue in the conventional graciloplasty as well as in the SSG. The gross histology changes, the conversion in fibre type composition and the amount of connective tissue in the pulled through muscle part of the SSG is similar to other locations in the SSG as well in the conventional graciloplasty. This means that in chronical stimulated skeletal muscles, the pulled through part is as viable as other muscle parts.

The recorded pressures of the SSG are at least similar to the conventional graciloplasty. With stimulation the relative increase of the pressure of the SSG is superior to the conventional graciloplasty. The ability of the two techniques to sustain longlasting contractions are the same, whereas $25 \mathrm{~Hz}$ is an ideal stimulation frequency for both techniques. This implies that from a histology point of view the SSG is competitive with the conventionally wrapped muscle, and the generated pressures of the SSG are at least as good as of the conventional graciloplasty. 


\section{References}

1. Dening $\mathrm{CL}$

Transplantation of the gracilis muscle for incontinence of urine

JAMA 1926;82:822-824.

2. Salmons $\mathrm{S}$, Henriksson J

The adaptive response of skeletal muscle to increased use

Muscle \& Nerve 1981;4:94-105.

3. Bacten $\mathrm{C}$, Geerdeg $\mathrm{B}$, Adang $\mathrm{E}$, Heineman $\mathrm{E}$, Konsten \, Engel $G_{3}$ Kester $A_{4}$ Spaans $F$, Soeters $\mathrm{P}$

Anal dynamic graciloplasty in the treatment of intractable faccal incontinence

N Eng J Med 1995;332:1600-1605.

4. Janknegt RA, Baeten CGMI, Weil EHJ. Spaans $F$

Electrically stimulated gracilis sphincter for treatment of bladder sphincter incontinence Lancet: 1992;340:1129-1130.

5. Janknegt RA, Heesakkers JPFA, Weil EHJ, Baeten CGMI

Electrically stimulated gracilis sphincter (dynamic graciloplasty) for treatment of intrinsic sphincter deficiency: a pilot study on feasibility and side effects

J Urol 1995;154:1830-1833.

6. Rosen HR, Feil W, Novi $G_{1}$ Z Züch $\subseteq$,

Dabulberg S, Schiessel R.

The electrically stimulated (dymamic) sraciloplasty for faecal incontinence with a modified muscle slling

Int I Colorect Dis 1994: 9:184-186.

7. Lavenith $\mathrm{MG}_{*}$ Visser $\mathrm{R}_{\mathrm{i}}$ Schrijvers wan Schendel IMC, Bosman FT

Muscle fibre typing in routinely processed skeletal muscle with monoclonal antibodies Histochemistry 1990;93:497-499.
8. Mokrusch T, Engelhardt A. Eich horn KF, Prischenk $G$, Prischenk $\mathbb{H}_{\text {, Sack }} G_{\text {, }}$ Neundorfer B

Effects of long-impulse electrical stimulation on atrophy and fibre type composition of chronically denervated fast rabbit muscle

J Neurol 1990;237:29-34.

9. Shatari T, Teramoto T, Kitajima M, Minamitani $H$

Conversion of the rabbit gracilis muscle for transposition as a neoanal sphincter by electrical stimulation

Jpn J Surg 1995; 25;233-236.

10. Rouanet $P$, Bacou $\mathbb{F}$

Changes in fibre type, metabolic character and acetyllcholinesterase forms in rabbit skeletal muscle following stretch and electrical stimulation

Neuromusc Disord 1993;3:401-405.

11 Hudlicka O, Hoppeler $\mathrm{H}_{x}$ Uhimann $\mathrm{E}$ Relationship between size of the capillary bed and oxidative capacity in various skeletal muscles

Pflugers Arch 1987;410:369.

12. George BD, Williams NS, Patel J, Swash M, Watkins ES

Physiological and histochemical adaptation of the electrically stimulated gracilis muscle to neoanal sphincter function

$\mathrm{Br}$ J Surg 1993;80:1342-1346.

13. Ronsten J, Bateten CG, Havenith M, Oei 'TK Evaluation of gracilis muscle transposition for faecal incontinence with magnetic resonance imaging

Eur J Rad 1993;16:190-192.

14. Lucas CM, wan der Veen IH, Grandjean PA, Penn OC, Wellens $\mathrm{HJ}$

What is the ideal pulse frequency for skeletal muscle stimulation after cardiomyoplasty?

Pacing Clin Electrophysiol 1991: $14(5$ pt 1$): 778-782$. 


\section{Electrical stimulated graciloplasty in the male goat: an animal model for urethral pressure measurement}

\section{Chapter 5}

This chapter was published as:

ELECTRICAL STIMULATED GRACIOPLASTY IN THE MALE GOAT: AN ANIMAL MODEL FOR URETHRAL PRESSURE MEASUREMENT.

Heesakkers JPFA, Jianguo W, Geerdes BP, Baeten CGMI, Janknegt RA.

Neurourology and Urodynamics 1996;15:545-553. 


\section{Introduction}

The dynamic urinary graciloplasty is used to treat urinary incontinence in humans." Up till now ten patients with urinary incontinence received dynamic urinary graciloplasty in our hospital. In some patients the results are good, in others disappointing. The results of the dynamic anal graciloplasty for faecal incontinence are good. ${ }^{2}$ The differences between the dynamic urinary graciloplasty and the dynamic anal graciloplasty are the location of the graciloplasty and the higher pressure which is needed to stop urine. Based on these two differences animal experiments are performed to improve the results of the dynamic urinary graciloplasty.

So far the dynamic urinary graciloplasty is wrapped around the bladder neck in humans, because the wrap around the bulbous urethra might cause stricturition. ${ }^{3}$ However, the bulbous urethra is favourable with regard to gracilis muscle anatomy. To test the bulbous urethra location with the split sling graciloplasty (SSG), an animal model had to be developed for urethral pressure measurements. This model should be able to mimic the human anatomy as good as possible. The ideal animals are primates, because they walk erect. They are however difficult to obtain. Since dogs have a not compressible penile bone and pigs have too short muscles, the male goat was chosen. In an acute male goat experiment we investigated the possibility of urethral pressure measurement. We also compared the difference in generated pressure of the graciloplasty wrapped around the urethra to the graciloplasty wrapped around the bladder neck. To our knowledge this is the first article which describes the urethral pressures recorded in male goats with and without graciloplasty. The effect of muscle wraps on urethral pressures is described.

\section{Materials and methods}

In order to explain the used technique the goat anatomy of the bladder neck, urethra and gracilis muscle as well as the related topography is given.

\section{ANATOMY}

In adult male goats the penis, of which the proximal $8 \mathrm{~cm}$ is situated in the pelvis, is about $35 \mathrm{~cm}$ long. After having passed the equivalent of the urogenital diaphragm, a 8 $\mathrm{cm}$ long sigmoid shaped penis is present which is laterally accompanied by the retractor penis muscle. This is the bulbous part of the penis. Just outside the pelvis the strong bulbospongiosus muscle is located. The final part of the penis is about $19 \mathrm{~cm}$ long. Outside the pelvis the penile shaft is easily accessible and not surrounded by glandular tissue. The penile shaft is similar to that of human beings and consists of a 
side of the corpus spongiosum two stiff corpora cavernosa are situated. The penile shaft is surrounded by a strong layer of connective tissue. This connective tissue layer and the corpora cavernosa prevent the penile shaft from easy compression and distention. The penis in erected state is therefore mainly lengthwise and does not thicken. Just outside the pelvis the urethral diameter enlarges and is situated more to the exterior of the penile shaft. In contrast to dogs the penis of the male goat lacks a penile bone. The bulbous penile shaft is situated close to the origin of the gracilis muscle. Compared to humans the gracilis muscle in goats is a broad muscle which originates from the pubic bone and ends tendinous-like at the knee. The muscle is thicker at the anterior side of the leg. The main arteries enter at the inside anterior border of the gracilis origin and come from the profunda femoris artery. The artery crosses the muscle obliquely and branches proximally into smaller arteries. The main nerve enters proximal to the artery and runs rectangular to the muscle fibre direction. The topography of the arteries and nerves makes it possible to split the muscle and have a ventral part which stays in situ, and a dorsal strip of about $4 \mathrm{~cm}$ width which can be used for wrapping, without disturbance of the nerve and blood supply.

\section{MATERIAL}

Ten 12 week old Dutch Landrace goats weighing about $20 \mathrm{~kg}$ were anaesthetised and put in the lithotomy position. During anaesthesia they all had stable blood pressures, pulse rates and ventilation rates. System blood pressure, ECG, ventilation rates and pressures were monitored continuously. The experiment was approved by the Institutional Animal Care and Use Committee of the University of Maastricht, Maastricht, the Netherlands.

\section{TECHNTQUE}

A first urethral pressure profilometry (UPP) was performed after cutting the penile shaft about $10 \mathrm{~cm}$ distally to the outrance of the pelvis, in order to get access to the urethra. A 6 french catheter (Gaetec) mounted with one microtip transducer was introduced in the $60^{\prime}$ clock position upstream just to the membranous urethrat. The UPP was performed with a puller (AMT Sittard, NL) at a speed of $1 \mathrm{~mm} / \mathrm{s}$. The transducer was connected online to an ambulatory urodynamic computer program. Urodec 500 (Dantec, Denmark). In order to get access to the penis outside the pelvis with the retractor penis muscle the scrotum was split (figure 1). 


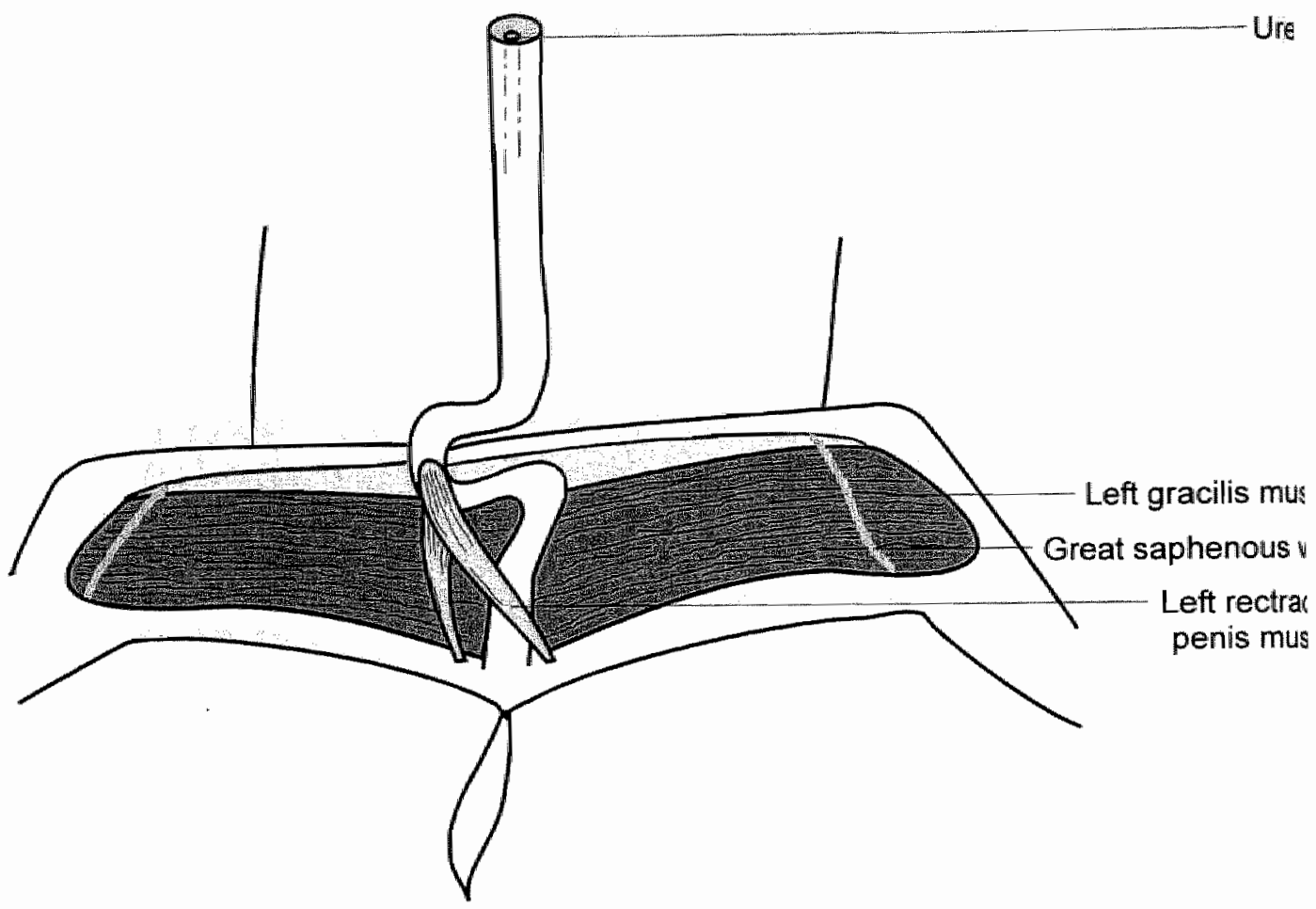

Figurel

Anatomical topography of the dissected penile shaft oniside the pelois and of the gracilis muscle. The retwactor penis muscles are both intact. The scroinm is left owt ws well as the dissected skin. The penile shaft is cut $15 \mathrm{~cm}$ outside the pelwis.

"To construct the bulbous graciloplasty, $5 \mathrm{~cm}$ of the urethra with the corpus spongiosum was dissected from the corpora cavernosum (figure 2). Four $\mathrm{cm}$ of the dorsal part of the gracilis was used for the wrap by splitting the muscle lengthwise keeping the nerves and bloodvessels intact. The distal part of the split part was detached at the tendinous part at the knee (figure 3). A split sling technique for the gracilis wrap was used. In this technique, the distal part of the muscle is pulled through a longitudinal split, which is made in the proximal part of the muscle, after a wrap around the bulbous urethra or bladder neck. In this way more circular compression onto the urethra can be achieved. 'The gracilis passed the corpus spongiosum dorsally and came back ventrally. The distal part was put through the split and sutured to the 
contrallateral side of the pelvis near the midline, after having passed the bulbous urethra once again (figure 4).

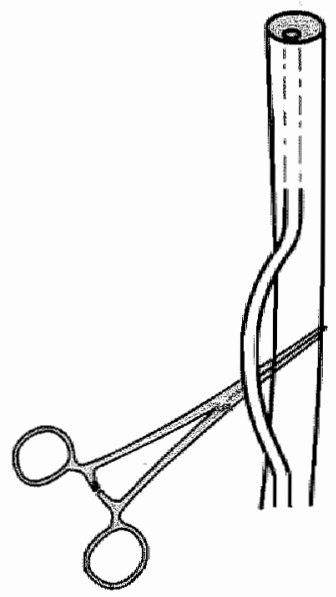

Figure 2

Detail of exposed male goat pens witb dissected arethra located in the corpus spongiasum.

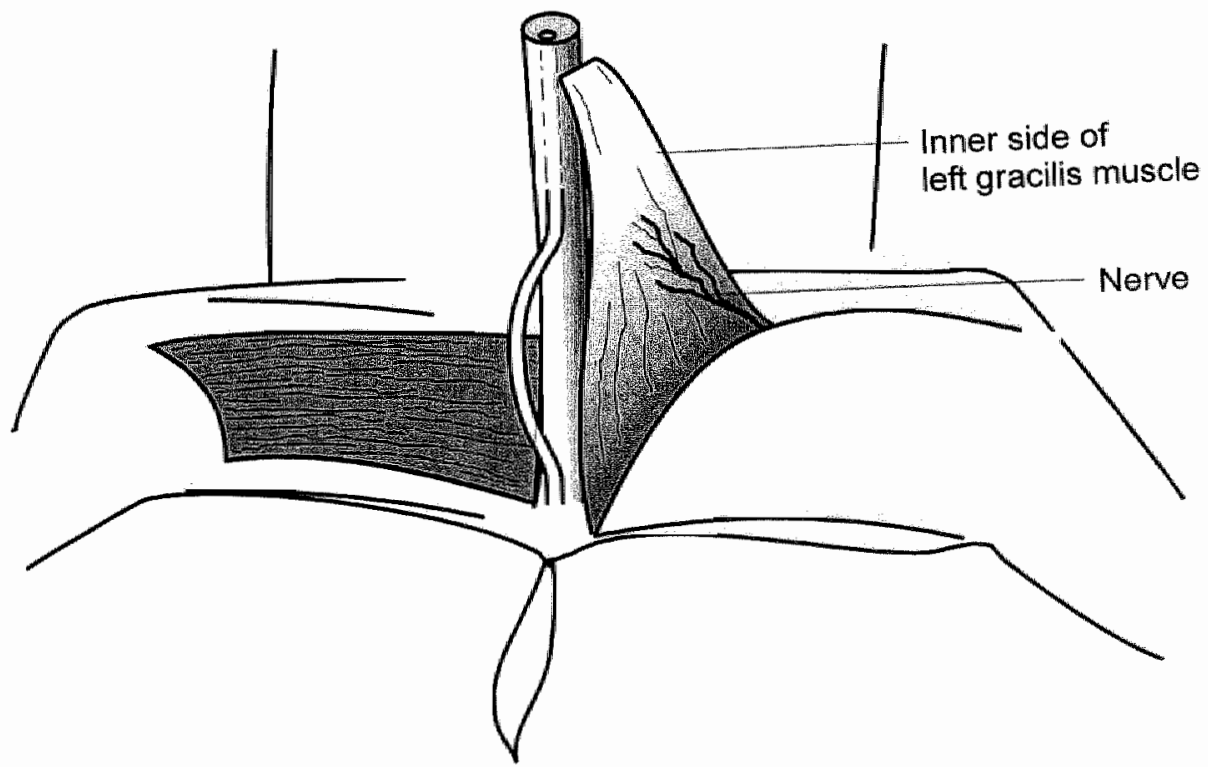

Figure 3

Anatomy of the dissected gracilis which is cut at the tendon and lifted to the medial side. The lacation of antery and nerve can be seen al the inside of the gracilis. 


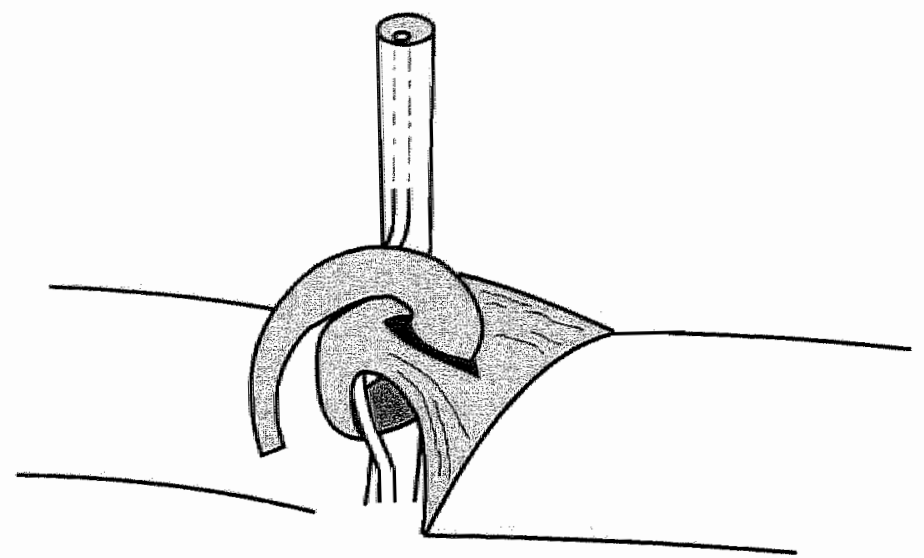

Figgure 4

Gractloplasty with the split sling technique. The gracilis is wrapped around be dissected corpus spongiosum and pulled througb the proximal slit. Afterwards it will be sutured to the medial opposite side.

Afterwards the second UPP wasperformed retrogradely without stimulation of the muscle. Hereafter, the gracilis nerve was stimulated with an external pulse stimulator. The location with the highest response was used and stimulated with an amplitude of 2.0 Volts, a frequency of $25 \mathrm{~Hz}$ and pulses of $210 \mu \mathrm{s}$. A third UPP was performed during this phase.

For the gracilis wrap around the bladder neck, an abdominal incision was made and the bladder neck was exposed. The bladder was opened and the microtip-mounted catheter was introduced downstream just to the pelvic outrance. The catheter was pulled back and UPP was recorded. The same split sling technique was used for the bladder neck wrap, made with the gracilis of the other leg. The gracilis wrap was made by passing the pubic bone ventrally, which is easily done in quadrupeds. Another UPP with and without stimulation was performed in the same way as in the bulbous urethra. In five goats (numbers $1,2,5,6$ and 9 ) the right gracilis was used for the bulbous urethra; in the other goats the right gracilis was used for the bladder neck wrap. The urethral pressures were statistically compared with the paired Student T-test. Statistical significance was defined as $p<0.05$. 


\section{Results}

The mean native urethral pressures of the three main locations are listed in table 1.

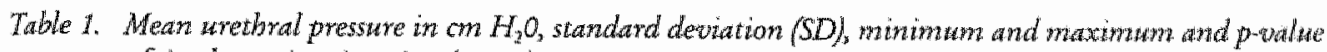
of in the native situation $(n=10)$.

\begin{tabular}{|c|c|c|c|c|c|c|c|}
\hline & Mean & $\mathrm{SD}$ & Min & $\operatorname{Max}$ & $\begin{array}{l}P \text { walue } \\
A \text { vs } B\end{array}$ & $\begin{array}{l}\mathrm{P} \text { valuep } \\
\mathrm{B} \text { vs } \mathrm{C}\end{array}$ & $\begin{array}{l}\text { value } \\
A \text { ws } C\end{array}$ \\
\hline A Bladder neck & 30 & 14 & 5 & 51 & 0.000 & & \\
\hline B. Pelvic outrance & 136 & 20 & 108 & 164 & & 0.000 & \\
\hline C. Bulbous urethra & 44 & 10 & 21 & 51 & & & 0.012 \\
\hline
\end{tabular}

The pressure is significantly higher at the pelvic outrance compared to the bulbous urethra, the pressure at the bulbous urethra is significantly higher than the bladder neck pressure.

The results at the bladder neck and the bulbous urethra after graciloplasty without stimulation are listed in table 2.

Table 2. Mean uretbral pressure in $\mathrm{cm} \mathrm{H}_{2} \mathrm{O}$, standard deviation (SD), minimum and maximum and prvalue after graciloplasty without stimulation $(n=10)$.

\begin{tabular}{lcccccl}
\hline & Mean & SD & Min & Max & p value $\begin{array}{l}\text { p value } \\
\text { vs native pressure }\end{array}$ \\
Bladder neck & 97 & 52 & 36 & 190 & 0.003 \\
Bulbous urethra & 122 & 44 & 56 & 195 & 0.162 & 0.000 \\
\hline
\end{tabular}

There is no difference between the bladder neck pressure and the bulbous urethral pressure after the graciloplasty. However a substantial variation is found in the both bladder neck and bulbous urethral pressures.

The mean pressures with stimulation are listed in table 3.

At both locations a pressure increase is observed which is about twice as high as the pressure without stimulation. The bulbous urethral pressure is significantly higher compared to the bladder neck pressure. 
Table 3. Mean wrethral pressure in on $\mathrm{H}_{2} \mathrm{O}_{3}$ stundard deviation (SD), minimum and maximum and pvalue affer graciloplasty with stimulation $(n=10)$.

\begin{tabular}{lccccccc}
\hline Mear & $S D$ & Min & Max & p value & $\begin{array}{l}\text { p value } \\
\text { vs native } \\
\text { pressure }\end{array}$ & $\begin{array}{c}\text { P value ws } \\
\text { without } \\
\text { stimulation }\end{array}$ \\
Bladder neck & 183 & 94 & 62 & 379 & & 0.001 & 0.001 \\
Bulbous urethra & 294 & 83 & 174 & 400 & & 0.006 & \\
\hline
\end{tabular}

If the highest urethral pressure is the threshold pressure for continence in goats, theoretically, continence with graciloplasty is achieved when the pressure is as high as the highest urethral pressure, i.e. the pelvic outrance pressure. Therefore a comparison is made of the pelvic outrance pressure and the pressure achieved with graciloplasty with and without stimulation. These results are listed in table 4 and table 5.

Table 4. Mean graciloplasty pressure in $\mathrm{cm} \mathrm{H}_{2} \mathrm{O}$, standard deviation (SD), minimum and maximum and pvalue compared to the pelvic outrance after graciloplasty writhout stimulation $(n=10)$.

\begin{tabular}{llllll}
\hline & Mean & SD & Min Max & p value \\
Pelvic outrance urethra & 136 & 20 & 108 & 164 & \\
Bladder meck & 97 & 52 & 36 & 190 & 0.076 \\
Bulbows urethra & 122 & 44 & 56 & 195 & 0.599 \\
\hline
\end{tabular}

Table 5. Mean graciloplasty pressure in con $\mathrm{H}_{3} \mathrm{O}_{\mathrm{s}}$ standard deviation (SD), minimum and maximun and p-waltue compared to the pelvic outrance after graciloplasty with stimwlation $(x=10)$.

\begin{tabular}{lccccl}
\hline & Mean & SD & Min & Max & p walne \\
Pelvic outrance urethra & 136 & 20 & 108 & 164 & \\
Bladder neck & 183 & 94 & 62 & 379 & 0.110 \\
Bulbous urechro & 294 & 83 & 174 & 400 & 0.001 \\
\hline
\end{tabular}


Although the mean pelvic outrance pressure is higher than the pressure of the bladder neck and bulbous urethra, the difference is not significant.

Table 5 shows no significant difference between the bladder neck pressure and the pelvic outrance pressure.However, the pressure generated around the bulbous urethra is significantly higher.

A representative UPP of the male goat after bulbous urethral graciloplasty with and without stimulation is depicted in figure 5 .

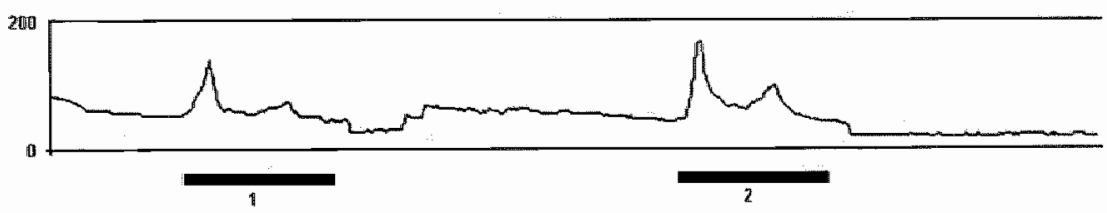

Figure 5

Representative UPP of the male gaat with bulbows graciloplasty without and with stimulation. The first bar under the curve is the area of bulbous graciloplasty without stimulation. The second bar is the same bulbous graciloplasty area with stimulation (pressures are in con $\mathrm{H}_{2} \mathrm{O}$ ).

\section{Discussion}

Urinary incontinence is still a difficult therapeutic problem, as demonstrated by the availabilityof more than 100 operative solutions. ${ }^{4}$ New methods to treat urinary incontinence are developed continuously. Since 1926, conventional graciloplasty is performed to replace a dysfunctional or absent urinary sphincter, but contradictory results have been reported. $5,6,7$ The basic problem has been that patients cannot achieve sustained contraction of the transposed muscle. At our clinic, electrodes connected to a programmable stimulator are added to the conventional graciloplasty. ${ }^{8}$ In this way the muscle can be trained to contract continuously. The ongoing electrical stimulation causes fast-twitch, fatigue-prone type 2 fibres to be transformed into slow-twitch, fatigue-resistant type 1 fibres. "In this process the histochemical composition of the gracilis muscle comes to resemble that of the sphincter. ${ }^{10}$ The contractility of the muscle is used to increase the urethral resistance. When the stimulator is switched off, by means of an external magnet, the muscle relaxes and the urethral resistance diminishes. In this way the patient can void. 
The results of dynamic urinary graciloplasty are not as good as those of dynamic anal graciloplasty. In order to reveal the reasons for failure we developed an animal model to investigate the dynamic urinary graciloplasty. Animal models were used earlier to examine new treatments of urinary incontinence or to examine urodynamics. $11,12,13,14,15,16$, So far we have not found any paper on urethral pressure experiments in male goats. In male goats the penile shaft is similar to that of man and consists of a urethra within a thin corpus spongiosum located ventrally. The urethra can be compressed, in contrast to dogs, because goats don't possess a penile bone. The bulbous penile shaft is situated close to the origin of gracilis muscle. ${ }^{17}$ Therefore we think that the anatomy of goats is suitable for dynamic urinary graciloplasty studies. This study proves that it is feasible to perform urethral pressure measurements in the male goat. It also shows that it is possible to use the goat gracilis to make a graciloplasty which can be activated on demand. In this way the human dynamic urinary graciloplasty can be mimicked and a comparison of pressures in the bladder neck and in the bulbous urethra can be made.

Table 1 shows significant differences of the pressure at the bladder neck, the pelvic outrance and the bulbous urethra. This can be explained by the anatomy. The lumen of the bladder neck is larger than the lumen of the bulbous urethra. The high pressure registered at the pelvic outrance probably is caused by the strong bulbospongiosus muscle.

The results of table 2 and 4 show that the recorded graciloplasty pressures without stimulation, are not as high as the pressure at the pelvic outrance, although the differences are not significant. This means that the non-stimulated graciloplasty acts like a sling. In contrast, the results of table 3 and 5 show that the gracilis can act like a sphincter when electrical stimulated. The recorded pressure is significantly higher than the native pressure in the pelvic outrance. Because of the high pressure, sudden abdominal pressure rises does not automatically mean leakage. The pressure of the dynamic urinary graciloplasty with stimulation at the bulbous urethra was significantly higher than at any other location. 'The pressure of the dynamic urinary graciloplasty with stimulation was significantly lower at the bladder neck, than at the bulbous urethra. The reasons so far remain unclear. Probably it is caused by the more direct relationship of the bulbous urethra and the gracilis muscle, which makes it possible to perform a muscle wrap that can put more force symmetrically and perpendicular to the urethra. Therefore, the bulbous urethra could be the ideal location for the dynamic urinary graciloplasty. From a technical point of view this would mean an improvement for male human beings, because it is easier to perform a dynamic urinary graciloplasty around the bulbous urethra than around the bladder neck. Chronic experiments have to proof whether the reported stricturing occurs at this location and how this can be avoided, for instance by making a less tight wrap or by using a lower stimulation amplitude. The amplitude we used in this study was 2 volts, because in 
humans this voltage largely transgresses the threshold of muscle contraction. It is likely that lower amplitudes can also be used to obtain continence, which means that the lifetime of the pacemaker is longer.

Several configurations of wrapping the muscle have been described. ${ }^{18}$ Rosen et al used the three-dimensional anal vectormanometry to show that the SSG is superior to the conventional wrap in humans. Modification of the sling resulted in more circular compression improving continence rates. ${ }^{20}$ Animal studies on SSG are lacking. In this study SSG proved worthwhile in the acute experiment. For performing the SSG the proximal muscle part has to be split and the distal muscle part has to be pulled through the proximal part. During contraction this might cause ischemia in the distal part of the muscle. Further work has to be done to investigate this aspect, because in order to act like a sphincter the graciloplasty must be able to contract lifelong. Compared to human beings the bladder neck dynamic urinary graciloplasty was performed not by passing the urogenital diaphragm, but by passing the pubic bone ventrally. In this way ischemia caused by compression of the graciloplasty by the urogenital diaphragm as observed in humans does not occur. ${ }^{8}$

To know whether the stimulated graciloplasty is able to sustain the high pressures in the long-term, chronic experiments have to be performed.

\section{Conclusion}

It is concluded from this study that the male goat is a useful animal model to perform urethral pressure measurements and to investigate the effects of muscle wraps on urethral pressures. It also shows that the SSG is a useful method to achieve significant higher pressures in an acute animal experiment. The pressures achieved at the bulbous wrethra are superior to the bladder neck pressures and to the pressures around the pelvic outrance. Further studies are needed to confirm the longterm effect of this technique on the urethra or bladder neck and the ability of the dynamic urinary graciloplasty to maintain longlasting contraction and therefore continence. 


\section{References}

1. Janknegt RA, Bacten CGMI, Weil EHJ, Spaans $\mathrm{F}$.

Electrically stimulated gracilis sphincter for treatment of bladder sphincter incontinence Lancet 1992;340.1129-1130.

2. Baeten CGM, Geerdes BP, Adang EMM, Heineman EH, Konsten I, Engel GL, Kester ADM, Spaans F, Soeters PB Anal dynamic graciloplasty in the treatment of intractable faecal incontinence N Eng J Med 1995;332:1600-1605.

3. Williams $\mathrm{NS}$, Fowler $\mathrm{CG}$, George BD, Blandy JP, Badenoch DF, Patel I

Electrically stimulated gracilis sphincter for bladder incontinence Lancer 1993;341:115-116.

4. I-Takelius L, Gierup J, Grotte G Urimary incontinence in children: Treatment with free autogenous muscle transplantation

Prog Pediatr Surg 1984;17:155-167.

5. Deming $\mathrm{CL}$

Transplantation of the gracilis muscle for incontinence of urine JAMA 1926;82:822-824.

6. Pickrell $\mathrm{K}$, Georgiade $\mathrm{N}$, Crawford $\mathrm{H}$, Maguire C, Boone A

Gracilis muscle transplant for correction of urimary incontinence in male children Ann Surg 1956:14:764.779.

7. Griffith IH

Tramsplantation of the gracilis muscle for the control of urinary incontinence in women

BrJ Urol $1960 ; 32: 7477752$.

8. Jankinegt RA, Heesakkers JPFA, Weil EHJ, Bacten CGMI

Electrically stimulated gracilis sphineter (dynamic graciloplasty) for treatment of intrinsic sphincter deficiency: a pilot study on feasibility and side effects

J Urol 1995;154:1830-1833.
9. Pette D, Vrbova $G$

Adaptation of mammalian skeletal muscle fibres to chronic electrical stimulation Rew Physiol Bioch P 1992;120:115-202.

10. Konsten J, Baeten CGM, Havenith MG, Soeters PB

Morphology of dynamic graciloplasty compared with the anal sphincter Dis: Colon Rectum 1993;36:559-563.

11. Guan Z, Kiruluta $G_{n}$ Coolsaet $\mathbb{B}_{\text {, Elhilali } M}$ Conscious minipig model for evaluating the lower urinary tract

Neurourol Urodynam 1994;13:147-158.

12. Mostwin JL, Karim $O M$, Van Koeveringe $G_{i}$ Seki $\mathbb{N}$

Guinea pig as an animal modell for the study of urinary bladder function in the normal and obstructed state

Neurourol Urodynam 1994:13:137-145.

13. Gruneberger $A D$

Development of a magnetic urethral closure and initial clinical experiences

Urologe A 1987;26: 106-111.

14. Moklaless I, Hassouna MM, Kiruluta GH, Seemeyer 'TA, Homsy YL, Coolsaet BL. Ellhilali MM

The evolution of artificial sphincter cuff in growing animals

J Uroll $1988 ; 140: 632-636$.

15. Devendra $G$, Diokno $A$, Davidson $D$, Alderson $T$, Valenzuela $P$, Banerian $K$ Use of artificial sphincter to bowel segment using rectus muscle interposition Urology 1993:41:268-271.

16. Sanford Ex Lockhart JL, Weinstein D Experimental investigation of an infolded bowel segment as an anti-incontinence mechanism without interposing the ileocecal valve

Uroll Res 1994;22(3):157-160. 
17. Nickel von $\mathrm{R}$, Schummer A, Seiferle E Anatomy of the domestic animals

Berlin Paul Parey Verlag 6th edition 1986, wol 2:360-376.

18. Williams NS, Patel J, George BD, Hallan RI, Watkins ES

Development of an electrically stimulated neoanal sphincter

Lancet 1991;338:1166-1169.

19. Rosen IR, Feil W, Nowi G, Zuch G,

Dahlberg S, Schiessel R

The electrically stimulated (dynamic) graciloplasty for faecal incontinence with a modified muscle sling

Int J Colorect Dis 1994;9:184-186. 
- 
Acute effect of the electrically stimulated urinary graciloplasty on energy metabolism of the gracilis muscle in male goats

Chapter 6

Submitted for publication 


\section{Introduction}

To perform dynamic urinary graciloplasty, two muscle electrodes and a pulse stimulator are implanted. Conversion of type II muscle fibres into type I muscle fibres, transforms the skeletal gracilis muscle. Impressive metabolic changes also occur. Changes in energy metabolism starts immediately and continues for weeks."

Adaptation starts after approximately fifteen minutes in which three phases can be recognised. During the first phase ATP, phosphocreatine and glycogen stores are drastically reduced. The potential of the fast-twitch skeletal muscle to adapt to the increased inflow of metabolites of the energy metabolism, by changing from anaerobic glycolytic metabolism to aerobic-oxidative metabolism, is of paramount importance especially for dynamic graciloplasty. Because muscle adaptations are needed for muscle survival, we looked how the energy metabolism in the non-adapted muscle would react to chronical tetanic stimulation, in order to have an impression of the magnitude of change in energy supply which makes adaptation mandatory. Therefore we examined the tissue content of high-energy phosphates and related compounds, being sensitive markers of an imbalance in muscle energy conversion. This was done in the distal gracilis muscle prior to split sling graciloplasty and in the acute phase of split sling graciloplasty. To mimic the clinical situation tissue specimens were taken after challenging tissue energy metabolism by stimulation of the transposed muscle.

\section{Materials and methods}

\section{ANIMALS}

Six 12 weeks old male Dutch Landrace goats (19-22 kg) fasted for $24 \mathrm{hr}$ were anaesthetised with intravenous Nesdonal (Thiopental sodium) $(1.0 \mathrm{~g} / 70 \mathrm{~kg})$ and maintained with $\mathrm{N}_{2} \mathrm{O} / \mathrm{O}_{2}(2: 1)$ and Halothane $(0.8-1.5 \%)$ in the lithotomy position. Ringer's lactate solution was given intravenously at a rate of $3 \mathrm{ml} / \mathrm{kg}$.h as maintenance of fluid replacement; additional Ringer's solution was also given to replace estimated blood loss. During anaesthesia the animals had stable blood pressures, pulse rates and ventilation rates. Systemic blood pressure, ECG and ventilation rates and pressures were monitored continuously. After the experiment the goats were sacrificed. The study was approved by the Institutional Animal Care and Use Committee of the University of Maastricht, Maastricht, the Netherlands.

\section{OPERATION}

First, the bulbous urethra, which is situated very close to the gracilis muscles, is exposed and prepared for the graciloplasty. Second, the gracilis muscle is dissected. In 
three goats the right gracilis muscle was used for the bulbous split sling graciloplasty; in three other goats the left gracilis was used. Before the gracilis is dissected at the tendon the first biopsy is taken by cutting a piece of at least $8 \mathrm{~mm}^{3}$ in the distal part of the muscle approximately $9 \mathrm{~cm}$ from the origin. A tenotomy is performed at the end of the muscle leaving the muscle isolated on its major neurovascular pedicle, which enters the muscle on the inner anterior side. The gracilis muscle is split lengthwise keeping the neurovascular bundle intact. A proximal part of about $12 \mathrm{~cm}$ long and 4 $\mathrm{cm}$ width is used for the graciloplasty. The muscle strip is wrapped around the bulbous urethra starting ventrally. The distal part of the gracilis muscle is brought through the belly of the gracilis muscle. In this way the split sling graciloplasty is constructed. The tendon is fixed to the firm tissue next to the midline on the contralateral side. The wrap is performed in such a fashion that there is close contact between urethra and gracilis muscle. Then the gracilis muscle is stimulated with an amplitude of 2.0 volts, a frequency of $25 \mathrm{~Hz}$ and a pulse duration of $210 \mu \mathrm{s}$. In this way a tetanic contraction is evoked. A stimulation period of $5 \mathrm{~min}$ is performed. The second biopsy is taken $5 \mathrm{~min}$ after the stimulation is stopped. This biopsy is taken at the same distance from the origin but at least $3 \mathrm{~cm}$ from the former biopsy spot. The time interval between the two biopsies is approximately $90 \mathrm{~min}$.

\section{ANALYTICAL ASSAY OF HIGH-ENERGY PHOSPHATES AND RELATED COMPOUNDS} The biopsies of the gracilis muscle were immediately frozen in liquid nitrogen and stored at $-80^{\circ} \mathrm{C}$. Prior to biochemical analysis the specimen were freeze-dried overnight at $-30^{\circ} \mathrm{C}$. The dry weight of the tissue specimen ranged from 8.9 to $16.1 \mathrm{mg}$. After weighing, the dried material was extracted at $-15^{\circ} \mathrm{C}$ with a mixture of perchloric acid $(3.0 \mathrm{~mol} / \mathrm{l})$ and dithiothreitol $(5 \mathrm{mmol} / \mathrm{l})$. The extraction volume was adjusted to the $\mathrm{d}$ y weight of the tissue specimen, i.e., $25 \mathrm{micromol} / \mathrm{mg} \mathrm{dry}$ weight. After grinding of the tissue with a glass rod in the extraction fluid, the whole mixture was rapidly frozen in liquid nitrogen and thawed to a temperature of $4{ }^{\circ} \mathrm{C}$. After centrifugation at $4^{\circ} \mathrm{C}$ at $1200 \mathrm{xg}$ for $5 \mathrm{~min}$, an aliquot of the supernatant was removed and neutralised with $\mathrm{KHCO}_{3}$. The neutralised supernatant was stored at $-80^{\circ} \mathrm{C}$ until further analysis. 'The content of adenine and guanine nucleotides (ATP, ADP, AMP, GTP, GDP and GMP), hypoxanthine ( $\mathrm{Hx}$ ), xanthine $(\mathrm{X})$, NAD, inosine monophosphate (IMP), inosine (D) and adenosine (A) was measured with high performance liquid chromatography (HPLC) as previously described by Van der Vusse et al. ${ }^{2}$ Phosphocreatine (PC) and creatine (C) were measured fluorometrically. ${ }^{3}$

\section{STATISTICAL ANALYSIS}

Intra-individual differences were analysed statistically with Wilcoxon's matched-pairs signed rank test with two-tailed possibility. A P-value smaller than or equal to 0.05 was considered as significant. 


\section{Results}

The findings of the chemical analysis of the gracilis muscle content of high-energy phosphates and related compounds are summarised in table 1.

\section{Table 1}

Content and standard deviation (s.d) a/ creatine (C), phosphocreatine (PC), adenine rucleotide triphosphate (ATP), adenine nucleotide diphosphate (ADP) and adenine nucleotide monophosphate (AMP), total adenine nucleatide content (TAN), energy charge (EC), guanine nucleotide triphosphate (GTP), guanine nucleotide diphosphate (GDP), guanine nucleotide monophosphote (GMP), inosine monophosphate (LMP) bypoxarthine (HIX), NAD, inosine (D) and adenosine (A).

All concentrations are in micromol/ gram dry weight, except for $E C$ and $C / P C$ which both are unitless. Biopsy $x$ is taken after exposure of the muscle prior to dissection for split sling graciloplasty. Biopsy 2 is taken afier 5 min of electrical stimulation of the split shing graciloplasty followed by 5 min of recovery. The elapsed wime between biopsy 1 and biopsy 2 is approximately 90 min. Asterise refers to statistical significant difference $(p<=0.05 \%$

\begin{tabular}{lcccc} 
& $\begin{array}{c}\text { BIOPSY 1 } \\
\text { MEAN }\end{array}$ & SD & $\begin{array}{c}\text { BNOPSY 2 } \\
\text { MEAN }\end{array}$ & SD \\
\hline C & 63.0 & 9.8 & 67.8 & 21.8 \\
PC & 63.1 & 6.7 & 56.7 & 13.9 \\
C/PC & 1.00 & 0.09 & 1.30 & 0.51 \\
ATP & 22.0 & 2.4 & $18.4^{* *}$ & 2.8 \\
ADP & 3.32 & 0.39 & 3.44 & 0.64 \\
AMP & 0.10 & 0.05 & 0.12 & 0.06 \\
T'AN & 25.4 & 2.7 & $21.9 *$ & 3.3 \\
EC & 0.93 & 0.01 & $0.91 *$ & 0.01 \\
GTP & 0.77 & 0.10 & $0.62 *$ & 0.10 \\
GDP & 0.10 & 0.02 & 0.10 & 0.05 \\
IMP & 0.19 & 0.06 & $0.71 *$ & 0.30 \\
I & 0.20 & 0.11 & 0.95 & 0.60 \\
A & 0.07 & 0.07 & 0.17 & 0.09 \\
HX & 0.00 & 0.00 & 0.19 & 0.14 \\
NAD & 1.97 & 0.24 & 1.85 & 0.41 \\
\hline
\end{tabular}

The level of ATP showed a significant decline in the transposed gracilis muscle after 5 min of stimulation followed by 5 min of recovery (biopsy 2), as compared to the pregraciloplasty condition (biopsy 1). The content of this high-energy phosphate after graciloplasty and stimulation was found to be reduced by $16 \%$ as compared to control muscle tissue. ADP and AMP levels were found to be unaffected by the procedure. Due to the decline in tissue ATP level both total adenine nucleotide content (TAN) and energy charge (EC) were significantly decreased in the second biopsy. The 
percentual decline in the tissue level of GTP was similar to that of ATP. Gracilis muscle IMP levels were significantly increased after graciloplasty and subsequent stimulation of the transposed tissue. No significant alteration could be observed in the tissue level of the (oxy)purines adenosine (A), inosine (I) and hypoxanthine ( $\mathrm{Hx}$ ). $\mathrm{Xanthine}$ remained under the level of detection (data not shown). The tissue content of phosphocreatine (PC) and creatine (C) did not change after graciloplasty and subsequent stimulation and recovery. Tissue content of NAD was in the order of 1.9 $\mu \mathrm{mol} / \mathrm{g}$ dry weight of gracilis muscle tissue. The contents were found to be similar in biopsy 1 and 2, which provides strong evidence that the volume occupied by muscle cells is similar in both sets of biopsies.

\section{Discussion}

Dynamic graciloplasty, which implies that after graciloplasty the fatigable skeletal muscle is gradually transformed into a fatigue-resistant muscle, is currently applied in patients suffering from faecal or urinary incontinence. A potential complication of the dynamic urinary graciloplasty is ischemia-induced necrosis of the distal part of the gracilis muscle. Clinical data obtained in a feasibility study indicate that this occurred in two out of seven patients. ${ }^{4}$ In the latter study the gracilis was wrapped around the bladder neck and therefore had to pass the stiff urogenital diaphragm. Strangulation by this diaphragm might disturb proper blood perfusion of the transposed gracilis muscle. Suggestions have been made that the dynamic urinary graciloplasty can be improved by graciloplasty outside the pelvis e.g. around the bulbous urethra.

Compared to the conventional muscle wrap, the so called split sling graciloplasty procedure seems superior because contraction forces are transmitted more rectangular to the urethra. An animal experiment showed that split sling graciloplasty around the bulbous urethra generates high urethral pressures. ${ }^{5}$ In this case the distal gracilis was brought through the proximal belly of the gracilis muscle. This may lead to ischemia in the distal part because of vascular compression by the proximal muscle belly. Therefore the need for muscle adaptation induced by chronical stimulation as mentioned in the introduction is even more important.

Male goats were used to study the possible occurrence of acute ischemia in the transposed gracilis muscle. In these animals it is feasible to make a bulbous urethral split sling graciloplasty because of the favourable anatomical position and length of the gracilis muscle and the urethra. Early investigations demonstrated that dissection of the gracilis muscle alone while keeping the main neurovascular supply intact does not alter the energy profile of the muscle. ${ }^{6}$ This implies that if changes in the energy profile occur they will be caused by the stimulated split sling graciloplasty, i.e., when the 
blood supply is challenged by increased mechanical activity of the transposed muscle. Prolonged ischemia in a skeletal muscle causes depletion of high-energy phosphates ${ }^{7,8}$, whereas muscle contraction is assumed to further aggravate this process.

In the present experimental set-up, an interval of 90 minutes combined with $5 \mathrm{~min}$ period of muscle stimulation followed by $5 \mathrm{~min}$ recovery was chosen. In this time period the energy profile would show whether ischemia occurs or not in the transposed and stimulated gracilis muscle.

The major energy sources during maximal muscular activity of short duration are the hydrolysis of ATP to ADP, PC degradation to creatine and anaerobic glycolysis." Under normal conditions, PC and ATP are resynthetised through oxidative metabolism. ${ }^{10}$ If regeneration of ATP is hampered, such as accurs under ischemic conditions, AMP is degraded further into IMP. ${ }^{11}$ Thereafter degradation of IMP to (oxy)purines ( $\mathrm{Hx}$ and $\mathrm{X})$ will readily occur. In the present study the gracilis muscle content of high-energy phosphates, PC and ATP, and related compounds were measured in order to delineate a possible effect of DUG and subsequent stimulation on tissue energy conversion. As indicated above depression of the tissue content of high energy phosphates can be considered as a sign of impaired perfusion of the transposed muscle.

The results in the present study show that a significant decrease in the tissue content of ATP, TAN and GTP occurred after a stimulated split sling graciloplasty. There is no significant decrease in PC.

The explanation for the decrease of ATP, TAN and GTP is that the second biopsies were obtained after a tetanic contraction of the gracilis of $5 \mathrm{~min}$. A muscle mainly consisting of fast type II fibres like the gracilis depends on anaerobic oxidation with a short time duration of ATP depletion. ${ }^{12}$ Therefore muscle contraction leading to a temporary ATP decrease can not be avoided because ATP is the ultimate energy source for contraction. ${ }^{13}$ Under ischemic conditions ATP depletion occurs" under normal perfusion conditions the depletion of ATP and CP is restored after exercise. Our findings show that the decrease of ATP and also GTP was not restored in the recovery period of five min before the second biopsy is taken. It is likely that a PC decrease also occurred during stimulation. Welsh and Lindinger found that in an ischemic skeletal muscle, followed by 5 min reperfusion, PC increased more quickly than ATP after restoration of flow. ${ }^{14}$ Since the second specimens were taken 5 min after split sling graciloplasty stimulation it is therefore comprehensible that in our study the tissue PC was not significantly changed at the end of the experimental protocol. PC obviously recovers to nearly normal levels during the 5 min recovery period after stimulating indicating that normoxic conditions were present in the nonstimulated muscle. These considerations lead to the conclusion that only during the stimulation period energy production does not meet the energy requirements. 
The increased tissue levels of IMP (table 1) also indicate that the energy metabolism is disturbed in the stimulated, transposed gracilis muscle. This disturbance of energy? metabolism in stimulated muscles was also reported by others. ${ }^{15.16}$ Accumulation of IMP occurred during the stimulation period, as energy demand and the supply are most likely in balance in the unstimulated, resting muscle. As indicated above IMP is produced from AMP when tissue perfusion fails to provide sufficient amounts of molecular oxygen to regenerate ATP in aerobic energy converting process. The fact that the drop in tissue A'TP exceeds the amount of IMP, accumulated in the affected gracilis muscle, indicates that IMP is further degradated to (oxy) purines, such as inosine, hypoxanthine and xanthine. Interestingly, no accumulation of these degradation products in the gracilis muscle could be observed under the present conditions. This indicates that the degradation products, which can easily pass cellular membranes, are removed from the gracilis muscle by adequate venous outflow, most likely during the resting period when stimulation was terminated.

\section{Conclusion}

This study presents indications that a stimulated split sling graciloplasty in quadrupeds during the acute phase leads to an unbalance in energy production and consumption in the affected gracilis muscle. The content of creatine and phosphocreatine not being changed means that the arterial supply of oxygen and substrates most likely is adequate to fulfil tissue energy requirements after the stimulation is stopped. The content of inosine and (hypo)xanthine not being increased implies that the venous return of the muscle is adequate to remove waste products of adenosine nucleotide degradation. From an energy supply point of view however the split sling graciloplasty in the period directly after transposition can't cope with stimulation, because a significant decrease of ATP was observed. It may be expected that the stimulated split sling graciloplasty is balanced with respect to energy supply and demand. The main reasons for this assumption are that the arterial and venous conditions of the transposed graciloplasty are adequate and that finally energy metabolism of skeletal muscle adapts to chronical stimulation in such a fashion that energy metabolism is balanced.' 


\section{References}

1. Green HJ, Dusterhafi $S$, Dux $L$, Petre D Metabolite patterns related to exhaustion, recovery, and transformation of chronically stimulated rabbitt fast-twittch muscle Pflugers Arch 1992: 420;359-366.

2. Van der Wusse GI, Jarissen W, $A$, Coumans WA, Kuipers $\mathrm{H}$, Does RIM. ten Hoor $\mathrm{F}$

Effect of Training and 15, 25-, and $42-\mathrm{km}$ contests on the skeletal muscle content of adenine and guanine nucleotide, creatine phosphate, and glycogen

Int J Sponts Med 1989;10:146-152.

3. Vander Vusse GJ, Coumans WA, Van der Veen FH, Drake $A$, Flameng $W$, Suy $x^{2}$

ATP, creatine phosphate and glycogen content in human myocardial biopsies: markers for the efficacy of cardioprotection during aortacoronary bypass surgery J Vasc Surg $1984 ; 18: 127-134$.

4. Jariknegt RA, Heesakkers JPFA, Weil EHJ, Baten CGMI

Electrically stimulated gracilis sphincter (dynamic graciloplasty) for trentment of intrinsic sphincter deficiency: a pillot study on feasibility and side effects IU Urol 1995;154:1830-1833.

5. Heesakkers Jo Wen J, Geerides $\mathbb{B}$, Baeten $C_{\text {, }}$ fankneegt $\mathrm{k}$

Electrical stimulated graciloplasty in the male goat: an animal model for urethral pressure measurement

Neurourol Urodyn 1996;15:545-553.

6. Lindsay Th

The in vivo gracilis muscle model of skeletal muscle ischemia

Invest Surg 199:47:17-26.

7. Idstrom JP, Soussi B, Elander A, Bylund-Fellenius $A C$

Purine metabolism after in vivo ischemia and reperfusion in rat skeletal muscle Am J Physiol 1990;258:1668-1673.
8. Lindsay $T$, Liazw $S_{3}$ Romaschin $A D$, Walker $P$

The effect of ischemia/treperfusion on adenine nucleotide metabolism and xanthine oxidase production in skeletal muscle I Vasc Surg 1990;12:8-15.

9. Spriet LL

ATP utilization and provision in fast-twitch skeletal muscle during tetanic contractions Am J Physiol 1989; 257:595-605.

10. Newsholme EA, Leech AR

Biochemistry for the medical sciences Toronto 1983: Wiley

11. Hara N, Mineo I, Kono N, Yarnada $Y$, Kawachi $M$, Cacao $H$, Yamasaki $T$, Wang $Y$, Nakajima $\mathrm{H}$

Inosine and adenosine formation in ischenic and non-ischemic contracting muscle of rats: difference between fast and slow muscles Res Comm Chem Path Pharm 1988; 60:309-321.

12. Dudley GA, Terjung RL

Influence of aerobic metabolism on IMP accumulation in fast-twitch muscle Anu J Physiol 1985; 248:C37-C42.

13. Sinkeler SPT, Binkhorst RA, Joosten EMG, Wewers RA, Coerwinkel MM, Oei TL AMP deaminase deficiency: study of the human skeletal muscle purine metabolism during ischemic isometric exercise Clinical Science 1987,72:475-482.

14. Welsh $D G$, Lindinger $M$ Energy metabolism and adenine nucleotide degradation in twitch-stimulated rat hindlimb during ischemia-reperfusion Am J Physiol 1993;264:655-661.

15. Brooke MH, Chokski R, Kaiser KK Inosine monophosphate production is proportional to muscle force in vitro Neurology 1986;36:288-291. 
16. Heller SI, Choksi R, Brooke MH

IMP respons: an indicator of metabolic

stress in workthing muscle

Muscle Nerwe 1986;9:515-518. 


\section{Dynamic urinary graciloplasty in male goats: a study on histology and urethral pressures}

\section{Chapter 7}

This chapter was published as:

DYNAMIC URINARY GRACILOPLASTY IN MALE GOATS: A STUDY ON HISTOLOGY AND URETHRAL PRESSURES.

Heesakkers JPFA, Jianguo W, de Bruïne A, wan den Bogaard A, Janknegt RA.

Neurourology and Urodynamics 1997;16:117-123. 


\section{Introduction}

Chapter 5 revealed that it is feasible to perform urethral pressure measurement in the male goat, and that it is technically possible to perform dynamic urinary graciloplasty at the bulbous urethra. Compared to the bladder neck, the split sling graciloplasty (SSG) at the bulbous urethra generated higher pressures in this experiment. 'Therefore, if the dynamic urinary graciloplasty at the bulbous urethra would be feasible and successful during a chronical experiment, three goals would be achieved. The first goal would be that stricturing could be avoided, although this was observed by others. ${ }^{2}$ The second goal would be that higher urethral pressures could be achieved by using the split sling technique. The third goal to be obtained, would be a more viable dynamic bulbous urethral graciloplasty compared to the bladder neck graciloplasty. The expected superiority of the bulbous urethral graciloplasty is explained by the related topography of gracilis muscle and bulbous urethra. At this level the graciloplasty stays more or less in the same horizontal plane. This does not lead to kinking of the gracilis muscle, causing insufficient vascular supply, which could endanger graciloplasty survival. Therefore the next experiment to be performed, was a chronical study on dynamic urinary graciloplasty in male goats to see whether long-term patency would be feasible.

The main issue was to see whether stricturition would occur or not. If stricturing would occur, further exploration of bulbous urethral graciloplasty would have to be stopped. Therefore this study was done in a limited number of goats.

\section{Material and methods}

T"wo male adult Dutch Landrace goats of 40 and $59 \mathrm{~kg}$ respectively were castrated 2 weeks before the first operation. One injection of $30 \mathrm{mg}$ oestradiol benzoate (Intervet, Boxmeer, the Netherlands) was given for handling comfort. After fasting overnight for the first operation the goats were in lithotomy position and anaesthetised with thiopental sodium (Rhone Merieux. Lyon, France) $1,0 \mathrm{~g} / 70 \mathrm{~kg}$ and maintained with $\mathrm{N}_{2} \mathrm{O} / \mathrm{O}_{2}(2: 1)$ and halothane $(0.8-1.5 \%)$. A continuous drip with Ringer solution was given during surgery and $1 \mathrm{~g}$ ampicillin-Na i.v. was given as antimicrobial prophylaxis just before surgery. The perineum was dissected free and the penis and the bulbous urethra were exposed and dissected. The right gracilis muscle was detached at its insertion at the knee, and the entrance of the neurovascular pedicle at the origin was exposed. 'Two muscle electrodes SP 5528 (Medtronic, Kerkrade, the Netherlands) were inserted in the muscle with the cathode placed near the nerve entry zone and the anode $3 \mathrm{~cm}$ more distally. A SSG was performed around the dissected penis at the bulbous 
urethra. With this technique, the gracilis muscle passes the penis ventraily and comes back dorsally. The distal gracilis part is pulled through a slit which is made in muscle fibre direction in the proximal part of the muscle. Afterwards the tendon of the pulled through muscle part is sutured close to the midline with non-absorbable sutures. An incision was made in the lower abdomen and the bladder was opened. Retrograde urethral pressure profilometry (AMT, Sittard, the Netherlands) was performed with and without muscle stimulation at a puller speed of $1 \mathrm{~mm} / \mathrm{s}$. A cystostomy was made with a 16 french silicone catheter and fixed with a mersilene pursestring suture. The two electrodes were tunnelled subcutaneously to the abdomen and connected to an external programmable pulse stimulator (Itrel II ${ }^{\mathrm{TM}}$, Medtronic, the Netherlands). The pulse stimulator was sutured to the abdominal wall. The abdominal cavity was closed whereafter the skin was closed intracutaneously with vicryl.

Ten days after implantation a stimulation program was started, in order to transform the gracilis from a fatigable skeletal muscle into a non-fatigable sphincteric muscle. Intermittent stimulation was started with a dutycycle of 0.1 seconds "on" and 1.2 seconds "off". The burst frequency was $25 \mathrm{~Hz}$ and the voltage was adjusted to the level of perception of muscle contraction in the perineum. The duty cycle was increased every two weeks with an external programmer (Model 7432, Medtronic). After 8 weeks the duty cycle was $100 \%$ "on". During the stimulation phase temperature was recorded every day. Antibiotics were administered when the temperature was above $38.6^{\circ} \mathrm{C}$.

The second operation was performed after 8 weeks under the same conditions as the first operation. The abdominal cavity as well as the bladder were opened. Urethral pressure profilometry was performed with and without stimulation. Afterwards biopsy specimens were taken at the graciloplasty site and put in fixative. Biopsy specimens from the left gracilis muscle, which was not used for graciloplasty, were taken as control biopsies. Other biopsy specimens were taken at the bulbous urethra with the wrapped graciloplasty. Urethral biopsy specimens for control were taken. more distally to the graciloplasty site.

The biopsy specimens underwent routine haematoxylin-eosin staining for global assessment, which was done by an experienced pathologist. Sirius red staining was done to detect connective tissue. Monoclonal antibody $\mathbb{R}_{11} D_{10}$ (Centocor, Leiden, the Netherlands) staining was used for colouring type I muscle fibres. For calculating the percentage of type I fibres, in every biopsy specimens all type I and type II muscle fibres were calculated, ranging from 480 to 922 . The percentage of connective tissue and the maximum minor diameter of type I and type II fibres were determined by using the Quantimet $570 \mathrm{C}$ (Leica). For determination of the percentage of connective tissue in every biopsy 10 high power fields with muscle tissue were taken for analysis. 
The mean fibre diameter was calculated on a total number of diameters in every biopsy specimen, ranging from 64 to 113 for type I fibres and from 51 to 127 for type II fibres. After the experiment the goats were sacrificed.

The study was approved by the Institutional Animal Care and Use Committee of the University of Maastricht, Maastricht, the Netherlands.

\section{Results}

During the stimulation phase both goats suffered from fever with temperatures reaching $41^{\circ} \mathrm{C}$. This could only be controlled by a daily dose of enrofloxacin (Bayer, Mijdrecht, NL) $5 \mathrm{mg} / \mathrm{kg} \mathrm{i.m.} \mathrm{The} \mathrm{first} \mathrm{goat} \mathrm{weighing} 40 \mathrm{~kg}$ at the start of the experiment was emaciated at the end of the experiment and lost $11 \mathrm{~kg}$ in weight. The second goat lost $8 \mathrm{~kg}$. It appeared during the second operation that the reason for the temperature rise was a chronical infection around the pulse stimulator. Both goats had pus collections around the stimulator. The infected stimulators did not influence the stimulation protocol. The urethra was easily accessible and urethral pressure measurement could be performed without problems.

The haematoxylin-eosin staining revealed no increase in fibrotic tissue around the bulbous urethra and corpus spongiosum at the graciloplasty site. No stricturing could be observed. Compared to the urethral biopsy specimen, taken more distally no differences could be observed. The percentage of type I fibres in the control biopsy specimen was 24 and $34 \%$ in the two goats respectively. After the stimulation this increased to respectively 84 and $82 \%$. The mean type I fibre diameter was $48 \mu \mathrm{m}$ (sd 12) in the control biopsy specimen and $41 \mu \mathrm{m}$ (sd 10) in the stimulated gracilis in the first goat. In the second goat this was $43 \mu \mathrm{m}$ (sd 9) and $38 \mu \mathrm{m}$ (sd 12) respectively. The mean diameter of type II fibres was $36 \mu \mathrm{m}$ (sd 8 ) in the control biopsy of the first goat and $34 \mu \mathrm{m}$ (sd 7) in the graciloplasty. This was $42 \mu \mathrm{m}$ (sd 10) in the control biopsy specimen and $43 \mu \mathrm{m}$ (sd 12) in the graciloplasty biopsy specimen in the second goat. The amount of connective tissue increased from 8 to $16 \%$ in the first goat and from 7 to $16 \%$ in the second goat. The histological results are listed in table 1 . The maximal wrethral pressures recorded at the first operation was $113 \mathrm{~cm} \mathrm{H}_{2} \mathrm{O}$ without stimulation and $170 \mathrm{~cm} \mathrm{H}_{2} \mathrm{O}$ with stimulation in the first goat. The recorded pressures in the second goat were 108 and $273 \mathrm{~cm} \mathrm{H}_{2} \mathrm{O}$ without and with stimulation respectively. After the training period the pressure with and without stimulation was 45 and $65 \mathrm{~cm}$ $\mathrm{H}_{2} \mathrm{O}$ respectively for the first goat, and 125 and $170 \mathrm{~cm} \mathrm{H} \mathrm{H}_{2} \mathrm{O}$ for the second goat. These results are also listed in table 1 . 
Table 1

Histological features of dynamic graciloplasty with chronical stimalation compared to control biopy specimens withow chronical stimulation; the listed maxinal wrethral pressures (cm $H_{2}$ O) are tatken with and without stimulation and are recorded before and after training of the graciloplasty.

\begin{tabular}{|l|c|c|c|c|}
\hline & \multicolumn{2}{|c|}{ GOAT 1 } & \multicolumn{2}{c|}{ GOAT 2 } \\
\hline & $\begin{array}{c}\text { without } \\
\text { stimulation }\end{array}$ & $\begin{array}{c}\text { with } \\
\text { stimulation }\end{array}$ & $\begin{array}{c}\text { without } \\
\text { stimulation }\end{array}$ & $\begin{array}{c}\text { with } \\
\text { stimulation }\end{array}$ \\
\hline type I fibres (\%) & 24 & 84 & 34 & 82 \\
\hline $\begin{array}{l}\text { type I fibre diameter } \\
(\mu \mathrm{m})\end{array}$ & $48(\mathrm{sd} 12)$ & 41 (sd 10) & 43 (sd 10) & 38 (sd 12) \\
\hline $\begin{array}{l}\text { type II fibre diameter } \\
(\mu \mathrm{m})\end{array}$ & $36(\mathrm{sd} \mathrm{8)}$ & $34(\mathrm{sd} 7)$ & $42(\mathrm{sd} \mathrm{10)}$ & 43 (sd 13) \\
\hline $\begin{array}{l}\text { connective tissue (\%) } \\
\text { maximal urethral } \\
\text { pressures before training } \\
\left(\mathrm{cm} \mathrm{H}_{2} \mathrm{O}\right)\end{array}$ & 8 & 16 & 7 & 16 \\
\hline $\begin{array}{l}\text { maximal urethral } \\
\text { pressures after training } \\
\left(\mathrm{cm} \mathrm{H}_{2} \mathrm{O}\right)\end{array}$ & 45 & 65 & 170 & 273 \\
\hline
\end{tabular}

\section{Discussion}

Up till now the dynamic urinary graciloplasty was only performed around the bladder neck, because the higher urethral calibre at the bladder neck probably would increase the closing properties of the graciloplasty. The theoretical drawback of the location at the bladder neck is the necessity to pull the free end of the gracilis muscle into the pelvis. The muscle makes a U-turn at its origin and passes the stiff urogenital diaphragm. Afterwards it has to make a full circle around the bladder neck. A fibrotic gracilis muscle was found at the bladder neck in two patients who failed the procedure. The reason for this fibrosis so far has not been revealed, but three possibilities exist. The first reason is strangulation of the graciloplasty by the stiff urogenital diaphragm. During operation, an opening in the urogenital diaphragm is meticulously constructed, in order to ensure no kinking or strangulation. However, after operation movements of the patient may cause narrowing of the opening in the urogenital 
diaphragm which can cause strangulation and finally fibrosis. This issue can be compared to the construction of the SSG as described by Rosen et al. ${ }^{3}$ In this muscle wap the distal part of the muscle is pulled through a longitudinal hole in the proximal part after being wrapped around a tubular structure (e.g. urethra). If continuous muscle stimulation takes place, the pulled through muscle part may be strangled by the proximal part, leading to ischemic fibrosis in the distal part. In a chronical rabbit model we compared the conventional muscle wrap with the SSG, in order to study the effects on muscle histology. ${ }^{4}$ Differences could neither be observed in fibrotic tissue, nor in global muscle change, nor in the type I/type II muscle fibre ratio nor in the muscle fibre diameter. The muscle histology in the pulled-through part changed as much as in other parts of the muscle.

A second reason could be that vascularisation is jeopardised by the complex bladder neck graciloplasty pathway. Especially the U-turn in the groin combined with the fullcircle muscle wrap could challenge vascularisation in the distal part of the graciloplasty. So far no data on this issue have been obtained.

The third explanation is the inability of the transposed skeletal muscle to adapt to continuous stimulation because of insufficient energy supply. If the transposed muscle is unable to receive enough energy for muscle contraction or to remove the waste products, ischemic fibrosis may occur. In an acute goat model we investigated the change in high-energy nucleotides during five minutes of fused muscle contraction followed by five minutes of relaxation. ${ }^{5}$ The outcome was that a disbalance in energy equilibrium occurs during continuous stimulation, that can partly be restored during relaxation. This was however an acute experiment in a non-trained muscle. "The capability of the muscle to adapt to continuous stimulation by long-term muscle training, was not taken into account in that study.

Whatever the cause of graciloplasty fibrosis around the bladder neck, a dynamic urinary graciloplasty outside the pelvis definitely has advantages: the graciloplasty configuration is less troublesome because the wrap stays in the same horizontal plane; the operation is less invasive because there is no abdominal access, and the urogenital diaphragm has not to be passed. One of the reasons we did not perform a dynamic urinary graciloplasty around the bulbous urethra so far is that others reported stricturing of the bulbous urethra, probably due to urethral ischemia. ${ }^{6}$ In our experiment no stricturing could be observed in both animals. The reasons for this observed difference remain speculative. Probably the technique of wrapping is different. If the gracilis is wrapped too tight, ischemia occurs no matter what the graciloplasty location is.

The results of muscle histology show that muscle training induces a remarkable increase in type I fibres, from approximately 30 to $80 \%$. Others reported comparable percentages of type I fibres of 20 to $30 \%$ of the goat latissimus dorsi muscles ${ }^{7}$ and the abdominal wall muscles in the native situation. ${ }^{8}$ Since these muscle have a comparable 
function as the gracilis muscle, the observed percentages seem representative. However, with stimulation percentages of $98 \%$ and $99 \%$ type I fibres for the latissimus dorsi have been reported. ${ }^{6,8}$ Glatz found that the enzymatic activity of lactate dehydrogenase and fructose-6-phosphate kinase, being indicators of anaerobic-glycolytic capacity, decreased only to $25 \% .^{6}$ This implies that type I fibres can possess some anaerobic capacity and don't have to function exclusively on aerobic metabolism. This also might imply that a minimal percentage of anaerobic capacity has to exist, expressed by either the percentage type II fibres or the enzymatic activity. Therefore it seems reasonable not to find the maximum of type I fibres after stimulation in another muscle. The stimulation protocol and the use of the stimulated muscle might also influence the percentage of type I fibres.

The type I fibre diameter without stimulation was slightly smaller than the reported diameters of the abdominal wall diameters.? The type I fibre diameter decreased in the two goats, whereas the type II fibres had the same diameter. The reason for this decrease is that the diffusion of oxygen is facilitated and therefore this can be regarded as a part of the adaptive process. ${ }^{9: 10,11}$

The amount of connective tissue doubled from 8 to $16 \%$ in both goats and is comparable to the percentages endomysial connective tissue mentioned by Lucas et al. ${ }^{8}$ In this study of the stimulated latissimus dorsi, the percentages ranged from 12.8 to $17.5 \%$. In the native gracilis muscle of the goat however the percentages are higher than in the goat latissimus dorsi. No reason for this difference can be mentioned at this moment. Because the percentage of connective tissue is only $16 \%$ and no totally fibrosed graciloplasty was found, as was the case in humans around the bladder neck, from a vascularisation point of view the bulbous dynamic urinary graciloplasty probably is superior to the bladder neck dynamic urinary graciloplasty. The pressure measurements showed remarkable results. The highest measured urethral pressures without stimulation were comparable and also in accordance with earlier reported urethral pressures in goats. ${ }^{1}$ The stimulated graciloplasties generated a bulbous urethral pressure of $170 \mathrm{~cm} \mathrm{H}_{2} \mathrm{O}$ and $273 \mathrm{~cm} \mathrm{H} \mathrm{H}_{2} \mathrm{O}$ respectively. This disparity in pressures is consistent with pressures found in a acute study of ten goats, where the mean bulbous urethral pressure with stimulation was $294 \mathrm{~cm} \mathrm{H} \mathrm{O}_{2}$, ranging from 170 $\mathrm{cm} \mathrm{H}_{2} \mathrm{O}$ to $400 \mathrm{~cm} \mathrm{H}_{2} \mathrm{O}$. After training the maximal urethral pressure with and without stimulation in the first goat dropped dramatically, whereas the maximal urethral pressure in the second was comparable to without stimulation and was lower than with stimulation. 'This was also noted by Konsten who mentioned that he had to increase the stimulation voltage during training to have the same effect. ${ }^{12} T$ wo reasons for the decrease in obtained maximal urethral pressures with training of the muscle have to be mentioned. One is that the volume of the muscle and therefore the cross sectional muscle area, responsible for muscle strength, decreases. ${ }^{13}$ Another is that during training the amount of fatigable, fast-twitch and strong type Il fibres decreases 
and the percentage slow-twitch, weaker type I fibres increases. The intended effect is that the stimulated muscle is capable of sustaining prolonged contraction, and therefore is able to provide all day continence. The drawback can be that the weaker muscle is not capable to close the urethra and is unable to hamper the loss of urine. With the remaining urethral pressures in this study, the first goat would probably not be able to close the urethra, necessary for maintaining continence, whereas the second probably would. Since it was not possible to perform leak point pressure measurements in this study, this has to be confirmed by other experiments.

\section{Conclusion}

This study with a chronically stimulated graciloplasty around the bulbous urethra in male goats proves that it is feasible to perform a dynamic urinary graciloplasty without causing stricturing of the bulbous urethra. Since muscle fibre transformation could be achieved, prolonged graciloplasty contraction is possible. The final generated urethral pressures after training most be capable to stop urine loss. With regard to the amount of fibrosis, the bulbous dynamic urinary graciloplasty is a good alternative for the bladder neck dynamic urinary graciloplasty. 


\section{References}

1. Heesakkers JPFA, Jianguo $\mathrm{W}$, Geerdes $\mathrm{BI}$, Baeten CGMI, Janknegt RA

Electrical stimulated graciloplasty in the male goat; an animal model for urethral pressure measurement

Neurourol Urodyn 1996;15:545-553.

2. Williams NS, Fowler CG, George BD,

Blandy JP, Badenoch DF, Patel J

Electrically stimulated gracilis sphincter for

bladder incontinence

Lancet 1993;341:115-116.

3. Rosen HR, Feil W, Novi $G$, Zuch $G$,

Duhlberg S, Schiessel $\mathbb{R}$

The electrically stimulated (dynamic)

graciloplasty for faecal incontinence with a modified muscle sling

Int J Colorect Dis 1994:9:184-186.

4. Heesakkers J, Geerdes B, Freling G, Janknegt $R$ Histological comparison of two types of dynamic graciloplasties in rabbits European Urology, in press

5. Heesakkers J, Wen J, Van der Vusse $G$, Janknegt $R$

Acute effect of the electrically stimulated urinary graciloplasty on energy metabolism of the gracilis muscle in male goats

submitted for publication

6. Glatz JFC, De Jong YF, Coumans WA, Lucas CM, Van Der Veen FH,

Van Der Vusse G]

Differences in metabolic response of dog and goat latissimus dorsi muscle to chronic stimulation

J Appl Physiol 1992;73:806-811

7. Tbebunjo $\mathrm{C}$

Type, diameter and distribution of fibres in some respiratory and abdominal muscles of the goat

Ver Res Comm 1993;17:171-182.
8. Lucas MHB, Van der Veen FH, Cheriex EC, Lorusso R, Havenith M, Penn OCKM, Wellens HIJ Long-term follow-up (12 to 35 weelks) after dynamic cardiomyoplasty IACC 1993;22:758-767.

9. Salmons S, Hendriksson J The adaptive response of skeletal muscle to increased use Muscle and Nerve 1981:4:94-105.

10. Hudlicka $O$, Hoppeler $\mathrm{H}$, Uhlmann $\mathrm{E}$ Relationship between size of the capillary bed and oxidative capacity in various skeletal muscles

Pflugers Arch 1987;410:369

11. George BD, Williams NS, Patel J, Swash M, Watkins ES

Physiological and histochemical adaptation of the electrically stimulated gracilis muscle to neoanal sphincter function Br J Surg 1993;80:1342-1346.

12. Konsten J, Baten $C G_{x}$ Spaans $\mathbb{F}$, Haventh $M G$, Soeters PB

Follow-up of anal dynamic graciloplasty for fecal incontinence World J Surg 1993;17:404×408.

13. Konsten J, Baten CG, Mavenith MG, Oei TK Evaluation of gracilis muscle transposition for fecal incontinence with magnetic resonance imaging Eur J Rad 1993;16:190-194. 
General discussion and scope of dynamic urinary graciloplasty

Chapter 8 
The issue expert urologists world wide have to deal with in the near future is whether there is a place for dynamic urinary graciloplasty in the treatment of incontinence or not. Therefore it is of paramount importance to optimise the operation technique. Afterwards dynamic urinary graciloplasty has to be positioned within the range of treatment options for urinary incontinence based on bladder outlet dysfunction. In order to have an indication of the magnitude of the problem of urinary incontinence it is important to know by approximation the prevalence of incontinence. As has been mentioned before, a wide disparity exists in the determination of the prevalence of urinary incontinence. The variation of the reported percentages largely depends on the used definitions and the examined population. ${ }^{1}$ Afterwards knowing the prevalence of incontinence, the type of incontinence and the severity of urine loss have to be determined. Then the best choice of therapy can be made, probably including graciloplasty.

Since dynamic urinary graciloplasty is a laborious and expensive procedure, its place in the range of treatment options most likely will be at the end of the line. Technology assessment or quality of life analysis could be one of the tools to determine the success of dynamic urinary graciloplasty as has been done already in dynamic anal graciloplasty., ${ }^{2,3}$ Sling procedures and the artificial urinary sphincter are nowadays regarded as the state of the art treatment for severe urinary incontinence caused by intrinsic sphincter deficiency. Since the artificial urinary sphincter still has $13 \%$ mechanical failures ${ }^{4}$ despite changes of the cuff design, some prefer sling procedures for treating intrinsic sphincter deficiency because of the good long term results. ${ }^{5,6}$ Dynamic urinary graciloplasty, if proven successful, most likely has to be positioned in the area of the above mentioned treatment modalities. Compared to the artificial urinary sphincter the principal advantage is the use of autologous material. The muscle electrodes and pacemaker, although they are foreign bodies, are not in the urethral area. Therefore the gracilis neosphincter will not be put at risk by low grade or high grade inlections. If the stimulator induces infection, it can be replaced without dismantling the graciloplasty. Another advantage of the use of living muscle tissue in the urethral area is that it can be used to treat fistulas or other urethral defects at the same time. The treatment of urethral fistulas with gracilis muscle tissue has been done for years." The third advantage of the use of gracilis tissue is that it does not hamper other treatments when graciloplasty fails. The use of autologous material is also advantageous in cases where foreign material is prone to cause problems, e.g. in areas with abundant scar tissue because of radiotherapy. These are situations where artificial sphincters are more likely to cause urethral erosions or infections because of the poor quality of the environmental tissue. ${ }^{3}$ Since the above mentioned advantages deal with the used material, foreign body versus autologous muscle, positioning of dynamic urinary graciloplasty at least should be done in those cases where the artificial urinary sphincter failed or is likely to fail. The main group of patients are those with urethral 
or perineal fistulas or patients who underwent radiotherapy.

However, the issue remains and has to be solved in the future whether these groups of patients are the ideal group for dynamic urinary graciloplasty. In patients with fistulas who need a solid coverage with vital sound muscle tissue graciloplasty will suit fine. In contrast, our experience in the group of patients who underwent radiotherapy is not good.

Based on the feasibility study we concluded that it is feasible to perform dymamic urinary graciloplasty in humans but that the technigue had to be improved. The rabbit studies show that it is possible to perform a split sling graciloplasty with the same histological changes and the tendency to have better urethral pressures. The goat studies revealed that dynamic bulbous graciloplasty is superior to dynamic bladderneck graciloplasty. If this is also true for human beings a better option for dynamic graciloplasty would be a split sling graciloplasty around the bulbous urethra. This is at least feasible in males. In the ongoing multicentered international study (see furcher) the split sling bulbous urethral graciloplasty is one of the treatment groups. It is: probably also possible in females by a transwaginal approach, an option which needs to be explored.

\section{New applications}

\section{INTERNATIONAL MULTICENTERED STUDY}

The direct result of the experiments described above is an international multicentered study. In this prospective study three groups of 20 patients will be enrolled who are treated with dynamic urinary graciloplasty. Comparisons are made between bladder neck graciloplasty and bulbous urethral graciloplasty. In a group of 20 female patients a dymamic urinary graciloplasty around the bladder neck will be performed, since a bulbous urethra is not available. The study also comprises two groups of male patients. In the first group dynamic urinary graciloplasty around the bulbous urethra will be performed. In the second the graciloplasty will be wrapped around the bladder neck. Comparisons will be made between these two groups. After hall a year the pulse stimulator will be switched off for one week to see whether symptoms reoccur. The final analysis will be made after one year. From this study data will be extracted on efficacy and safety of dynamic urinary graciloplasty. Moreover we hope to define the ideal patient population which suits dynamic urinary graciloplasty best. If this study turns out to be successful, a prospective randomised trial, comparing dynamic urinary graciloplasty with conventional treatments might be considered. 


\section{DOUBLE DYNAMIC GRACILOPLASTY}

Recently the first results were published on double dynamic graciloplasty for children with an impaired control ower anorectal and bladder function because of spina bifida." The publication is about two boys with partial spina bifida who suffered from urinary and faecal incontinence. The first boy was 17 years old and had an unstable bladder with a capacity of $254 \mathrm{ml}$. Urethral pressures could not be measured. Cystoscopy showed an open bladderneck. The anal rest and squeeze pressures were $83 \mathrm{~mm} \mathrm{Hg}$. The anorectal angle was blunted. No electric anal sphincter activiry could be detected during clinical neurophysiological examination. The second boy of 13 years also had an unstable bladder and motor urge, with a bladder capacity of $250 \mathrm{ml}$. Maximal urethral closing pressure was $29 \mathrm{~cm} \mathrm{H}_{2} \mathrm{O}$. The anal rest- and squeeze pressures were 59 and 69 $\mathrm{mm} \mathrm{Hg}$ respectively. There was incomplete rectal emptying. The anal sphincter was electrically inactive.

The two boys underwent urinary as well as anal graciloplasty. The urinary graciloplasty was a conventional graciloplasty located around the bladder neck. At the same time a CLAM-ileocystoplasty was performed to improve bladder compliance and capacity. During the second stage after 6 weeks two electrodes (model 4300, Medtronic, Kerkrade, the Netherlands) and one pulse stimulator (ltrel II ${ }^{\mathrm{TM}}$, model 7424, Medtronic, Kerkrade, the Netherlands) were implanted. The electrodes were both programmed as cathodes whereas the pulse stimulator was programmed as an anode. This created two electrical circuits from the pulse stimulator to both transposed gracilis muscles. Muscle fibre transformation was achieved by an 8 week training protocol. After two years patient 1 is dry. However he has to perform clean intermittent catheterisation. He is continent for stool but has to apply enemas because of faecal impaction. Maximal urethral closing pressure was 40 and $50 \mathrm{~cm} \mathrm{H}_{2} \mathrm{O}$ with and without gracilis muscle stimulation respectively. Anal rest and squeeze pressure were 66 and 159 $\mathrm{mm} \mathrm{Hg}$ respectively. The second patient is wet twice a week after 2 years. He is continent for stool. Maximal urethral closing pressure was 30 and $52 \mathrm{~cm} \mathrm{H}_{2} \mathrm{O}$ with and without stimulation respectively. Anal rest and squeeze pressure were $58 \mathrm{~mm} \mathrm{Hg}$ and $193 \mathrm{~mm} \mathrm{Hg}$ respectively. He has learned how to perform clean intermittent catheterisation in cases of urinary retention, which occurred once up till now. From the experiences with these boys we concluded that it is feasible to perform a double guaciloplasty. Patients with spina bifida seem an ideal group for dynamic graciloplasty because the operation area most of the time is blank and has not been influenced for instance by radiotherapy.

Overall success rates for the artificial sphincter, implanted in children with a neurogenic bladder of whom $86 \%$ had spina bifida, is reported to be $77 \% .{ }^{10}$ Although the success rate is good, revision however was necessary in $59 \%$ of patients. In addition if patients also suffer from faecal incontinence, no real solutions exist nowadays. One 
treatment is the Mitrofanoff procedure with bladderaugmentation for urinary incontinence combined with the applications via a colostony of antegrade continence enemas. ${ }^{11}$ Apart from the modest success rates it can be questioned whether a urinaty and a colostomy are ideal solutions for children with both faecal and urinary incontinence. Studies with artificial sphincters for faecal incontinence are currently also conducted. So far two artificial sphincters to treat urinary incontinence and faecal incontinence have not been applied. Therefore double dynamic graciloplasty in patients with urinary and faecal incontinence definitely is an option.

\section{New and future developments}

From the point of operation technique and variations the use of other muscles than the gracilis muscle can be explored. One can think of other muscles of the leg like the sartorius muscle which has been used in dogs ${ }^{12}$ or the stimulated gluteus muscle in humans. ${ }^{13}$ The use of the gracilis muscle as a free flap, leaving the innervating nerve intact, has already been mentioned above. ${ }^{14}$ Based on the results of the free flap gracilis muscle in a canine model a study in human beings will start shortly.

New developments of the pulse stimulator were released since our feasibility study occurred. "The latest pulse stimulator, the Itrel 3 with extra features has been designed and is implemented nowadays. For switching the Itrel I and Itrel II "on" or "off" patients have to use a magnet. A drawback of the magnet is that it can cause practical problems, like activating alarm systems, or altering and even wiping out information on credit cards. The Itrel 3 is operated with a remote control system which switches the magnet "on" or "off". Other possibilities are the programming of an upper limit and a lower limit for pulse frequency, pulse duration and pulse amplitude. Patients can alter some stimulation characteristics to their needs within programmed limits. Putting the pulse amplitude higher with a firmer muscle contraction e.g during sports now is an option.

Future developments are the use of a pulse stimulator with separate programming of pulse amplitude of the connected electrodes. In the two boys with the double graciloplasty it is not possible to have the urinary gracilis operated on another amplitude than the anal graciloplasty. Therefore one of the two, most of the time the anal gracilis, is programmed on a high amplitude which would not be necessary. If separated amplitude could be programmed the duration of the battery of the pulse stimulator would be longer, which saves costs. In a third female patient suffering from faecal and urinary incontinence due to spina bifida, two Itrel 3 pulse stimulators and four electrodes were implanted in order to have separate programming of the gracilis muscles. If the same result could be obtained. with one pulse stimulator and two 
electrodes this obviously would be a more ideal situation.

Development of dynamic urinary graciloplasty has started recently and it is likely that this will continue in the future. If this thesis contributes in understanding dynamic urinary graciloplasty, its potential and its limitations then its mission is completed. 


\section{References}

1. Diokno $\mathrm{AC}$

Epidemiology and psychosocial aspects of incontinence

Urol Clin N Am 1995;22:481-485.

2. Adang EMM, Engel GL, Konsten 】, Baeten CGMI

Quality of life after dynamic graciloplasty,

first results

Theor Surg 1993:8:122-124.

3. Baeten CGMI, Geerdes BP, Adang EMM,

Heineman E, Konsten J, Engel GL,

Kester ADM, Spaans F, Soeters. PB

Anal dynamic graciloplasty in the treatment

of intractable fecal incontinence

New Eng J Med 1995;332:1600-1605.

4. Mark SD, Webster $G$

Stress urinary incontinence due primarily to

intrinsic sphincter deficiency: experience with

artificial urinary sphincter and sling

urethropexy

J Urol 1994:151:420A.

5. Stephenson TP

Stress incontinence

Curr Opin Urol 1995;:184-186.

6. Swierzewski Si, Castilla JA, Faerber G,

McGuire E]

The pubovaginal sling for tertiary type-III

stress urinary incontinence. Long-term results

and outcomes

J Urol 1994;151:419A.

7. Ingelman-Sundberg $A$

Surgical treatment of urinary fistulae

Zentralbl Gyneakol 1978;100:1281.

8. Martins FE, Boyd SD

Post-operatiwe risk factors associated with artificial urinary sphincter infection-erosion Br J Uroll 1995;75:354.358.
9. Geerdes BP, Heesakkers JPFA, Heineman E, Spaans F, Janknegt RA, Baeten CGMI Simultaneous treatment of fecal and urinary incontinence in children with spina bifida using a double dynamic graciloplasty In: Geerdes BP: Dy namic graciloplasty; (patho) physiology of failure and success. Universitaire Pers Makastricht 1997;139-146.

10. Simeoni J, Guys JM, Mollard P, Buzelin JM, Moscovici J, Bondonny JM, Mel Y,

Lortat-Jacob $S$, Aubert D, Costa F, Galifer $\mathbb{B}_{\text {, }}$ Debeugny $P$

Artificial sphincter implantation for neurogenic bladder: a multi-institutional study in 107 children

BrJ Urol 1996;78:287-293.

11. Roberts JP, Moon S, Mallone PS

Treatment of neuropathic urinary and faecal incontinence with synchronous bladder reconstruction and the antegrade continence enema procedure

Br J Urol 1995; $75: 386-389$.

12. Bladou $F$, Houvenaeghel $G$, Delpero JR, Monges $G$, Serment $G$, Guerinel $G$

Construction of a urinary sphincter by means of electrically stimulated striated muscle: experimental procedure and urodynamic results on canine model

Int Surg 1996;81:94-98.

13. Guelinckx PI, Sinsel NK, Gruwez: IA, Habets F, Dom R

Gluteus muscle transposition for anal sphincter repair: the first ellectrically paced gluteoplasty

In: procedings of the 4 th international muscle symposium, Zurich 1995:226:229.

14. van Aalst VG, Werker PMN, Stremel RW, Petty G, Heilman SJ, Kon M, "Jobin GR, Barker JH Urinary incontinence improved outflow resistance by modified dynamic gracilloplasty Surgical Forum 1996:47:804-806. 
Summary and conclusions

Chapter 9 
In this thesis the feasibility and some modifications of the dynamic urinary graciloplasty as a treatment of intrinsic urethral sphincter deficiency are explored. Especially the combination of graciloplasty with the possibility of muscle fibre conversion using certain ways of electrical stimulation makes it possible to explore the possibility of optimising dynamic urinary graciloplasty.

Graciloplasty as a treatment of incontinence originates decades ago. The gracilis muscle, one of the adductors of the upper leg, has a favourable neurovascular entry near the origin of the muscle. Therefore the distal part can be dissected without the risk of innervation disturbances or the occurrence of muscle ischemia. Since the origin of the gracilis muscle is located close to the perineal part of the bladder outlet, it is technically possible to wrap the distal part around the urethra and even around the bladder neck.

In older days the drawback of the procedure was that the gracilis muscle, being a skeletal muscle, is fast and strong but also fast fatiguing. Therefore it can not sustain long-lasting contractions and patients can only keep up their continent state for a short period of time.

It has been known for about twenty years that tissue properties and especially the characteristics of muscles may change by chronic electrical stimulation. This means that skeletal muscles, whose function originally depends on anaerobic metabolism and a limited, fast depleting glycogen pool, can be changed into a muscle whose energy supply is based on aerobic metabolism. Consequently the changed muscle is able to continue its contraction for a long period nearly without fatigue. This process is reversible and tells us that a skeletal muscle is not static unchangeable tissue, but muscle tissue in a dynamic state.

The development of sophisticated pulse stimulators, containing electronic parameters which can be changed telemetrically, made it possible to change muscle characteristics after transposition of the muscle and after implantation of muscle electrodes and such a pulse stimulator. After reprogramming the pulse stimulator step by step, the muscle can be shaped phenotypically and genotypically into a muscle with sphincteric properties.

When the gracilis muscle is used in the treatment of urinary incontinence, the expression dynamic urinary graciloplasty stands for the procedure of muscle transposition, implantation of muscle electrodes and a pulse stimulator combined with the step by step change of the muscle characteristics.

The first chapter deals with epidemiology and current treatments of incontinence due to insufficient urinary sphincter closure. First some remarks are made on the terminology used today and the difficulties in interpreting data on prevalence of 
urinary incontinence. The mentioned treatments are listed in increasing levels of invasiveness. This starts with drug treatment for incontinence, followed by various forms of physical therapy. Finally the main surgical options are described, like bladder neck suspension techniques, slings, injectables and artificial urinary sphincters.

Chapter two reviews muscle plasticity and especially the dynamic features of muscles with respect to adaptation to different activity patterns. The chapter describes the way in which muscles are able to adapt to changes like increasing stimulation by electrical stimulation.

Chapter three describes the operation technique of dynamic urinary graciloplasty used in the first feasibility study. The chapter describes gracilis muscle anatomy, innervation, blood supply and function. In the feasibility study the bladder neck was chosen as the location for the gracilis muscle transposition. The study is presented in seven patients as well as the results and an analysis of the failed patients. One of the striking facts is the disparity in patient characteristics. The advantage of this variety is that this kind of study shows whether dynamic urinary graciloplasty is feasible or not. The drawback however is that it is not possible to identify the ideal patient for dynamic urinary graciloplasty.

Based on the analysis of failures in patients 3,5 and 7 it can be concluded that the operation technique failed in patient 3 and that the distal part of the gracilis muscle; the wrap around the bladder neck, caused the failures in parients 5 and 7 . Another conclusion is that the electronic devices are functioning without failing. Technically it was difficult to develop the gracilis muscle in such a way that a $100 \%$ muscle wrap could be made around the bladder neck. Other issues were the gracilis muscle passing the urogenital diaphragm and the resulting oblique configuration of the distal gracilis part around the bladder, because it has to be pulled up high in the pelvis. It is concluded from these data that for improvement of the results of dynamic urinary graciloplasty, priority number one is to put efforts in changing construction and location of the dynamic urinary graciloplasty.

Chapter four describes a chronic rabbit experiment. Here a new construction of the neosphincter was tested. In order to have a more right angled configuration of the muscle wrap in relation to the urethra, a split sling graciloplasty construction was performed. The split sling neosphincter construction was compared with the conventional gracilis muscle wrap. Muscle fibre transformation was analysed histologically for both types of graciloplasty. A comparison was made for the two types of graciloplasty with respect to muscle histology and pressures generated by the two graciloplasty techniques in order to have data on the possible improvement of the sphincter construction. 
Although no statistical significance was obtained, the generated pressures were comparable to the conventional split sling and a trend could be observed to higher pressures. The changes in graciloplasty histology were observed for two reasons. The first was to see whether good muscle fibre conversion was achieved in order to have fatigue-resistant muscle tissue. The second was to see the histology changes in the pulled through part of the split sling graciloplasty. Especially the percentage of connective tissue was looked at, in order to have an impression of the contracting potential of the distal part and the risk of occurrence of necrosis. The histological deterioration in the split sling graciloplasty was the same as in the conventional graciloplasty. Especially the distal part of the split sling graciloplasty did not change in a more severe way. From this study we concluded that the split sling graciloplasty had at least the same performance as the conventional graciloplasty.

Chapter five is about the accessibility of the male goat urethra for urethral pressure measurement, and the comparison of acute graciloplasty around the bladder neck and the bulbous urethra. The comparisons are made with and without direct muscle stimulation. From this study can be concluded that the male goat is a suitable animal model for urethral pressure measurement. This implied that we could continue with a chronic animal experiment. Another conclusion was that the non-stimulated bladder neck graciloplasty as well as the bulbous urethra graciloplasty increased the urethral pressures at their location. The generated pressures were comparable to the highest native urethral pressure at the pelvic outrance. However with stimulation the bulbous urethral pressures exceeded significantly the bladder neck graciloplasty pressure as well as the pressure at the pelvic outrance. Therefore the stimulated graciloplasty has sphincteric properties: by active stimulation the pressure can be increased significantly compared to the resting state of the graciloplasty. The latter has the function of a sling operation: urethral resistance is increased by tightening of the urethra, whereas closure and total desobstruction on demand would be an ideal neosphincter.

An extension of the experiment was done in the same animals to see how energy supply would change by muscle stimulation of graciloplasty in non-adapted muscles. This experiment is described in chapter six. Muscle biopsies were taken before graciloplasty and after the combined session of graciloplasty, muscle stimulation during several minutes and a relaxation period. It turned out that a partial recovery in the unbalanced muscle takes place since energy supply is restored during the recovery period. Venous outflow of the muscle is also adequate since metabolites which are indicative for a severe lack of oxygen were washed away during the recovery period. The drop in adenosine triphosphate however showed that an unbalance in non-adapted muscles occurs. This observation stresses the need for training of a muscle used for chronic stimulation. Not only the conversion from fast-twitch fatigable muscle fibres 
to slow-twitch fatigue-resistant muscle fibres has to be achieved but also an adaptation in energy supply as opposed to demand in order to guarantee the delivery of adequate amounts of energy for continuous muscle contraction.

Since urethral pressure measurements were possible in the male goat and since the directly stimulated bulbous graciloplasty proved to be superior compared to the bladder neck graciloplasty, a chronic experiment with the split sling bulbous urethral graciloplasty performed in male goats was started next. The principal question was whether urethral stricturing would not occur, because this would imply that an extrapelvine bulbous urethral graciloplasty would be feasible. Another question was whether and to what extent the urethral pressure would change during muscle conversion as compared to the acute situation. The experimental design and the results are described in chapter seven. No stricturing was observed and the urethra was easily accessible for urethral pressure measurement after stimulation. In the trained gracilis muscle the urethral pressures increased with stimulation as compared to the nonstimulated trained graciloplasty. The generated pressures with muscle stimulation were however lower after training than the pressures of the stimulated graciloplasty in the untrained transposed gracilis muscle. From this chronic experiment was concluded that bulbous urethra was a better suited location for the dynamic urinary graciloplasty in male goats and that the stricturing as described by others did not occur.

To summarise, dynamic urinary graciloplasty is feasible and split sling graciloplasty around the bulbous urethra has advantages over the conventional graciloplasty around the bladder neck. Therefore a multicentered international study with incorporation of these innovations is performed as the next step of the exploration of the dynamic urinary graciloplasty for urinary incontinence. 


\section{Samenvatting}

In dit proefschrift is de haalbaarheid van de dynamische urinaire gracilisplastiek als behandeling van intrinsieke sluitspier zwakte van de blaas onderzocht. Tevens zijn enkele aanpassingen in diermodellen getest met als doel om een beter functionerende dynamische urinaire gracilisplastiek te ontwikkelen. De laatste jaren is de mogelijkheid ontstaan om met elektrische stimulatie de fysiologische karakteristieken van spierweefsel te veranderen. Die elektrische stimulatie wordt verzorgd door een geïmplanteerde elektronische puls stimulator. De combinatie van gracilisplastiek en het kunnen veranderen van spierkarakteristieken maken het mogelijk om de optimalisatie van de dynamische urinaire gracilisplastiek te onderzoeken.

De gracilisplastiek, zonder elektrische stimulatie als operatieve behandeling tegen urineverlies, is al tientallen jaren bekend. Voor zover de schrijver dezes bekend dateert de eerste beschrijving uit 1926. In dat jaar beschreef Leroy Deming in de Journal of the American Medical Association (JAMA) voor het eerst de gracilisplastiek als behandeling tegen urineverlies veroorzaakt door een epispadie, een aangeboren afwijking waarbij o.a. de sluitspier van de blaas niet goed is angelegd.

De gracilis spier is een lange, slanke, graciele skeletspier die aan de binnenzijde van het bovenbeen loopt en als taak heeft om de knieën naar elkaar toe te brengen, samen met andere, veel sterkere spieren. De oorsprong is aan de binnenzijde van het onderste gedeelte van het schaambeen, de aanhechting is aan het scheenbeen, net onder de knie. Omdat de belangrijkste zenuwtakken en bloedvaten bij de lies de gracilis spier binnenkomen is het mogelijk om de spier bij de aanhechting los te maken, zonder dat hij afsterft. Dan is ongeveer $30 \mathrm{~cm}$ spier beschikbaar om rondom de plasbuis of rondom de blaashals te wikkelen. Deze operatietechniek heet de transpositie van de gracilis spier, het resultaat van de operatie heet gracilisplastiek.

Indien patiënten na zo"n gracilis transpositie de knieën tegen elkaar drukken, wordt automatische de gracilisplastiek aangespannen en de plasbuis dichtgedrulkt. Het nadeel van deze ingreep is dat de gracilis deze aanspanning sllechts korte tijd kan vollhouden; na enkele minuten verslapt de spier. Daardoor is de gracilisplastiek alléén niet in staat om bij mensen met een niet of slecht werkende sluitspier het urineverlies te verhelpen. De eerste beschreven lange termijn resultaten van de gracilisplastieken waren dan ook nauwelijks bemoedigend.

Sinds een twintigtal jaren is het bekend dat langdurige elektrische stimulatie weefselkarakteristieken kan veranderen. Dit betekent dat skeletspieren, waarvan het functioneren afhangt van de zuurstofarme stofwisseling en een beperkte, snel slinkende glycogeen voorraad, omgezet kunnen worden in een skeletspier die functioneert op basis van zuurstofrijke stofwisseling. Dit heeft tot gevolg dat de spier in staat is om 
gedurende lang tijd samen te trekken. Dit proces is omkeerbaar en betekent dat een skeletspier niet bestaat uit statisch, onveranderbaar weefsel, maar een dynamisch geheel is. Dit geheel kan zich binnen zekere grenzen aanpassen aan de omstandigheden. Momenteel bestaan geavanceerde stimulatoren, waarvan de elektronische componenten via afstandsbediening zodanig beïnvloed kunnen worden dat het stimuleringspatroon verandert. Hierdoor is het mogelijk om na transpositie van een skeletspier spierelectroden te implanteren en deze te verbinden met een tevens geimplanteerde puls stimulator. Daarna kunnen via de afstandsbediening de puls karakteristieken aangepast worden, zodat geleidelijk de skeletspier omgebouwd wordt tot een spier met sluitspier karakteristieken. Dynamische Urinaire Gracilisplastiek is het totale proces van gracilisspier transpositie, de implantatie van spierelektrodes en puls stimulator in combinatie met de omzetting van de skeletspier tot een sluitspier.

Het eerste hoofdstuk gaat over de mate waarin ongewild urineverlies voorkomt en de gangbare behandelingen van ongewild urineverlies door intrinsieke sluitspier zwakte. Eerst worden enkele opmerkingen gemaakt over de problemen die optreden bij het interpreteren van de gegevens die beschikbaar zijn over het vóórkomen van ongewild urineverlies. De vermelde behandelingen worden genoemd in opklimmende mate van uitgebreidheid. Eerst worden de meest gangbare behandelingen met medicijnen vermeld, waarna de verschillende vormen van fysiotherapie volgen. Als laatste worden de meest gangbare operatieve technieken opgenoemd, zoals blaashals ophangingstechnieken, sling procedures, injectie technieken en de implantatie van kunstsluitspieren.

Hoofdstuk 2 beschrijft de mechanismen van spierplasticiteit. Vooral de dynamische kenmerken van spieren, met betrekking tot hun aanpassingsvermogen aan verschillende activiteitspatronen, worden belicht. Het hoofdstuk beschrijft de mechanismen waarmee spieren in staat zijn om zich aan te passen aan weranderingen zoals toenemende activiteitsperioden door elektrische prikkeling.

In hoofdstuk 3 wordt de operatietechniek beschreven die toegepast is tijdens de eerste haalbaarheidsstudie. Het hoofdstuk beschrijft de anatomie van de gracilis spier, de verantwoordelijke zenuwbanen, aders en slagaders en de functie van de gracilis spier. In de eerste haalbaarheidstudie is de blaashals gebruikt als plaats waar de gracilis spier om getransponeerd werd. De studie beschrijft de resultaten in een serie van zeven patiënten en geeft een analyse van de patiënten waarin de operatietechniek gefaald heeft. Een van de opvallendste aspecten is de diversiteit van patiënten-kenmerken. Het voordeel van deze diversiteit is dat aangetoond kan worden of de operatie techniek al of niet technisch mogelijk is. Het nadeel is dat in een serie met zo'n beperkt aantal patiënten de ideale patiënten groep niet gedefinieerd lkan worden. 
Gebaseerd op de analyse van patiënt 3,5 en $7 \mathrm{kan}$ geconcludeerd worden dat de operatietechniek faalde in patiënt 3. Het laatste gedeelte van de gracilis spier (het gedeelte dat om de blaashals werd geslagen) functioneerde niet goed en veroorzaakte het falen in patiënt 5 en 7 . Technisch was het lastig om de gracilisplastiek zodanig aan te leggen dat het mogelijk was een circulaire transpositie van $100 \%$ spierweefsel te verkrijgen. Andere aandachtspunten waren het passeren van de peesplaat van de bekkenbodem en de schuine structuur van de gracilisplastiek rondom de blaashals. Dit laatste wordt veroorzaakt omdat het laatste gedeelte van de gracilisspier hoog in het bekken getrokken moet worden. Uit deze analyse werd geconcludeerd dat voor verbetering van de resultaten prioriteit gegeven moest worden aan het veranderen van de vorm van de gracilisplastiek, en aan de locatie waar de gracilisplastiek moest worden gelegd.

Hoofdstuk 4 behandelt een nieuwe constructie van de gracilissluitspier in een konijnenmodel. In plaats van een spiraalvormige lus rondom de plasbuis, is een doorhaalplastiek getest. Het laatste gedeelte van de spier wordt door het eerste gedeelte gehaald zodat een soort strop gevormd wordt. De drukken en het spierweefsel in de twee gracilisplastiek constructies werden met elkaar vergeleken, nadat beide plastieken chronisch gestimuleerd waren zodat omzetting van de spiervezels had plaatsgevonden. De drukken in de doorhaalplastiek waren vergelijkbaar en vertoonden een trend naar hogere drukken, alhoewel de verschillen niet significant waren. Bij vergelijking van de weefselkarakteristieken was de spieromzetting in de twee plastieken identiek. De veranderingen van het spierweefsel was in beide plastieken vergelijkbaar. Met name in het doorgehaalde gedeelte van de doorhaalplastiek nam het percentage bindweefsel niet meer toe dan in het resterende gedeelte of in de spiraalvormige plastiek. Ook de verstoring van de normale weefselstructuur was overal gelijk. Dit betekent dat het doorgehaalde gedeelte niet extra te lijden had onder eventuele verwurging van het eerste gedeelte van de spier. De conclusie was dat de doorhaalplastiek op zijn minst zo goed was als de traditionele plastiek.

De nieuwe plastiek moest nu op verschillende plaatsen in een diermodel getest worden. Dit staat beschreven in hoofdstuk 5 . Om een dier te hebben van vergelijkbare grootte als de mens werd gekeken in hoeverre de bok geschikt was. In een acuut diermodel werd gekeken in hoeverre drukmetingen in de plasbuis van de bok mogelijk is. Om ook een indruk te hebben van de mogelijkheid om een gracilisplastiek aan te leggen, werd bij tien bokken een doorhaal gracilisplastiek om zowel de blaashals alsook de plasbuis gelegd. Hierna werden de drukken in de plasbuis gemeten met en zonder elektrische stimulatie van de spier. Het bleek dat de druk zonder stimulatie net zo hoog of hoger was dan de plaats met de hoogste druk in de plasbuis in de normale situatie. Met stimulatie was de druk ter plaatse van de plastiek rondom de plasbuis significant. 
hoger dan de druk bij de blaashals. De conclusie was dat de plasbuis beter geschikt is als plaats voor de gracilisplastiek en dat de gestimuleerde spier werkt als een echte sluitspier en niet zozeer als een passieve versteviging.

In hoofdstuk 6 wordt gekeken naar de effecten van elektrische chronische stimulatie op een niet getrainde spier. Dit experiment werd gedaan bij 6 bokken. Hiertoe werden spierbiopten genomen voor stimulatie en werden deze wergeleken met het totaal van gracilisplastiek, 5 minuten stimulatie gevolgd door 5 minuten rust. In de biopten werden stoffen bepaald die iets vertellen over de energiehuishouding in de spier. Hierdoor werd een indruk verkregen van het eventuele tekort aan energie aanvoer door chronische stimulatie van de spier. Het bleek dat de ongetrainde spier slechts voor een gedeelte in staat is om tijdens een herstellingsperiode van 5 minuten de energiebalans te herstellen. Daarom is het essentieel dat een skeletspier in opklimmende mate getraind en omgebouwd wordt, voordat hij continu moet gaan samentrekken.

Hoofdstuk 7 beschrijft een chronisch bokkenmodel. Bij twee bokken werd een doorhaal gracilisplastiek aangelegd om de plasbuis. Spierelectroden werden geimplanteerd en verbonden met een puls stimulator die ook geimplanteerd werd. Hierna werden de gracilisplastieken onderworpen aan een trainingsprogramma om de spierkarakteristieken te veranderen. Bekeken werd in hoeverre spieromzetting had plaatsgevonden en hoe de druk zou veranderen door chronische stimulatie. De belangrijkste reden om dit experiment uit te voeren was echter om te zien in hoeverre vernauwing op zou treden van de plasbuis ondat dit door anderen gesuggereerd was. De uitkomst was dat de ombouw van de spier goed was verlopen en dat geen vernauwing was opgetreden. Na training waren de drukken in de plasbuis met elektrische activatie van de spier lager dan de drukken voor training met elektrische stimulatie. Geconcludeerd werd dat de plasbuis beter geschikt is als locatie voor de gracilisplastiek dan de blaashals en dat de genoemde vernauwing niet hoeft op te treden.

De algemene conclusies van deze experimenten zijn dat de dynamische urinaire gracilisplastiek technisch haalbaar is, dat de doorhaalplastiek een beter optie is dan de klassieke spiraalplastiek, en dat de plasbuis een betere locatie is dan de blaashals. In een multicentrische internationale studie wordt momenteel bekeken wat de toegevoegde warde is van de dynamische urinaire gracilisplastiek voor het arsenaal van incontinentie behandelingen. 



\section{Dankwoord}

Men heeft naast een duidelijk plan vooral discipline nodig om binnen gelimiteerde tijd, naast ander bezigheden, een proefschrift te realiseren. Een strak keurslijf, voorzien van oogkleppen, komt dan goed van pas, ondanks dat dit niet tot de garderobe van deze promovendus behoort. Nu het wetenschappelijk inhoudelijke gedeelte van dit proefschrift klaar is, zou ik dan ook het dankwoord willen laten functioneren als de catharsis van het promotieproces.

Rudi Janknegt en Cor Baeten zijn de geestelijke stimulatoren geweest, waarbij vooral de soepele dwang waarmee ik in de goede richting werd geduwd, genoemd en geroend moeten worden. Bij sommigen werkt dit perfect. Ruud, jouw inspanningen om de organisatie rondom de experimenten en de promotie voor elkaar te krijgen, waren mij zeer waardevol. Cor, zonder jouw briljante idee om het potentieel aan spierdynamica te verplaatsen van het hart naar het bekken, was dit proefschrift nooit gerealiseerd. Wen Jianguo, dear Chinese passer-by, your major contribution based on mutual understanding of mental processes, proves that an individual mind can stay strong, despite the influence of Maoism, Confucianism, or Catholicism. Thanks!

Bas, hartelijke dank voor jouw praktische en inhoudelijke ondersteuning tijdens de experimenten. Matti, Eric, Ronald, Peter en François bedankt voor de hulp bij het temmen van de beestenboel. De medewerkers van het CPV: Joyce, Nicole, Peter, Mai, dank voor jullie hulp voor de verzorging en begeleiding van de dieren tijdens de experimenten. Ton van den Bogaard, jouw realiteitszin en proefdierkennis maakten de proeven vaak ontnuchterend simpel.

De medewerkers van de afdeling Pathologie, met name Jan, John, Cor, Gerard en Adriaan bedank ik voor de hulp bij de analyses. Roel, jouw hulpvaardigheid op ieder tijdstip wordt erg gewaardeerd.

Ger van der Vusse en Wil Coumans van de afdeling Fysiologie, hartelijk dank voor het meedenken en de nauwkeurige bepalingen. Gerbrig Beukema en Robert van Lieshout, bedankt voor alle inspanningen.

Eveline, Carla, Cynthia, Jan, Pat en vooral Ivan Bourgeois van Medtronic: bedankt voor jullie hulp op alle fronten. Een goede buur is beter dan een verre vriend, zeker bij het uitvoeren van experimenten. Tedereen van de afdeling Urologie, ontzettend bedankt. Jullie enthousiasme en hulp was in tijden van maximale ontreddering zeer welkom en ondersteunend. Het verzoek om kopiëerkaarten, klappers, patiëntenstatussen, specifieke urodynamica of het uittikken wan brieven werd altijd gehonoreerd. Een speciaal dankwoord gaat naar de leden van de medisch urologische staf die begrip hadden voor het wel eens samenlopen van omstandigheden, wardoor zij een mouw moesten passen aan de dagelijkse routine. Mijn paranymfen Clemens en Hugo wil ik hartelijk danken voor geestelijke, praktische en ceremoniële ondersteuning. 
In de aanloop naar het realiseren van dit proefschrift bedank ik de volgende autoriteiten: de Rotterdam School of Management voor het aanleren van rationele planningskills en zelfbeperking; Dirk Gouma (nu AMC) en Peter Kitslaar van de afdeling Chirurgie voor het zetten van de eerste schreden op toegepast wetenschappelijk gebied, en de Bourgogne-regio voor het veraangenamen van het leven. Mijn ouders die altijd in mij geloofden en mij steunden; moge ik hun vertrouwen nooit beschamen, en als laatste Lydia, mijn onvoorwaardelijke steun en toeverlaat, die ons gezin voorlopig verrijkte met een fantastische zoon en zo bescheiden is dat ik dit boekje niet exclusief aan haar mocht opdragen. 


\section{Curriculum vitae}

De author was born on the 8th of February 1961. In 1979 he finished grammar school at the Dr. Knippenbergcollege in Helmond. In 1985 he obtained the doctoral degree of Medicine at the Catholic University of Nijmegen. The propadeutics degree in Law was obtained in 1986. In 1987 he graduated as a Master in Business Adminstration at the Rotterdam School of Medicine. He was in military service from 1987 until summer 1988. In 1990 he graduated as a medical doctor. From August 1990 until February 1992 he worked as a resident at the Department of Surgeny at the University Hospital Maastricht (head: Prof.dr G. Kootstra). From February 1992 until July 1994 he worked as a research fellow at the Department of Urology, University Hospital Maastricht

(head: Prof. dr. R.A. Janknegt). In July 1993 he started his training as a urologist with a residency at the Department of Surgery at the University Hospital Maastricht (head: Prof.dr G. Kootstra). Since July 1995 he works as a urologist in training at the Department of Urology, University Hospital Maastricht (head: Prof. dr. R.A. Janknegt). 